\title{
How Do Valuations Impact Outcomes of Asset Sales with Heterogeneous Bidders?*
}

\author{
Alexander S. Gorbenko \\ USC Marshall
}

\begin{abstract}
Differences among bidder type-specific outcomes of asset sales are theoretically related to differences in their valuations and participation. The lead application to quantify these relations is takeover auctions: bidders are classified into strategic and financial, and their bids are available. I structurally estimate valuations from all bids. The positive difference in premiums paid by strategic and financial bidders is driven by the difference in dispersions of valuations (e.g., strategic bidders' synergies are more dispersed) and numbers of bidders of each type. The difference in average valuations is relatively unimportant. My approach is general enough to help explain differences among bidder type-specific outcomes in other competitive settings with limited bidder data.
\end{abstract}

Keywords: mergers and acquisitions, takeover auctions, strategic bidders, financial bidders, takeover premiums, heterogeneous agents

JEL Classification Numbers: D44, G32, G34

*I am grateful to the anonymous referee, Kenneth Ahern, Ulrich Hege, Arthur Korteweg, Andrey Malenko, Kevin Murphy, Toni Whited (the editor), and seminar participants at London Business School, Norwegian School of Economics and University of Southern California for helpful comments. I thank Jessica Yang for excellent research assistance. Author's email address: gorbenko@usc.marshall.edu. 


\section{Introduction}

In economics and finance, asset sales attract bidders of different types. In mergers and acquisitions and intercorporate asset sales, bidders for a target company or a division can be classified as strategic (operating companies) and financial (private equity funds); domestic and foreign; public and private; firms in the same industry and outsiders. In bankruptcy auctions, bidders for a bankrupt company's assets include the incumbent management and outsiders. In Treasury and CDS auctions, banks and their customers compete for shares of a new issue of Treasuries and set the CDS cash settlement price. These settings often involve multibillion transactions, so it is important to understand how outcomes of asset sales are affected by bidder asymmetries.

In this paper, I offer a methodology to quantify the impact of differences among bidder type-specific valuations for an asset on outcomes of various competitive asset sales. For example, it can be valuable to know whether takeover premiums paid by financial and strategic buyers are related to differences in operational synergies, or whether prices paid by the incumbent management and outsiders are driven by information asymmetries. Three factors complicate this study. First, valuations are unobservable to the outsider. Second, there may be limited information about losing bidders' types and bids. Third, many asset sales, such as mergers and acquisitions, have few formal rules, or these rules are unobservable to the outsider.

To measure valuations in the presence of these complications, I develop an extension of the structural model of informal asset sales introduced by Gorbenko and Malenko (2014). For a given asset, same-type bidders share the type-specific average valuation component, which is publicly observable, and differ in the individual valuation component with a type-specific dispersion, which is privately observable. If the format of the sale were known, each valuation would result in a specific equilibrium bid, and hence unobservable valuations could be point-estimated from observable bids. However, when the sale format is unknown to the outsider, the same bid can be rationalized by multiple combinations of valuations and sale formats. The model recognizes this indeterminacy and allows to recover bounds but not point estimates of valuations from bids by imposing restrictions on bidding that hold in many models of asset sales. For example, the winning bidder's valuation must be above its bid, while the losing bidder's valuation must be above its formal committing bid, if any, and below the winning bid. ${ }^{1}$ Together with parametric assumptions on valuation distributions, recovered intervals of bidders' valuations are used to estimate properties of average valuations and their dispersions via an empirical model similar to ordered Probit.

I focus on the setting of strategic and financial bidders competing in takeover auctions because detailed data on these bidders are available in the SEC filings of target companies. I later return to the general

\footnotetext{
${ }^{1}$ These restrictions are introduced by Haile and Tamer (2003). Gorbenko and Malenko (2014) introduce an additional assumption to interpret informal non-committing bids, which often feature in financial asset sales.
} 
question of studying the impact of valuations on outcomes in other settings with limited bidder data. For each auction in 2000-2012, I collect the number of strategic and financial bidders as well as their bids. Similarly to Gorbenko and Malenko (2014), I allow bidders' average valuations to depend on target characteristics. I also extend the model in two ways. First, I allow average valuations to change with the number of competitors and over time, in response to changes in economic conditions: my data contain periods of economic expansions and downturns, including the dot-com bust and the financial crisis. Second, I allow dispersions of valuations to depend on target characteristics and economic conditions.

I find that across the sample, the average strategic bidder is willing to pay a $27.9 \%$ premium to the current value of the target, while the dispersion of strategic bidders' valuations for the same target is $31.2 \%$ of its value. Average valuations of strategic bidders are unaffected by market conditions, however their dispersions are higher during the financial crisis. Across the sample, the average financial bidder is willing to pay a $18.6 \%$ premium, while the dispersion of financial bidders' valuations for the same target is only $18.1 \%$ of its value. The difference between strategic and financial bidders' average valuations and their dispersions is statistically and economically meaningful. Average valuations of financial bidders spike during the dot-com bust period, and their dispersions are substantially higher during the crisis despite their lower participation but lower during the dot-com bust period. I replicate real-data takeover outcomes via model simulations assuming that average valuations and their dispersions are equal to their estimated values and show that the model fits the data well.

Having recovered valuations, I return to the main goal of the paper, to quantify the impact of differences among bidder types on outcomes: the difference in takeover premiums paid by strategic and financial bidders. First, I perform the univariate analysis to study the impact of bidder properties on premiums one by one. I sequentially change the difference between type-specific average valuations, their dispersions, and numbers of strategic and financial bidders, and repeat model simulations. Second, I perform the multivariate analysis by simultaneously including all four factors into the OLS regression of premiums. I repeat this analysis in the simulated data both at estimated and counterfactual parameters as well as in the real data. Contrary to the common intuition, both analyses reveal that the difference in dispersions and numbers of strategic and financial bidders but not the difference in average valuations (despite being significant) significantly impact the difference between strategic and financial premiums. Specifically, the multivariate analysis shows that the difference in dispersions explains $68.3 \%$ of the difference in premiums, and an additional strategic (financial) bidder above the average number explains $8.6 \%(-5.3 \%)$ of the difference. The dummy for the strategic acquirer, which captures potentially omitted factors, is insignificant, implying that the four factors explain the difference between premiums well.

Intuitively, in asset sales with many participants, an increase in the dispersion of valuations or the number of bidders of a particular type substantially increases the expected highest valuation within this 
type and, in turn, the expected type-specific premium. At the same time, the expected competing type's premium remains relatively unaffected. As a result, the difference between expected premiums substantially increases. Similar effects but on a smaller scale occur with an increase in the average valuation of bidders of a particular type: the expected highest valuation within this type only changes one-to-one with the average valuation. The impact of the dispersion of valuations is likely to be muted in settings, where the average number of participants is low.

I expect to see the dominant impact of valuation dispersions on outcomes in other settings in finance, in which competition is typically high and dispersions are plausibly different across types of bidders. For example, domestic bidders are typically more informed about targets than foreign bidders. Valuations of domestic bidders are therefore likely more dispersed than valuations of foreign bidders, because the latter group would not revise their valuations much from their ex-ante expected values. In this case, higher takeover premiums of domestic acquirers can stem from higher dispersion of their valuations but not from their higher average valuations. For similar reasons, in bankruptcy auctions, valuations of the incumbent management are likely more dispersed. It is also plausible that dispersions of valuations substantially impact outcomes in settings where multiple assets are sold simultaneously, such as CDS and Treasury auctions.

Unfortunately, in many settings, information on types of losing bidders and their bids is unavailable. I show how the lack of this information can affect inference. First, I use simulations to show that average valuations and their dispersions can be recovered when at least some information about losing bidders is available. Specifically, it is sufficient to know (1) types but not bids of individual losing bidders, or (2) the probability of a losing bidder to be of certain type, if individual types are unknown. At the same time, attempts to extract information on types of losing bidders from auction outcomes, such as type-specific probabilities of winning, without having any prior typically lead to biased estimates. Second, I use real data on strategic and financial bidders in takeovers to re-estimate valuations by assuming that data on losing bidders are limited. The ranking of estimated average valuations and their dispersions is unaffected. These results suggest that it is possible to understand how valuations and participation affect outcomes of asset sales in a wide variety of settings with limited bidder data.

Overall, my results caution against simple associations of differences in type-specific outcomes with differences in type-specific average valuations and advocate for the need of structural models of competition in asset sales. The naive approach to establish a reverse connection between valuations and outcomes is to run a regression of the winning bid on various characteristics of the asset and economy, and the winner type-specific indicator variable. If one such indicator variable is significantly higher (lower) than others, it can be tempting to interpret this as evidence that bidders of a type associated with the indicator value the asset, on average, higher (lower) than other types. For example, a common view is that because strategic 
acquirers pay higher premiums than financial acquirers, they should have systematically higher valuations. This interpretation relies on the implicit assumption that each winner type-specific indicator variable proxies for the only omitted variable, the difference between the average valuation of a type associated with the indicator and the average valuation of a fixed bidder type. This paper shows that this interpretation omits the potentially strong impact of competition on outcomes. In contests with multiple bidders, the winning bid comes from the bidder with the highest valuation and hence is determined by whole distributions of valuations (and, in particular, valuation dispersions), as well as numbers of bidders of each type. In other words, the winner type-specific dummy in the regression of the winning bid simultaneously proxies for multiple important omitted variables related to competition. ${ }^{2}$ In practice, proxying for omitted properties of valuations is difficult. However, it is possible to estimate them from information about types and bids of both winning and losing bidders via a model of competitive bidding.

My paper is related to the literature that studies bidder heterogeneity via structural empirical models of asset sales. I build on the informal model of auctions by Gorbenko and Malenko (2014) to estimate typespecific properties of bidders' valuations from their bids, and focus on the setting of strategic and financial bidders in takeovers. There are four key differences between the papers. First, and most importantly, Gorbenko and Malenko (2014) study how valuations are different across types, while I push the idea further and quantify the impact of type-specific valuations on outcomes of asset sales. Estimation of the model of valuations is only an intermediary, but important, step to show that the difference in type-specific valuation dispersions is the main driver of the difference in premiums paid by strategic and financial bidders. Second, I extend the model to recover valuations in settings, where losing bidder data are limited, making it applicable to a wide variety of asset sales typically considered in the financial literature. Third, I expand the data set to include periods of the financial crisis and after-crisis, which allows me to study how valuations change over time. Finally, dispersions of valuations in my paper are not constant but depend on target and economy characteristics, which allows me to study target- and time-specific differences in whole valuation distributions.

Using a structural model, Dimopoulos and Sacchetto (2014) find that initiating bidders in takeovers have, on average, higher valuations for the target than non-initiating bidders. ${ }^{3}$ My paper defines bidders more broadly as those companies who signed confidentiality agreements, and documents more competition in takeover contests. High competition implies that the difference between valuation dispersions of initiating and non-initiating bidders can also be an important driver of takeover outcomes. Li, Taylor, and Wang

\footnotetext{
${ }^{2}$ E.g., in contests with two types of bidders and distributions of valuations with two parameters (e.g., normal or log-normal), there are four omitted variables in regressions of the winning bid.

${ }^{3}$ Gorbenko and Malenko (2016) develop a general theory of deal initiation when bidders have private versus common values (e.g., strategic versus financial synergies) for the target, in which differences between valuation distributions of initiating and non-initiating bidders arise endogenously.
} 
(2017) employ a structural model to study inefficiencies in the M\&A market due to equity misvaluation. ${ }^{4}$ They do not distinguish between bidder types. In my paper, misvaluation periods, to some extent, are captured by period indicator variables. In particular, high valuations and takeover premiums of financial bidders during the crisis can be explained by their ability to identify misvalued companies in the volatile market.

My approach to estimate valuations and link them to outcomes of asset sales can also be useful in other settings with heterogeneous bidders, in which bidder-level data are limited. Hege, Lovo, Slovin, and Sushka (2013) show that in intercorporate asset sales, excess returns to sellers are greater in acquisitions by financial bidders and develop a related theoretical model. My results suggest that this finding can be driven by more dispersed financial bidders' valuations for individual target divisions, perhaps because individual divisions are more likely to be mispriced than publicly traded firms. In the context of bankruptcy auctions, Strömberg (2000) develops the model of an auction, in which a bankrupt firm's assets can either return to the incumbent owner-manager or be sold to new owners. In the context of Treasury auctions, Hortaçsu and Kastl (2012) show that bank dealers learn information about competition from their customers' bids and adjust their bids to earn higher expected profits. Chernov, Gorbenko, and Makarov (2013) allow for differences between bank dealers and their customers in their theoretical model of CDS auctions. It is possible that differences between incumbents' and outsiders', or between banks' and customers' distributions of valuations, not yet estimated in these three settings, are important drivers of auction outcomes.

The structure of the paper is as follows. Section 2 motivates the need for a structural empirical model of asset sales via examples, describes the process of a typical informal asset sale, introduces the model, and explains the estimation procedure to recover properties of valuations. Section 3 presents data on takeover auctions and summary statistics, and provides the basic OLS analysis of premiums paid by strategic and financial bidders. Section 4 reports model estimates, explains their economic magnitudes, and discusses various robustness checks. Section 5 studies the impact of valuation properties and bidder participation on takeover outcomes in both the simulated and real data. Section 6 explains how to estimate valuations in other settings, when data on losing bidders are limited. Section 7 concludes.

\section{Empirical model of informal asset sales}

I first motivate the need for a structural empirical model to measure bidders' valuations and understand the impact of bidder asymmetries on outcomes of asset sales. I then explain how informal asset sales, such as mergers and acquisitions, are typically conducted. Finally, I present the empirical model of asset sales

\footnotetext{
${ }^{4}$ Martos-Vila, Rhodes-Kropf, and Harford (2013) show that in theory, valuations of both strategic and financial bidders can also be affected by debt misvaluation.
} 
that takes into account their free-form nature and bidder heterogeneity.

\subsection{Motivating examples}

A common interpretation of differences in type-specific outcomes of asset sales is that bidders of different types have, on average, different valuations, or maximum willingness to bid, for an asset. For example, in takeover contests, a common view is that because strategic acquirers pay higher premiums than financial acquirers, they should have systematically higher valuations. Similarly, it is tempting to conclude that domestic bidders have different average valuations of assets than foreign bidders, or, in the setting of Treasury and CDS auctions, that banks have different average valuations of securities than their customers.

This interpretation omits the potentially strong impact of competition on outcomes. In contests with multiple bidders, the winning bid comes from the bidder with the highest valuation and hence is determined by whole distributions of valuations (and, in particular, valuation dispersions), as well as numbers of bidders of each type. The following three examples illustrate that differences among type-specific dispersions of valuations and participation can have a significant impact on type-specific average winning bids, which does not stem from differences in average valuations:

Example 1. Suppose two types of bidders compete for an asset. Bidders of type $a$ equally likely value the asset at either a $0 \%$ or $30 \%$ premium to the value of its current owner. Bidders of type $b$ equally likely value it at either a $10 \%$ or $20 \%$ premium. All valuations are independent. Hence, average valuations of types $a$ and $b$ are the same, but type $a$ 's valuations are more dispersed. Suppose the asset sale proceeds as a simple ascending auction, in which each bidder drops out at its valuation, the winner is the bidder with the highest valuation, and the payment is the valuation of the second-highest bidder. Suppose there is one bidder of type $a$ and one bidder of type $b$ in each contest. Then, type- $a$ bidder wins the contest when its valuation is high and pays, on average, a $15 \%$ premium upon winning. Type- $b$ bidder wins when type- $a$ bidder's valuation is low and pays a $0 \%$ premium. Even though their average valuations are the same, type- $a$ acquirer pays, on average, a $15 \%$ higher premium than the type- $b$ acquirer.

Example 2. Suppose now that bidders of type a equally likely value the asset for sale at either a $14 \%$ or $16 \%$ premium to its current value. Everything else equal, this makes type $a$ 's valuations less dispersed. Suppose there is one bidder of type $a$ and one bidder of type $b$ in each contest. Then, type- $a$ bidder wins the contest when type- $b$ bidder's valuation is low and pays a $10 \%$ premium upon winning. Type- $b$ bidder wins when its valuation is high and pays, on average, a 15\% premium. Type- $a$ acquirer pays, on average, a $5 \%$ lower premium. Hence, it appears that the ranking of dispersions of valuations has a strong impact on the ranking of average payments, even though average type-specific valuations are the same.

Example 3. Consider valuation distributions of Example 1 and assume there are $N_{a}>1$ bidders of type $a$ and one bidder of type $b$ in each contest. If $N_{a}$ is very high, the winner would usually be a type- $a$ 
bidder, who would pay close to a $30 \%$ premium on average. Type- $b$ bidder wins only when valuations of all type- $a$ bidders are low, in which case it pays the premium of $0 \%$. Therefore, type- $a$ acquirer pays a $30 \%$ higher premium. In contrast, if there is one bidder of type $a$ and a high number $N_{b}>1$ of bidders of type $b$ in each contest, then both types of acquirers would pay the same $20 \%$ premium. Hence, it appears that the number of bidders of each type has a strong impact on the ranking of average payments.

The examples can be generalized to more realistic distributions of valuations. They imply that, e.g., in asset sales with two types of bidders and distributions of valuations with two parameters (e.g., normal or log-normal), there are four factors affecting the difference in type-specific outcomes. These are differences in type-specific average valuations and their dispersions and the number of bidders of both types. This paper studies the impact of each of the factors on outcomes.

The major challenge in relating properties of valuations to outcomes of any asset sale is that valuations are unobservable. It is difficult to find empirical proxies or instruments for these even for winning bidders, let alone for losing bidders, whose identities are typically unknown. Instead, I use a model of asset sales to recover valuations from all observable outcomes of an asset sale, i.e., winning and losing bids and numbers of all bidder types. Unfortunately, bidder-level data are unavailable in many asset sales. Among few exceptions are takeover auctions, in which detailed data are reported in SEC deal backgrounds. As a result, the market for takeovers is the lead setting to study bidder asymmetries. However, insights obtained in this market are also relevant in other settings with multiple bidder types, in which bidder data are limited. In Section 6, I modify the model to recover valuations in settings, when data on losing bidders are incomplete.

Any model of asset sales provides an equilibrium mapping of valuations into bids and hence can be inverted to recover at least some information about valuations from bids. In contrast to formal asset sales, which proceed according to formal rules, asset sales typically studied in the financial literature, such as mergers and acquisitions, are informal: they lack hard rules and commitment. The challenge is then to come up with a plausible, detail-free model that is consistent with their free-form nature. I briefly overview features of typical informal asset sale processes and then present a model that suits them.

\subsection{Institutional background}

The most widely studied informal asset sale setting is takeovers. The process of a typical takeover auction has been described in detail by Hansen (2001), Boone and Mulherin (2007), and Gorbenko and Malenko (2014). If a target firm decides to sell itself, its advisor (an investment bank) contacts various parties who, in their view, might be interested in acquiring the firm. The interested parties, or bidders, sign confidentiality agreements, upon which they may receive access to non-public information about the target. Takeover auctions have similarities with "English" or "ascending-bid" auctions, in which bidders keep increasing 
their offers until only one bidder is willing to continue. It then pays according to its final offer and acquires the target. In contrast to formal auctions, i.e., for Treasuries or CDS, there is notable lack of rules and commitment before the parties reach the final outcome. First, bidding proceeds in several rounds, but the target does not commit to their number or length. Second, most bids outside of the final round are non-binding or informal in the sense that bidders do not commit and are free to decrease or withdraw them, in contrast to typically studied binding or formal bids. Third, bidders can leave and rejoin the auction at will, whereas leaving means losing in most other auctions. Fourth, bidders often change bids by a large discrete amount. Fifth, the target often negotiates final offers with bidders, whereas in standard auctions, the seller does not have any input into the process beyond setting its ex-ante rules. Finally, the target can renege on an already signed takeover agreement if another party arrives with a sufficiently attractive offer after the auction but before merger completion.

The process of a typical intercorporate asset sale, in which individual divisions of a target firm are sold, is very similar to that of a typical takeover auction. The process of a typical bankruptcy auction in the U.S. does not allow for non-binding bids and usually includes a hard deadline on bids set by courts, but is otherwise similarly unstructured. It is clear that a formal model that captures the true process of an asset sale in these settings is bound to be complex, yet may still omit or misspecify important elements. My empirical model intentionally saves on complexity by combining a few "structural" assumptions that hold across many different models with a "reduced-form" assumption on valuation distributions.

\subsection{Valuations of bidders}

Consider asset sale $i$. Suppose there are $N_{i}$ bidders. Each bidder $j$ in asset sale $i$ belongs to one of the two types: $t_{i, j} \in\{a, b\}$. For example, takeover deal backgrounds typically classify bidders into strategic $(a=s)$ and financial $(b=f)$. The model is easily extendable to any finite number of types $T>2$. Having observed non-public information about the asset, each bidder learns its valuation defined as the maximum amount it is willing to pay for the asset. ${ }^{5} \mathrm{I}$ assume that valuation of bidder $j$ is given by

$$
V_{i, j}=M_{i} \exp \left\{\mu_{t_{i, j}}+\varepsilon_{i, j} \sigma_{t_{i, j}}\right\}
$$

where $M_{i}$ is the value of the asset under its current management, and $\exp \left\{\mu_{t_{i, j}}+\varepsilon_{i, j} \sigma_{t_{i, j}}\right\}$ is the bidderspecific valuation premium (or discount, if it is below one). The premium is the sum of a type-specific

\footnotetext{
${ }^{5}$ The maximum willingness to pay includes synergies but is not limited to them. E.g., it also accounts for the outside option of losing the contest, overvaluation, private benefits of control. Using announcement returns, Gorbenko and Malenko (2014) show that in takeover auctions, synergies are unlikely to fully account for the maximum willingness to pay, which I confirm in unreported results.
} 
public common component, $\mu_{t_{i, j}}=X_{i}^{\prime} \beta_{t_{i, j}}$, and a bidder-specific private component, $\varepsilon_{i, j} \sigma_{t_{i, j}}{ }^{6}$ The public common component captures factors that are attractive to all bidders of the same type: $X_{i}$ contains publicly observable asset characteristics and aggregate market conditions. The private component captures factors such as synergy and suitability of the asset for each bidder. The magnitude of the private component can also be affected by asset characteristics and the environment. To capture this, I extend Gorbenko and Malenko (2014) and model the type-specific standard deviation of valuation premiums as $\log \sigma_{t_{i, j}}=\log \sigma_{t_{i, j}}^{0}+Y_{i}^{\prime} \delta_{t_{i, j}}$, where $Y_{i}$ is a subset of $X_{i}$ and includes the constant term. The logarithm is used to ensure that standard deviations are positive. I assume that $\varepsilon_{i, j}$ have standard Normal distributions.

In the remainder of the paper, I focus on valuation premiums, because they are of similar magnitude and hence easier to compare across industries, time, and types of asset sales than absolute valuations:

$$
\log v_{i, j} \equiv \log \left(\frac{V_{i, j}}{M_{i}}\right)=\mu_{t_{i, j}}+\varepsilon_{i, j} \sigma_{t_{i, j}}
$$

To avoid confusion between valuation premiums, which a bidder can pay for the asset if it wins the contest, and realized premiums, which the actual winning bidder pays for the asset, in the remainder of the paper I simply refer to valuation premiums as valuations. As a result, I call $\mu_{t_{i, j}}$ the type-specific average log-valuations, and $\sigma_{t_{i, j}}$ the type-specific dispersion of log-valuations. In each asset sale, there are three potential sources of differences between types of bidders. They can have different average valuations, dispersions of valuations, and participation rates. The first source is captured by $\beta_{a}$ and $\beta_{b}$. The second source is captured by $\sigma_{a}$ and $\sigma_{b}$. The first two sources are unobservable and require an empirical model to be recovered. Whether types of bidders are similar or different along these dimensions in a particular asset sale is an empirical question.

${ }^{6}$ It is reasonable to think of the value of the asset, $M_{i}$, as also consisting of the public common component, which is specific to the seller's type, and a seller-specific private component. Under this interpretation, the model implicitly assumes that upon winning, each bidder plans to retain the seller's synergies and incrementally improve upon them. The alternative assumption could be that upon winning, each bidder plans to restructure the asset by removing its pre-existing synergies. In the current model but not under the alternative assumption, a non-zero $\hat{\beta}_{t_{i, j}}$ can then be interpreted as evidence that incremental improvements are asset-specific. In addition, both in the current model and under the alternative assumption, a non-zero $\hat{\beta}_{t_{i, j}}$ can also be interpreted as evidence that the seller's and bidder's types are different. E.g., even when an operating company is the target of a takeover process, in which bidders are other operating companies, the two sides of the deal are not randomly selected and hence do not share valuation distributions. I explore robustness of my results to this and multiple other assumptions regarding the model, sample selection, and estimation in Section 4.2. 


\subsection{Bidding behavior}

I do not commit to an interpretation of bids implied by any particular model of asset sales. Instead, I employ the incomplete empirical model of auctions introduced in Gorbenko and Malenko (2014). I rely on the three assumptions common to a broad variety of models:

Assumption 1. Bidders do not make formal bids exceeding their valuation.

Assumption 2. Bidders do not allow opponents to win at a price they are willing to beat.

Assumption 3. Bidders do not make informal bids if their valuation is below the value of the asset under its current management.

The motivation for these assumptions is as follows. Any formal bid is potentially a winning bid, so it is irrational for a bidder to bid more than its valuation, motivating Assumption 1. Assumption 2 means that for a rational bidder, losing is worse than winning an asset at a price below its valuation but above the competing bid, as it results in a positive surplus. Finally, Assumption 3 means that if a rational bidder learned that it values the asset below its current value, it would not invest time and resources and submit either formal or informal bids because even its best offer would be unattractive to the seller. The three restrictions on bidding strategies subsume all bidding patterns observed in informal asset sales, as discussed in Section 2.2. Reasonable modifications of Assumptions 1-3 lead to quantitatively similar results.

\subsection{Estimation strategy}

Let $b_{i, j}$ denote the formal bid submitted by bidder $j$ in asset sale $i$. If the bidder only submits an informal bid, Assumption 3 implies that such bid is equivalent to a formal bid of $M_{i}: b_{i, j}=M_{i}$. If the bidder does not submit any bid, this is equivalent to a formal bid of zero: $b_{i, j}=0$. I renumber bidders within each asset sale in the descending order by their highest bid: $b_{i, 1} \geq b_{i, 2} \geq \ldots \geq b_{i, N_{i}}$.

Next, I write the likelihood of asset sale $i$ 's outcome as a function of valuation distributions, given the realization of bids $b_{i}=\left(b_{i, 1}, b_{i, 2}, \ldots, b_{i, N_{i}}\right)^{\prime}$, types $t_{i}=\left(t_{i, 1}, t_{i, 2}, \ldots, t_{i, N_{i}}\right)^{\prime}$, and model parameters $\theta=$ $\left(\beta_{a}, \beta_{b}, \delta_{a}, \delta_{b}\right)^{\prime}$. Four different bidder-level events, interpreted through the lens of Assumptions 1-3, affect this likelihood: the assumptions bound admissible valuations of each bidder in an event-specific way. For example, the likelihood of one such bidder-level event, when bidder 1 submits a formal bid $b_{i, 1}$ and wins, is equal to $l_{i, 1}\left(v_{i, 1} \mid X_{i}, b_{i, 1}, t_{i, 1} ; \theta\right)=\operatorname{Prob}\left\{b_{i, 1} \leq v_{i, 1} \mid X_{i}, t_{i, 1} ; \theta\right\}=1-\Phi\left(\frac{\log \frac{b_{i, 1}}{M_{i}}-X_{i} \beta_{t_{i, 1}}}{\sigma_{t_{i, j}}^{0} e^{Y_{i} t_{i, 1}}}\right)$. The likelihoods of other three events, when (1) bidder $j>1$ submits a formal bid $b_{i, j}$ and loses; (2) bidder $j>1$ submits an informal bid of any size and loses; and (3) bidder $j>1$ does not submit any bid, are provided in Appendix A. 
Because bidder-level event likelihoods are independent, the asset sale-level likelihood is simply their product. A caveat here is that all likelihoods rely on observability of bidders' types. In practice, some losing bidders' types are unobservable, as illustrated in Section 3 for the case of takeover auctions. To deal with this issue, I use a two-step estimation procedure of Gorbenko and Malenko (2014). In short, when type is unobservable, I substitute the likelihood of the bidder-level event, $l_{i, j}(\cdot)$, with the expected likelihood, $\mathbb{E}\left[l_{i, j}(\cdot)\right]$. This likelihood is the weighted sum of the likelihoods conditional on type $t_{i, j}$ with the weights pre-estimated from the data on fully observable types.

Parameter estimates are obtained by maximizing the joint expected log-likelihood across all asset sales and bidders over the set of parameters of valuation distributions, $\theta$ :

$$
\log L\left(v \mid N_{a}, N_{b}, N_{u}, X, b, t ; \theta\right)=\frac{1}{\sum_{i=1}^{I} N_{i}} \sum_{i=1}^{I} \sum_{j=1}^{N_{i}} \mathbb{E}\left[\log l_{i, j}\left(v_{i, j} \mid X_{i}, b_{i, j}, t_{i, j} ; \theta\right)\right] .
$$

Here, $N_{a, i}, N_{b, i}$ and $N_{u, i}$ are numbers of bidders of type $a, b$, and bidders with unobservable type, such that $N_{a, i}+N_{b, i}+N_{u, i}=N_{i}$.

\subsection{Identification}

Identification of the model is similar to other ordered Probit-like models. Suppose an increase in a single control variable, $x \in X$, ceteris paribus, increases the average log-valuation of type $a, \mu_{a}$. This increase results in, on average, higher equilibrium bids by type $a$. Inverting the logic, a joint increase in average winning and losing bids by type $a$ with an increase in $x$ increases boundaries on valuations of type $a$ and identifies a positive sensitivity of $\mu_{a}$ to $x$. Next, suppose a similar increase in $x$, ceteris paribus, increases the dispersion of log-valuations of type $a, \sigma_{a}$. This increase results in an, on average, higher dispersion of equilibrium bids by type $a$ : higher winning bids but potentially lower losing bids. Inverting the logic, an increase in the average distance between bids by type $a$ with an increase in $x$ (e.g., an increase in average winning bids alone or a decrease in average losing bids alone) widens boundaries on valuations of type $a$ and identifies a positive sensitivity of $\sigma_{a}$ to $x$.

Note that if an increase in $x$ increases $\mu_{a}$ or $\sigma_{a}$ and, in turn, the average winning bid by type $a$, estimated sensitivities of $\mu_{b}$ and $\sigma_{b}$ to $x$ can also be affected. This is because by Assumption 2, an increase in the winning bid by type $a$ increases the upper boundary on valuations of losing bidders of both types. However, this effect is economically and numerically small: in asset sales with many bidders, an increase in the winning bid far in the right tail of the distribution of valuations only marginally affects inference of expected valuations of losing bidders. ${ }^{7}$

\footnotetext{
${ }^{7}$ Further muting this effect, if an increase in $x$ strengthens bidders of type $a$, it can result in lower equilibrium bids by type $b$, as fewer such bidders may find it worthwhile to seriously compete. Using simulations, in unreported results similar to those
} 


\section{Data and summary statistics}

To understand how valuations impact outcomes of asset sales in practice, I focus on the setting of strategic and financial bidders competing in takeover auctions. I focus on this setting both because it an important case of bidder heterogeneity and because data on these bidders are available in the SEC filings of target companies. For brevity, throughout the rest of the paper, I refer to valuations of strategic and financial bidders as strategic and financial valuations, and to bids and premiums paid by strategic and financial bidders as strategic and financial bids and premiums.

\subsection{Data description}

I analyze a sample of corporate takeovers announced and completed in the period from January 1, 2000 to May 2, 2012. This is an expansion of the sample in Gorbenko and Malenko (2014), which stops in September 6,2008 . The sample comes from the mergers and acquisitions database of the Securities Data Corporation (SDC). The sample satisfies the following conditions: (1) the target is a publicly traded non-financial US company; (2) bidders seek $100 \%$ of target shares; (3) winning bids are made in cash only ${ }^{8}$; (4) the deal is not a spin-off, recap, self-tender, exchange offer, repurchase, minority stake purchase, acquisition of remaining interest, or privatization; (5) the deal is an auction (two or more potential bidders sign confidentiality agreements); (6) final deal value (the winning bid) is included in the database or SEC EDGAR filings; (7) deal backgrounds are available in the SDC or SEC EDGAR filings.

For each takeover $i$, I collect the total number of bidders $N_{i}$ and the number of known strategic and financial bidders $N_{s, i}$ and $N_{f, i}$. The identities of $N_{i}-N_{s, i}-N_{f, i} \geq 0$ bidders not provided in the deal background are unknown. I record whether each bidder made any informal or formal bids, as well as their highest formal bid, if any (including public bids after the takeover announcement).

I collect data on the market values of the targets (1) four weeks prior to the takeover announcement and

in Gorbenko and Malenko (2014) I show that the empirical model recovers true parameters well, when the data-generating theoretical model exhibits realistic deviations from the standard "ascending-bid" auction paradigm. In contrast, alternative approaches, which either assume that the model of bidding is fully known or do not impose valuation restrictions at all, often recover true parameters with bias.

${ }^{8}$ Winning stock bids can introduce substantial bias because the winning bid is used to bound all valuations in an auction, and there is no guarantee that the observable market value of a stock bid is the same as the unobservable value to a bidder. In fact, theory suggests that bidders offer stock when the market overvalues it (Shleifer and Vishny, 2003; Rhodes-Kropf and Viswanathan, 2004. Also, see Li, Taylor, and Wang, 2017 for a structural estimation of inefficiencies in the M\&A market due to mispricing of equity). Losing formal stock bids, on the other hand, are rare and only bias a given bidder's valuation. Treating market values of stock bids as bidder values, I re-estimated the model using a sample of auctions completed in 2000-2008, in which the winning bid contained more than $50 \%$ cash, and obtained similar results. 
(2) one day prior to any press release related to the company potentially selling itself (only if it occurred no more than a year before the takeover). A press release, typically resulting in a stock price increase on the following day, occurred for 144 out of 589 targets, or $24.5 \%$ of the sample. Whenever there is a press release, I use (2) as a measure of variable $M_{i}$ in the model; otherwise, I use (1).

Target characteristics come from the quarterly COMPUSTAT database. Specifically, I collect firm size defined as the book value of the target's total assets, market leverage, market-to-book ratio, cumulative cash flow over the last four quarters, cash and short-term investments, R\&D expenses, and intangible assets (all measured as ratios to the target's book value).

The time interval covered in my data, 2000-2012, includes periods of dramatic changes to economic and financial markets, most notably two economic downturns. The set of aggregate market characteristics includes dummies for five periods: 2000-2001 (the dot-com bust), 2002-2005 (post dot-com), 2006-August 2008 (boom, pre-Lehman bankrupcty), September 2008-2009 (the crisis), and 2010-2012 (post crisis). I also include the market return, defined as the cumulative return on the S\&P 500 index over the 12 months prior to the announcement date, and the credit spread, defined as the difference between the rates on Moody's Baa bonds and 10-year Treasury bonds a day before a measure of the target's market value was taken.

Finally, the set of characteristics includes the number of bidders and its interaction with period dummies. The number of bidders is unlikely to correlate with any given bidder's valuation but can correlate with average strategic and financial valuations in an auction. Intuitively, even within types, bidders are likely different in ways observable to competitors but not to the researcher. When participation is cheaper, weaker bidders enter auctions, so the average valuation of all participants is lower. Gentry and Stroup (2017) develop a theoretical model of auction participation with a single type of bidders, which results in a negative relationship between participation and average valuations. Likewise, I expect to obtain negative coefficients associated with the number of bidders. ${ }^{9}$ Interaction between period dummies and the number of bidders also seems important: previous research shows that merger activity changes over time and is correlated with the state of economic and financial markets (Harford, 2005; Martos-Vila et al., 2013). An unanswered question is how much of this time variation is driven by time variation in a given bidder's valuation versus average valuations due to time variation in participation. The variation in a given

\footnotetext{
${ }^{9} \mathrm{My}$ model approximately captures this intuition by allowing average valuations to depend on the number of bidders but not allowing bidders within a given type to be ex-ante different in ways observable to competitors but not to the researcher: the only admissible difference is in the private component, $\varepsilon_{i, j} \sigma_{t_{i, j}}$, obtained post-due diligence. In Section 4.2 , I modify the model to include an ex-ante bidder- but not researcher-observable valuation component in a way that allows me to estimate it without modeling the endogenous entry stage of an asset sale. The estimation results are similar to the main model and suggest that the number of bidders captures the unobservable ex-ante bidder heterogeneity well. In Section 5.3 , I discuss the potential impact of endogenous entry on the link between valuations and outcomes of asset sales.
} 
bidder's valuation across periods is then captured by period dummies. The variation in the quality pool of potential participants, which can result in a faster or slower decline in average valuations with the number of participants, is captured by interaction terms.

I filter out unreasonable values of exogenous variables that are likely to be accounting mistakes. I am left with 589 takeover auctions and 7176 bidders.

\subsection{Summary statistics and OLS analysis}

Table 1 shows bidder participation in all auctions, auctions won by a strategic or financial bidder, across top five Fama-French industries by number of deals, and across five periods. Many results are similar to summary statistics in Gorbenko and Malenko (2014). In particular, the average number of bidders per auction is 12 ; more financial than strategic bidders participate in a typical auction; auctions won by financial bidders attract more bidders; financial bidders only win approximately $40 \%$ of auctions. At the same time, there are two notable differences. The first difference is that I know the type of $55 \%$ of potential bidders, in contrast to $45 \%$ in the previously studied subsample of 2000-August 2008. This change reflects an increase in quality of deal backgrounds. In dot-com and post dot-com periods, deal backgrounds report types of $26.5 \%$ and $37.2 \%$ bidders, whereas in the post crisis period, this number is $67.3 \%$. The number of bidders across periods is stable and only takes a notable dip during the crisis. Across the last three periods with good coverage of bidder types, the number of strategic bidders is stable, while the number of financial bidders is much lower during the crisis. My estimation strategy assigns probabilities to bidders with unobservable types and suggests that it is also low in the dot-com period. The second notable difference is that average strategic and financial takeover premiums increase correspondingly by 5 and 6 percentage points relative to the subsample of 2000-August 2008 to $51.2 \%$ and $42.7 \%$. The increase comes from the crisis and, to a smaller extent, the post crisis period, in spite of the low number of bidders during the crisis. The simple difference between average strategic and financial premiums is significant at the $5 \%$ level. ${ }^{10}$

Table 2 shows target characteristics in all auctions, auctions won by a strategic or financial bidder, across industries, and across periods. Compared to the subsample of 2000-August 2008, the average size of the target is lower ( $\$ 607$ million versus $\$ 654$ million). An average strategic deal is larger (\$398 million versus $\$ 318$ million), while an average financial deal is smaller ( $\$ 959$ million versus $\$ 1,168$ million). Deals in periods of economic downturn are for targets with higher leverage and lower M/B ratio than average. Deals in the dot-com period are much smaller than average. Differences between each target characteristic,

\footnotetext{
${ }^{10}$ Not shown in the table, the number of informal and formal bids per auction, 4 and 1.34, is remarkably stable between subsamples of 2000-August 2008 and September 2008-2012. In the latter subsample, the number of strategic and financial bids per auction is higher but is fully compensated by a lower number of bids by bidders of an unobservable type. This is because more participants, including those who bid, are classified as strategic or financial in latter periods.
} 
except for intangibles, in strategic and financial deals are significant at the $5 \%$ level.

Table 3 compares strategic and financial premiums across industries, periods, and deals in the low versus high tertile of target characteristics. Strategic premiums are higher in most subsamples; the difference between premiums is positive and significant in periods of economic stability and for small, relatively unlevered, high-M/B ratio targets. Table 4 complements Table 3 with the multivariate OLS analysis of premiums, where "Strategic Acquirer" dummy captures the difference between premiums. When only controls unrelated to bidder participation are included, the dummy is positive and significant at the $5 \%$ level. Significance drops to the $10 \%$ level if the number of bidders and its interactions with periods are included. However, if the crisis period is dropped, the dummy is significant at the $1 \%$ level. The last two columns of the table show that the difference seems to be unaffected by target and market characteristics. Similar regressions in other settings led researchers to interpret the dummy as capturing systematic differences between valuations of two bidder types (in our case, strategic and financial). Such interpretations omit the potentially strong impact of intense competition in takeover auctions and, in turn, of dispersions of valuations and numbers of competing bidders. The OLS regression in the subsample, in which strategic bidders directly compete with financial bidders in the same auction, reveals that the difference between premiums is insignificant and provides the basic insight that competition matters. The OLS dummy likely captures a number of omitted variables, the difference between average valuations being only one of them. ${ }^{11}$ Armed with a model to recover valuations, I study which properties of valuations and participation result in the observed order of premiums.

\section{Estimation}

I estimate two versions of the empirical model presented in Section 2: with and without the dependence of dispersions of valuations on target and market characteristics. Both models result in similar estimates of average valuations and fit the data well. The first model allows for easier visual comparison of dispersions of valuations both between strategic and financial bidders and across multiple model modifications I consider in Sections 4.3 and $6 .{ }^{12}$ The second model fits the data slightly better. In addition, it provides target-level

\footnotetext{
${ }^{11}$ The additional difficulty is that premium regressions do not have a straightforward link to selection, or allocation of targets with certain characteristics to bidders of different types. In particular, size, M/B ratio, and R\&D have approximately the same impact on strategic versus financial premiums, yet Table 2 shows that strategic bidders acquire smaller targets with higher M/B ratio and R\&D. In Section 5.1, I show that the impact of these characteristics on valuations, which endogenously determine both premiums and allocation of targets to bidders of different types, can help explain descriptive statistics in Table 2 .

${ }^{12}$ In addition, the model, in which dispersions of valuations depend on target and market characteristics, takes substantially longer to estimate, which is critical for more computationally intensive model modifications.
} 
estimates of dispersions of valuations, which I use to explain the difference in type-specific premiums.

\subsection{Estimation results}

I follow the estimation strategy outlined in Section 2.5. At the first stage, I recover the probability that a bidder of an unobservable type is either strategic or financial. My results are not substantially different from Gorbenko and Malenko (2014), so I omit them here. At the second stage, I maximize the expected likelihood of observing all winning formal, losing formal, informal, and no bids across all bidders in all asset sales, using first-stage estimates of the probability that bidders of an unobservable type are either strategic or financial. The results are reported in Table 5. First, I interpret average valuation determinants in the simpler model with constant dispersions of valuations. Second, I interpret determinants of dispersions of valuations in the more general model. ${ }^{13}$ Finally, I discuss economic magnitudes of average valuations and dispersions of valuations across various subsamples.

\subsubsection{Constant dispersions of valuations}

The first three columns of Table 5 show that average strategic valuations are positively associated with $R \& D$ expenditures and negatively associated with target size and M/B ratio. Average financial valuations are positively associated with target's cash and negatively associated with M/B ratio. Target size can matter for strategic bidders because synergies between operating companies can have decreasing returns to scale. ${ }^{14}$ More surprising are different signs of valuation sensitivities to R\&D expenditures, M/B ratio, and cash, all of which are often used to proxy for the firm's investment opportunity set. Negative sensitivities to M/B ratio can mean that this control captures different investment opportunities than $\mathrm{R} \& \mathrm{D}$ and cash, or, more likely, that it is a worse proxy for investment opportunities and primarily captures market overvaluation of the target. Both average strategic and financial valuations are positively although insignificantly associated with leverage. In contrast to Gorbenko and Malenko (2014), neither the return on S\&P 500 nor the credit spread is significantly associated with valuations: period dummies capture the impact of market conditions. The coefficients associated with both periods of economic downturn and the period preceding the crisis are positive and significant for financial but not strategic bidders.

As conjectured, both average valuations are lower in auctions with higher participation: the coefficients

\footnotetext{
${ }^{13}$ The estimated coefficients in the model reveal sensitivities of average log-valuation premiums and dispersions of logvaluation premiums to target and market characteristics. Sensitivities of actual valuation premiums share signs and significance with these.

${ }^{14}$ Alternatively, the focus on deals completed in cash only can bias the size coefficient downwards, because strategic bidders pay with stock for larger targets. The robustness check in Section 4.2 confirms this intuition, finding a larger but still significant size coefficient in the sample that includes deals in combinations of cash and stock.
} 
associated with the number of bidders are negative and highly significant. This result is in line with theoretical predictions of Gentry and Stroup (2017). Average valuations decline with the number of bidders faster for strategic bidders. Furthermore, the coefficients associated with interaction terms for both periods of economic downturn and the period preceding the crisis are negative and significant for financial but not strategic bidders.

The joint implication of all coefficients associated with periods of economic activity and participation is as follows. Normally, the pool of potential financial bidders is ex-ante uniform, whereas the pool of potential strategic bidders is ex-ante dispersed, as captured by coefficients associated with the number of bidders. In periods of economic downturn, ex-ante top financial bidders have higher valuations than normally, as captured by coefficients associated with period dummies. This is likely because more firms are undervalued by the market relative to their fundamentals, and top financial bidders have the best expertise to identify and acquire such firms. However, the pool of potential financial bidders is shallower, which considerably lowers the average valuation across all financial auction participants, as captured by coefficients associated with interaction terms. Both effects are absent from valuations of strategic bidders. A formal way to compute the impact of participation controls on valuations is provided in Appendix E.

The estimated dispersion of strategic and financial log-valuations, which captures the post-due diligence bidder-specific private component, is approximately $25 \%$ and $15 \% .{ }^{15}$ For reasonable changes in target and market characteristics, the private component is the strongest valuation shifter for strategic bidders. However, it is weaker than the effect of market conditions for financial bidders. Financial bidders typically lack bidder-specific operational synergies and instead aim to acquire targets to implement target- and marketspecific restructuring and exit strategies. Small differences in these strategies result in small dispersion of the private valuation component, so that financial valuations are mostly captured by target and market characteristics. Strategic bidders often aim to acquire targets to extract bidder-specific operational synergies, which are not necessarily captured by target and market characteristics. Large differences in synergies among strategic bidders result in high dispersion of their private valuation component.

\subsubsection{Target-specific dispersions of valuations}

The remaining six columns of Table 5 present the results of the general model. Controls that affect dispersions of valuations, $Y$, include all controls in $X$ except for the number of bidders and its interactions

\footnotetext{
${ }^{15}$ The dispersion of actual log-normally distributed valuation premiums is computed as $\sqrt{e^{2 \hat{\mu}_{t}+2 \hat{\sigma}_{t}^{2}}-e^{2 \hat{\mu}_{t}+\hat{\sigma}_{t}^{2}}}, t \in\{s, f\}$. It is primarily affected by the estimate of dispersions of log-valuations. I analyze magnitudes of strategic and financial dispersions of valuations in Section 4.1.3.
} 
with period dummies. ${ }^{16}$ An intuitive way to understand estimates of dispersions is as follows. The constant term, $\hat{\sigma}_{t}^{0}, t \in\{s, f\}$, is $26.1 \%$ for strategic and $22.9 \%$ for financial bidders. Consider a target with sampleaverage target characteristics shown in the first row of Table 2, and consider sample-average levels of SP500 return and credit spread, $7.8 \%$ and $259 \mathrm{bp}$. Denote these average controls as $\bar{Y}$. In the baseline post dotcom period, dispersions of log-valuations of strategic and financial bidders for $\bar{Y}$ are $\hat{\sigma}_{s}$ (post dot-com) $=$ $\hat{\sigma}_{s}^{0} e^{\bar{Y} \hat{\delta}_{s}}=0.261 \times 0.791=20.7 \%$ and $\hat{\sigma}_{f}$ (post dot-com $)=12.8 \%$. A unit increase in any control $y \in Y$ results in a multiplicative increase in the dispersion by $e^{\hat{\delta}_{t, y}}$. E.g., during the crisis, dispersions of log-valuations of financial bidders for a target with characteristics $\bar{Y}$ increase to $\hat{\sigma}_{s}$ (crisis) $=0.128 \times e^{0.645}=24.4 \%$, while dispersions of strategic bidders remain unchanged.

Table 5 shows that in the general model of valuations, the impact of the crisis and the pre-crisis period, and $R \& D$ expenditures shifts from average valuations to their dispersions. Financial valuations are more dispersed during the crisis and, to a lesser extent, after the crisis, possibly because in these periods, it became harder to correctly estimate target misvaluation and potential financial synergies. Further, financial valuations are less dispersed in the boom period before the crisis and, interestingly, in the dot-com period, possibly because companies for sale in this period were similar and, as a result, financial and managerial improvements for them were commonly known. Strategic dispersions are positively associated with R\&D (at a $10 \%$ significance level), possibly because the presence of patents and growth options implies more diverse strategic synergies among bidders. Target size and M/B ratio (target size, cash flow, and intangibles) are negatively associated with dispersions of strategic (financial) valuations. As with average valuations, the implication is that M/B ratio possibly captures market misvaluation or different investment opportunities than R\&D. Low cash flow and high asset tangibility increase the variety of financial and operational restructuring strategies that financial bidders can pursue and imply more diverse financial synergies. Leverage has a non-linear effect on both strategic and financial dispersions; in addition, controlling for leverage in dispersions unlocks the similar significant impact of leverage on average valuations. Strategic (financial) bidders are presented with higher and more dispersed valuations for moderately (highly) levered targets, possibly because strategic synergies with a target that optimally manages its business (financial synergies with a target in financial distress) are high and more diverse.

To understand why in the general model of valuations the impact of various controls shifts between average valuations and dispersions, consider $\mathrm{R} \& \mathrm{D}$ and apply intuition behind identification explained in Section 2.6. If $\mathrm{R} \& \mathrm{D}$, in truth, is positively associated with dispersions of valuations of strategic bidders, then the model with constant dispersions underestimates dispersion of strategic valuations for high-R\&D targets. In contests with many bidders, high strategic premiums for high-R\&D targets are therefore interpreted as

\footnotetext{
${ }^{16}$ These factors are multicollinear with period dummies in the equation for dispersions, which makes coefficient estimates
} unstable and difficult to interpret. In turn, this instability affects counterfactual analyses. 
resulting from high average strategic valuations. The impact on dispersions is restored if they are modeled as target-specific. A similar intuition applies to the impact of leverage and the results in the crisis and pre-crisis period.

\subsubsection{Economic magnitudes of average valuations and dispersions}

For the general model of valuations, Table 6 complements Table 3 by comparing average strategic and financial valuations and their dispersions across industries, periods, and deals in the low versus high tertile of target characteristics. The numbers are obtained from estimates in Table 5. Across all auctions, the difference between average strategic and financial valuations is positive and significant: $27.9 \%$ versus $18.6 \%$ above the current value of the target. This difference remains positive and significant in all subsamples except for the dot-com period and the Wholesale, Retail industry. Similarly, across all auctions, the difference between dispersions of strategic and financial valuations is positive and significant: one standard deviation of valuations, on average, accounts for $31.2 \%$ versus $18.1 \%$ of the target value. The difference is positive and significant in all subsamples except for the crisis period, in which dispersions of strategic and financial valuations increase to $53.5 \%$ and $39.0 \%$. This is also the subsample, in which the number of financial bidders is lower than usual, but they pay, on average, a higher premium than strategic bidders. ${ }^{17}$ Overall, a casual comparison of Tables 3 and 6 shows that larger differences between strategic and financial takeover premiums are associated with larger differences between both average valuations and valuation dispersions. This result implies that the difference in premiums is unlikely to be attributed to a single omitted variable: the difference in valuations.

In Appendix E, I show that the dollar magnitude of changes in valuations in response to changes in market conditions is also substantial and can reach hundreds of millions of dollars. I also provide further evidence that few financial bidders become much stronger competitors in the crisis period by decomposing the winning bidders' private valuation component into shares retained by the bidder and received by the target through the payment. In particular, winning financial bidders retain $16.0 \%$ of their private valuation component during the crisis, compared to the sample-average share of $8.6 \%$.

\footnotetext{
${ }^{17}$ If bidders are ex-ante different within a type and the number of bidders in the model of valuations does not capture this additional heterogeneity well, the number of bidders can be positively associated with my measure of the post duediligence dispersion of valuations. A high dispersion of valuations of financial bidders during the crisis is not explained by this critique, because the number of financial bidders in this period substantially decreases. In Section 4.2, I explicitly allow for the unobservable ex-ante heterogeneity within a type. The estimated ranking of dispersions of strategic and financial bidders across periods remains unaffected.
} 


\subsection{Robustness analysis}

My results are robust to a large number of model modifications. In particular, I: (1) include deals completed in combinations of cash and stock with the fraction of stock in the total bid not exceeding $50 \%$; (2) modify definitions of controls, e.g., normalize cash balances by the market instead of book value of assets and normalize valuations by the target's enterprise instead of market value; (3) include various additional controls, e.g., industry dummies, target ownership characteristics, and measures of industry concentration; (4) control for both target and joint target-bidder leverage for strategic bidders, and past performance for financial bidders; ${ }^{18}$ (5) relax Assumptions 1-3. E.g., in case of Assumption 3, I allow a bidder to submit a bid if its valuation is above $90 \%$ of the target's value; in case of Assumption 2, I allow bidders to forfeit auctions, in which the highest bid is slightly below their valuations to account for bidding costs; (6) estimate the model on a subsample of takeover auctions, in which I know types of all bidders who (i) submit formal bids; (ii) submit formal and informal bids; (iii) sign confidentiality agreements; (7) allow for fat tails in the distribution of valuations ( $t$-distribution); (8) attempt to account for bidders' incentives to preempt both participating and potential rivals; ${ }^{19}(9)$ allow the current value of the target, $M_{i}$, to depend on the unobservable private component of the target management's valuation, and for a bidder to restructure the asset by removing this pre-existing component (e.g., synergies) upon winning; (10) explicitly allow for exante heterogeneity within a bidder type observable by bidders but not by the researcher, which is proxied by the number of bidders in the main version of the model. The final two robustness checks require non-trivial model modifications and are therefore described in detail in Appendix D. In all robustness checks, the sign and significance of coefficients in the valuation model, as well as the resulting impact of valuations and participation on takeover premiums, remain unaffected.

Taken together, my analysis shows that average valuations and their dispersions substantially change

\footnotetext{
${ }^{18} \mathrm{I}$ do not observe the identity and characteristics of a non-public, losing strategic bidder, therefore estimation of this model has to rely on strong assumptions. I assume that a strategic bidder of an unknown identity is drawn randomly from the set of U.S. public corporations in the same 2-digit SIC industry as the target. Similar strong assumptions are required to study the effect of financial bidders' past performance. The detailed description of the methodology and results are available upon request.

${ }^{19}$ Without imposing additional model structure, bidders' incentives to preempt participating rivals can be addressed similarly to robustness check (5). Specifically, I modify Assumption 2 to allow bidders with valuations below $b_{i, 1}(1+\alpha)$ to forfeit auctions, in which the winning bid, $b_{i, 1}$, signals the winning bidder's potential to bid up to $b_{i, 1}(1+\alpha)$. I estimate the model for a range of $\alpha \in[0,20 \%]$. It is more difficult to control for bidders' incentives to preempt potential rivals from entering the asset sale without a model of entry, which would require imposing substantial additional structure. Instead, I estimate the model in a subsample of auctions with the high number of bidders (at or above 5, or 10), in which potential entrants were likely not preempted.
} 
across targets and time. Both appear to simultaneously comove with takeover premiums, implying a nontrivial link between them. Next, using model simulations, I attempt to disentangle the impact of valuation properties and participation on strategic and financial premiums.

\section{Takeover premium determinants}

\subsection{Simulated allocations and premiums for estimated valuations}

I first confirm that the model fits the data well and therefore can be used to study takeover premiums. I simulate auction outcomes, i.e., the type of the winner and the takeover premium for each auction in the data using my estimates as valuation determinants. I create 1000 simulated samples and study average statistics. A caveat is that my model is incomplete; while Assumptions 1-3 provide an upper and lower bound on takeover premiums (The first-highest valuation and higher of the target's market value and the second-highest valuation, respectively), they alone are insufficient to pinpoint premiums exactly. To simulate premiums, I impose an additional assumption:

Assumption 4. A buyer gives away a fraction of the difference between the first- and second-highest valuation that depends on target and market characteristics $X$ and a zero-mean shock.

Note that Assumption 4 generally implies violation of the Revenue Equivalence Principle, because takeover premiums are not assumed equal to second-highest valuations. This is to be expected in auctions with asymmetric bidders and discrete bid changes (see, e.g., Krishna, 2009 and Avery, 1998). I simulate auction outcomes in two stages. First, I estimate the fraction of the difference between the expected firstand second-highest valuation, which is paid to the target, as a function of real-data auction outcomes. Second, I use this estimate to obtain takeover premiums in the simulated data. The detailed procedure is provided in Appendix C. ${ }^{20}$

Table 7 shows simulation results for models with both constant and target-specific dispersions of valuations. Comparison of Panels A and C with Table 1, and Panels B and D with Table 2 shows that simulated premiums and allocations (characteristics of targets acquired by bidders of different types) from both models closely resemble real data. The difference between strategic and financial premiums is significant at

\footnotetext{
${ }^{20}$ Two alternative assumptions is that a buyer, first, pays the second-highest valuation and, second, gives away a fixed percentage of the target's value over and above the second-highest valuation. The first assumption holds if the Revenue Equivalence Principle is applicable, which does not have to be the case in my setting. The second assumption better describes auctions, in which bidding proceeds in discrete increments. The results are unaffected if either of these alternative assumptions is used.
} 
the $5 \%$ level in almost all of the 1000 simulated samples. Because the simpler model does not allow for target-specific dispersions, it slightly misallocates from financial to strategic acquirers those targets, who according to the general model have a smaller difference between two type-specific dispersions. These are "mature" targets that are, on average, larger (smaller), have higher leverage and lower M/B ratio than a typical target acquired by a strategic (financial) bidder in the real data. To the extent that these targets are in need of financial and managerial restructuring, financial bidders are presented with more dispersed financial synergies. The general model allocates these targets better.

Before I move to the analysis of the impact of valuations on premiums, it is worth discussing their impact on allocations. In contrast to premium regressions in Table 4, which do not have a straightforward link to allocations, valuations shape both premiums and allocations and are therefore naturally aligned with descriptive statistics in Tables 2 and 7. Specifically, strategic valuations are negatively (positively) affected by the target's size and M/B ratio $(\mathrm{R} \& \mathrm{D})$, which aligns with strategic bidders acquiring smaller, higher-R\&D targets than financial bidders. In fact, the positive impact of $R \& D$ on valuations is strong enough to overcome the smaller negative effect of M/B ratio, which is positively correlated with $R \& D$, resulting in strategic bidders acquiring higher-M/B ratio targets than financial bidders.

Because of the better fit, I use the general model for the remainder of the section. I revisit the simpler model, which is easier to estimate and visually compare across model modifications, in Section 6 .

\subsection{Simulated allocations and premiums for counterfactual valuations}

Having established that the model performs well at capturing takeover outcomes, I proceed with the analysis of takeover premium determinants. To understand which properties of valuations and participation drive takeover premiums, I sequentially change them, simulate the counterfactual data, and compare strategic and financial premiums via the univariate regression. Specifically:

1. I change each estimated average strategic and financial log-valuation by the same type-specific constant, so that on average across all auctions, (i) average valuations of strategic and financial bidders are equal to each other and exactly in the middle of estimated values; (ii) dispersions of valuations remain equal to their estimated values.

2. I change each estimated dispersion of log-valuations of strategic and financial bidders by the same type-specific constant, so that on average across all auctions, (i) dispersions of valuations of strategic and financial bidders are equal to each other and exactly in the middle of estimated values; (ii) average valuations remain equal to their estimated values.

3. I increase the number of either strategic or financial bidders by $50 \%$ in each auction. ${ }^{21}$

\footnotetext{
${ }^{21}$ Alternative ways to set average valuations or their variances equal to each other across all auctions, e.g., equal to the
} 
As before, in all cases I create 1000 simulated samples. Table 8 presents the results. Panel A shows that when average valuations are equal across all auctions, financial bidders are allocated a slightly higher fraction of targets than before. The difference between strategic and financial premiums across simulated samples is $8.2 \%$ (a small decrease from $11.8 \%$ in the simulated data under estimated parameters). The difference is significant at the $5 \%$ level in $97.2 \%$ of simulated samples. Panel B shows that when dispersions of valuations are equal across all auctions, financial bidders are allocated a substantially higher fraction of targets than before. Strategic bidders pay a 1.0\% higher premium across simulated samples. The difference is significant at the $5 \%$ level in only $4.5 \%$ samples. Panels $\mathrm{C}$ and D show that when the number of strategic (financial) bidders is higher by $50 \%$ in each auction, financial bidders are allocated a substantially lower (slightly higher) fraction of targets than before, and strategic bidders pay a 18.6\% (8.5\%) higher premium. These differences are significant at the $5 \%$ level in $100 \%$ (96.3\%) simulated samples.

The univariate analysis reveals that contrary to common intuition, the impact of dispersions on premiums is substantially stronger than that of average valuations. The average takeover auction has approximately 12 participants. Because strategic valuations are very dispersed, the highest strategic valuation in an auction with many participants is typically far in the right tail of its distribution of valuations, so that a strategic winner pays a high premium. Because financial valuations are less dispersed, the highest financial bidder only wins in an unlikely case when there are no strong strategic bidders, upon which it pays a lower premium. The effect of average valuations on the highest valuation within a type are on a smaller scale than the effect of valuation dispersions. As a result, the difference between strategic and financial premiums collapses when dispersions but not average valuations are set equal. The impact of the difference in dispersions is likely to be muted in settings, where the average number of participants is low.

Table 9 extends the univariate analysis to subsamples by comparing counterfactual premiums across industries, periods, deals in the low versus high tertile of target characteristics, and individual firm scenarios. I set average valuations or variances of valuations equal within a given subsample of auctions and not across all auctions. In almost all subsamples and individual firm scenarios, the difference between strategic and financial premiums disappears when variances of valuations but not average valuations are set equal. The immediate practical implication is that in any industry and economic period, companies that plan to put themselves up for sale and expect the sale to attract substantial interest should pay primary attention to bidder heterogeneity when inviting potential bidders and evaluating their revenues from the sale.

estimated average valuation or variance of valuations of strategic or financial bidders, do not affect the results. If the number of either strategic or financial bidders is decreased rather than increased by $50 \%$, the impact on premiums is of similar magnitude and in the opposite direction. 


\subsection{OLS analysis of simulated data}

To further understand the composition of premiums, I conduct a multivariate analysis by revisiting OLS regressions of premiums in Section 3.2. I simultaneously include interaction terms between the strategic acquirer dummy and four previously omitted variables: differences between average valuations, their dispersions, and numbers of strategic and financial bidders. Table 10 shows the average results across 1000 samples of simulated data both at estimated and counterfactual parameters. I also report the fraction of samples, in which coefficients associated with the strategic acquirer dummy and its interactions with bidder properties are significant at the $5 \%$ level.

The first column of Table 10 shows that in the simulated data at estimated parameters, the standalone strategic acquirer dummy is significant. When the interaction term with the difference in average valuations is additionally included, this term is significant at the $5 \%$ level in $52.2 \%$ samples. The dummy remains significant, implying that the difference in average valuations does not fully explain the difference in premiums. When the interaction term with the difference between dispersions is additionally included, this term is significant at the $5 \%$ level in $72.9 \%$ samples. At the same time, the difference in average valuations remains significant in only $24.5 \%$ samples, and significance of the strategic acquirer dummy substantially decreases. Finally, when two interaction terms with numbers of strategic and financial bidders are addition-

ally included, they both are typically significant across simulated samples. The strategic acquirer dummy remains significant in only $36.6 \%$ samples. This result indicates that the four previously omitted variables combined explain the difference between takeover premiums well.

Using estimates of sensitivities of takeover premiums to bidder properties and across-sample differences in average strategic and financial valuations and their dispersions, reported in Table 6 to be $9.3 \%$ and 13.1\%, it is possible to decompose the impact of bidder properties on the difference in premiums. The difference in average valuations (their dispersions) accounts for $0.093 \times-0.205=-1.9 \%(0.131 \times 0.615=8.1 \%)$ of the target value in the difference in premiums equal to $11.8 \%$ of the target value. In relative terms, this is $-16.2 \%(68.3 \%)$ of the difference in premiums. Even though differences in both average valuations and their dispersions are statistically significant, the impact of average valuations on the difference in premiums is smaller and statistically insignificant. An additional strategic (financial) bidder above the average number of $4.5(7.6)$, reported in Table 7 , accounts for $(\log (1+5.5)-\log (1+4.5)) \times 0.061=1.02 \%(-0.63 \%)$ of the target value in the difference between premiums. In relative terms, this is $8.6 \%(-5.3 \%)$ of the difference in premiums. Similar analysis in the simulated data at counterfactual parameters indicates that the difference in dispersions of valuations and numbers of strategic and financial bidders but not the difference in average valuations primarily impact the difference in premiums. The only exception is the case, when dispersions of valuations of two bidder types are equal: here, the difference in average valuations naturally becomes more prominent. 
The next-to-last column of Table 10 adds four previously omitted variables to the OLS regression in the real data. The difference in dispersions but not in average valuations, again, emerges as the important driver of the difference in premiums and accounts for approximately the same percentage of it as in the simulated data. Numbers of strategic and financial bidders are insignificant. This result obtains because in contrast to the simulated data, in which numbers of strategic and financial bidders are known, in the real data I use expected numbers obtained via the first-stage predictive regression of the two-stage estimation procedure. Using noisy estimates of true participation attenuates the significance of the associated coefficients. The last column of Table 10 treats numbers of strategic and financial bidders as mismeasured regressors and applies the minimum-distance estimator of the errors-in-variables model of Erickson, Jiang, and Whited (2014) (the highest order of cumulants used is five). While coefficients associated with numbers of strategic and financial bidders remain insignificant, their signs (as well as signs of coefficients associated with other previously omitted variables) now align with those in the simulated data. ${ }^{22}$

My analysis shows that the major driver of the difference in takeover outcomes completed by strategic and financial bidders is not the difference in type-specific average valuations but in their dispersions. This result cautions against simple associations of the difference in type-specific outcomes of various asset sales with the difference in their average valuations. ${ }^{23}$

\footnotetext{
${ }^{22}$ A caveat is that the estimator of Erickson, Jiang, and Whited (2014) assumes independent measurement errors, while in my sample, numbers of strategic and financial bidders have to add up to the well-measured total number of bidders, implying a negative correlation between measurement errors.

${ }^{23}$ In practice, e.g., an increase in average valuations or their dispersions of strategic bidders would increase their relative strength and, in turn, their participation and likely decrease participation of financial bidders. In other words, participation changes jointly with valuation properties. While modeling the endogenous entry stage is beyond the scope of this paper, I perform various robustness checks to examine whether the difference in takeover premiums is differently affected by properties of valuations when they are linked to participation in a reasonable way. I assume that a small $1 \%$ increase in the average strategic valuation increases (decreases) the number of strategic (financial) bidders by $g_{s}$. A similar increase in the average financial valuation impacts participation in opposite directions by $g_{f}$. A small $1 \%$ increase in the dispersion of strategic valuations increases (decreases) the number of strategic (financial) bidders by $h_{s}$. A similar increase in the dispersion of financial valuations impacts participation in opposite directions by $h_{f}$. I consider multiple reasonable combinations of $\left(g_{s}, g_{f}, h_{s}, h_{f}\right)$ and run regressions on $X_{i}$, valuation properties, and participation similar to those in Table 10. The difference in dispersions still emerges as the major factor explaining the difference in takeover premiums. The result is robust with respect to $\left(g_{s}, g_{f}, h_{s}, h_{f}\right)$, so it is unlikely to be overturned in the model with true endogenous entry.
} 


\section{Heterogeneous-bidder asset sales with limited bidder data}

The advantage of the setting of strategic and financial bidders competing in takeover auctions is that data on bidder types and their formal and informal bids are available. In other settings, such as takeover contests among domestic and foreign bidders or bankruptcy auctions, researchers may have limited data, if any, on losing bidders. For example, before 2000, SEC deal backgrounds were less informative and rarely classified bidders into strategic and financial. Alternatively, whenever these data are available, they are costly to collect. For example, without reading takeover deal backgrounds, one usually only observes the identity of the winning bidder and the winning bid. ${ }^{24}$ In this section, I modify the model to recover valuations from limited bidder data. I show that average valuations and their dispersions can still be reliably estimated, allowing for a better understanding of their impact on asset sale outcomes in a variety of settings considered in the financial literature.

When data on losing bidders are limited, both the first and second stage of the estimation can be affected. If one only lacks data on losing bids and some losing bidders' types, the inference of unobservable bidders' types remains unchanged. If one lacks data on all losing bidders' types, the first stage of the estimation has to be either substituted with the external estimate of probabilities of participants' types (e.g., by consulting with market professionals) or merged with the second stage to jointly determine probabilities of types and valuations. If one lacks data on losing bids, the second stage of the estimation also has to be corrected because Assumptions 1-3 interpret the lack of these data as the lack of bids, leading to downward-biased estimates of average valuations. An alternative assumption that helps alleviate this bias in asset sales with many participants is that an asset sale can be approximated by a standard "clock" model of the ascendingbid auction. This approach to model auctions is common in the industrial organization literature (see, e.g., Donald and Paarsch, 1996 and Paarsch and Hong, 2006). In the "clock" model, the winning bidder pays the price at which the second-highest bidder drops out (i.e., its valuation, if valuation differences are private). Hence, the alternative assumption point-identifies the second-highest bidder's valuation. The "clock" model is a useful approximation of free-form asset sales with many participants (e.g., takeover or bankruptcy auctions), because competition is intense, so it is unlikely that the winning bidder would have incentives to bid substantially above its strongest competitor's valuation. ${ }^{25}$

\footnotetext{
${ }^{24}$ Databases, such as SDC, include data on a losing bidder only if there is a public announcement of a previously terminated merger agreement of this bidder with the target or a post-announcement round of bidding. Such cases are rare; in fact, most of the competition occurs in a private sale process and is not collected by SDC.

${ }^{25}$ While the "clock" model only corrects the second-highest bidder's valuation but not lower valuations, this is usually sufficient in, e.g., takeover auctions, where the number of non-winning formal bids per auction is 0.34 (almost always between zero and one). Both the main model, which relies on Assumptions 1-3 and all losing bidder data, and the "clock" model, which relies on winning bidder data only, would then locate the second-highest bidder (or bidders with lower valuations) with
} 
I first perform simulations to study performance of the modified model of valuations when data on losing bidders are limited. Then, I apply the modified model to the data on takeover auctions under the assumption that I only observe winning bids, and show that it recovers the ranking of type-specific average valuations and their dispersions well. Estimation details of the modified model are provided in Appendix B.

\subsection{Simulations}

I simulate data on a sample of asset sales, in which potential bidders belong to one of two types, $t \in\{a, b\}$. The parameters of each simulation are reported in Table 11. For each parameterization, I simulate outcomes of 1000 asset sales with limited data (the type of the winner and the winning bid only, as well as types of losing bidders). The winner is the bidder with the highest valuation, while the winning bid is equal to the second-highest valuation. I then compare average acquirer type-specific winning bids and estimate four parameters of interest, $\mu_{t}$ and $\sigma_{t}$ for $t \in\{a, b\}$.

Rows 1-5 of Table 11 assume that the set of competing bidders is fixed and known in every asset sale. Rows 1-3 study two-bidder contests that are similar in spirit to Examples 1 and 2 in Section 2.1. I show that when $\sigma_{a}>\sigma_{b}$ and $\mu_{a}$ changes, acquirers of type $a$ offer, on average, a higher payment. The comparison of average type-specific winning bids is thus uninformative about the ranking of average typespecific valuations. At the same time, the model of asset sales precisely estimates means and dispersions of valuations even in the absence of information about losing bids. Rows 4 and 5 study contests, in which there are multiple participants of one type (19 versus 1), similarly in spirit to Example 3 in Section 2.1. It becomes harder, for the same sample size, to infer properties of valuations when winning bids come from bidders with valuations in far right tails of valuation distributions: estimates are not as precise as those with few bidders. Despite this, the model still provides close estimates of means and dispersions of valuations.

Rows $6-8$ of Table 11 assume that the set of competing bidders can vary across asset sales. Specifically, I assume that there are four bidders per asset sale, and each bidder's type $t$ is drawn independently from the set $\{a, b\}$ with probability of each type $50 \%$. I then estimate the parameters of interest under different assumptions about information the researcher has about losing bidders, from most to least generous. In row 6 , the researcher knows types of losing bidders but not their bids. In row 7 , the researcher only knows the type of the winning bidder and the fact that each participating bidder is of type $a$ with probability $50 \%$. Estimates obtained under both information assumptions are in the close neighborhood of true parameter values. Hence, even without any data on individual losing bidders, a researcher can obtain good estimates of valuation properties provided that two conditions are satisfied: (1) the ascending-bid "clock" auction

high (or low) precision. 
model is a reasonable description of the asset sale process; (2) the researcher has a good prior belief about the probabilities of bidder types. Finally, in row 8 , the researcher does not even know the probability with which each bidder belongs to a given type, and estimates it together with properties of valuations from distributions of type-specific winning bids. ${ }^{26}$ While intuitive, this approach results in biased estimates, implying that at least some information about losing bidders is necessary. ${ }^{27}$

\subsection{Application to data on strategic and financial bidders}

A practical test of the estimation procedure that uses limited bidder data is to compare its outcome to the that of the full-data procedure. I apply the estimation procedure based on winning bids only to the data on strategic and financial bidders in takeover auctions. Specifically, I ignore all information on losing bidders, assuming that only the type of the winning bidder and the winning bid, as well as the number of competing bidders in the auction, are known. Clearly, there are not enough data to estimate all covariates of the model in Section 4 with desired levels of significance. For this reason, I focus on two simpler models. In the simplest model, shown in the first three columns of Panel A of Table 12, the valuation of each bidder is an i.i.d. draw from the type-specific distribution without any covariates. When the probability of bidder types is known, strategic bidders are estimated to have higher average and more dispersed valuations than financial bidders. In the first three columns of Panel B, I allow average type-specific valuations to differ across periods of economic activity and obtain similar results. When I supplement data on winning bidders with data on types but not bids of losing bidders, strategic bidders are estimated to have higher average valuations but the difference in dispersions is insignificant. The last three columns of Panels A and B show estimates assuming that the researcher knows nothing about participation rates of strategic and financial bidders and estimates them simultaneously with other parameters of interest. Strategic bidders

\footnotetext{
${ }^{26}$ Let $p_{a, i}$ be the probability that a bidder in asset sale $i$ is of type $a$. Let $w_{a, i}\left(p_{a, i} ; \theta\right)$ be the probability that a bidder of type $a$ wins asset $i$, which depends on the probabilities of bidder types and distributions of their valuations. It can be shown that for any $\theta, w_{a, i}\left(p_{a, i} ; \theta\right)$ is strictly increasing in $p_{a, i}$, which implies that an estimate $\hat{p}_{a, i}\left(\hat{w}_{a, i} ; \theta\right)$ can be obtained from an estimate $\hat{w}_{a, i}$ simultaneously with estimating $\theta . \hat{w}_{a, i}$ can be obtained via a Probit or Logit model from data on winning bidders only. Additional details are available upon request.

${ }^{27}$ Intuitively, there is no guarantee that a restricted minimum of the model's log-likelihood function, when the probability of bidder types is known, is equal to an unrestricted minimum, when this probability is one of the optimization parameters. The estimation procedure works well for $N=2$, i.e., in two-bidder contests, and results in a bias for $N>2$. As a result, it is applicable when the researcher is interested in, e.g., comparing the winning bidder with its strongest rival of an unknown type under the assumption that other potential bidders are not serious, or focusing on the public round of bidding in takeovers, which rarely exceeds two bids. Alternatively, the estimation procedure can be used in conjunction with even weaker information on probability of bidder types than point estimates: e.g., a restriction that $x \%$ to $y \%$ of bidders of a certain type participate in a given asset sale can substantially decrease bias.
} 
are estimated to have higher average valuations but the difference in their dispersions is insignificant. While the ranking of average valuations is the same, as Section 6.1 illustrates, parameter inference has to be taken cautiously in this case.

Overall, my results show that while the lack of data on losing bidders and the approximation of the free-form sale process with the "clock" model appear to be restrictive, the ranking of estimated average valuations and their dispersions remains unaffected. The difference in dispersions still emerges as a major driver of the difference in outcomes of asset sales with many participants.

\section{Conclusion}

Differences among bidder type-specific outcomes of asset sales in economics and finance are unlikely to be explained by average differences among bidder types alone. Using data on winning and losing bids made by strategic and financial bidders in takeover auctions, I show that the difference in dispersions of withinauction valuations as well as numbers of the two bidders' types affect the difference in takeover premiums more substantially than the difference in average valuations. This result implies that sellers should pay primary attention to bidder heterogeneity when inviting potential bidders and evaluating their revenues from the sale. My approach to study differences in type-specific outcomes is general enough to be applied to other asset sales with heterogeneous bidders. Two potential avenues of future research could be, first, to understand how properties of valuations and participation costs affect bidders' participation decisions and, in turn, observable numbers of bidders of each type across asset sales. The key challenge would be to come up with an incomplete model of participation that, similarly to the model of bidding, would capture properties of many different formal models of participation via several simple general assumptions. Second, estimated differences between bidder types could be used to devise theoretically optimal selling mechanisms that would result in the highest seller revenue. 
Table 1: Descriptive statistics of bidder participation and winning bids in auctions won by strategic and financial bidders, across industries, and periods

The table shows descriptive statistics (mean, standard deviation, and median) of bidder participation for auctions won by different types of bidders, across top 5 industries by number of deals from the 12-industry classification of Fama and French (1997), and across five periods of economic activity. Number is the number of auctions. Bidders is the number of bidders who signed confidentiality agreements, which is composed of Strategic bidders, Financial bidders, and Unknown bidders, those for whom information about their type is not provided in deal backgrounds. The winning bid is in units of the target's market value. Standard deviations are reported in parentheses. Medians are reported in brackets. The sample covers $01 / 01 / 2000$ to $05 / 02 / 2012$.

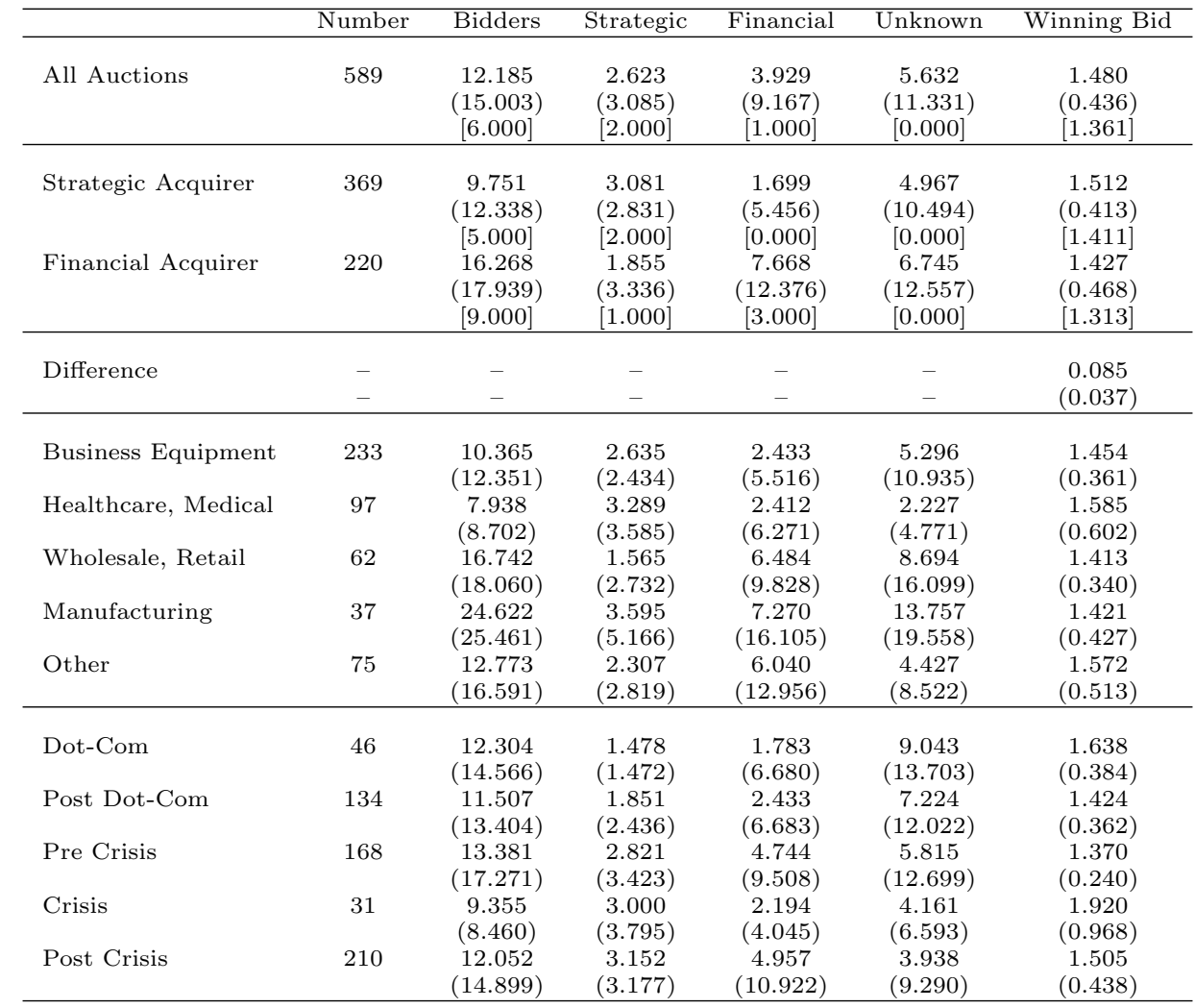


Table 2: Descriptive statistics of target characteristics in auctions won by strategic and financial bidders, across industries, and periods

The table shows descriptive statistics (mean, standard deviation, and median) of target characteristics for auctions won by different types of bidders, across top 5 industries by number of deals from the 12industry classification of Fama and French (1997), and across five periods of economic activity. Size is equal to book value (in $\$$ millions); Leverage is the ratio of book value of debt to the sum of market value of equity and book value of debt; $M / B$ Ratio is the ratio of the sum of market value of equity and book value of debt to book value of the target; Cash Flow is the sum of the last four quarterly cash flows; and Cash is the sum of cash, short-term investments, and marketable securities. Cash Flow, Cash, REDD, and Intangibles are normalized by target size. Standard deviations are reported in parentheses. Medians are reported in brackets. The sample covers 01/01/2000 to 05/02/2012.

\begin{tabular}{|c|c|c|c|c|c|c|c|}
\hline & Size & Leverage & M/B Ratio & Cash Flow & Cash & R\&D & Intangibles \\
\hline All Auctions & $\begin{array}{c}607.357 \\
(1906.204) \\
{[186.566]}\end{array}$ & $\begin{array}{c}0.168 \\
(0.231) \\
{[0.053]}\end{array}$ & $\begin{array}{c}1.467 \\
(1.123) \\
{[1.221]} \\
\end{array}$ & $\begin{array}{l}-0.006 \\
(0.280) \\
{[0.066]}\end{array}$ & $\begin{array}{c}0.257 \\
(0.238) \\
{[0.190]}\end{array}$ & $\begin{array}{c}0.019 \\
(0.038) \\
{[0.003]}\end{array}$ & $\begin{array}{c}0.181 \\
(0.209) \\
{[0.089]}\end{array}$ \\
\hline Financial Acquirer & $\begin{array}{c}397.655 \\
(952.681) \\
{[151.959]} \\
959.085 \\
(2834.173) \\
{[285.937]} \\
\end{array}$ & $\begin{array}{c}0.125 \\
(0.204) \\
{[0.017]} \\
0.241 \\
(0.256) \\
{[0.144]} \\
\end{array}$ & $\begin{array}{c}1.628 \\
(1.256) \\
{[1.304]} \\
1.195 \\
(0.785) \\
{[1.024]}\end{array}$ & $\begin{array}{c}-0.028 \\
(0.303) \\
{[0.058]} \\
0.030 \\
(0.232) \\
{[0.074]} \\
\end{array}$ & $\begin{array}{c}0.308 \\
(0.246) \\
{[0.247]} \\
0.173 \\
(0.199) \\
{[0.094]} \\
\end{array}$ & $\begin{array}{c}0.025 \\
(0.041) \\
{[0.013]} \\
0.009 \\
(0.029) \\
{[0.000]} \\
\end{array}$ & $\begin{array}{c}0.176 \\
(0.199) \\
{[0.092]} \\
0.190 \\
(0.224) \\
{[0.082]} \\
\end{array}$ \\
\hline Difference & $\begin{array}{c}-561.430 \\
(161.178) \\
\end{array}$ & $\begin{array}{l}-0.116 \\
(0.019)\end{array}$ & $\begin{array}{c}0.433 \\
(0.094)\end{array}$ & $\begin{array}{l}-0.058 \\
(0.024)\end{array}$ & $\begin{array}{c}0.134 \\
(0.020) \\
\end{array}$ & $\begin{array}{c}0.016 \\
(0.003) \\
\end{array}$ & $\begin{array}{c}-0.014 \\
(0.018)\end{array}$ \\
\hline Business Equipment & $\begin{array}{c}542.384 \\
(2317.830)\end{array}$ & $\begin{array}{c}0.087 \\
(0.157)\end{array}$ & $\begin{array}{c}1.471 \\
(0.958)\end{array}$ & $\begin{array}{l}-0.032 \\
(0.317)\end{array}$ & $\begin{array}{c}0.354 \\
(0.236)\end{array}$ & $\begin{array}{c}0.029 \\
(0.034)\end{array}$ & $\begin{array}{c}0.222 \\
(0.212)\end{array}$ \\
\hline Healthcare, Medical & $\begin{array}{c}428.917 \\
(747.013)\end{array}$ & $\begin{array}{c}0.140 \\
(0.211)\end{array}$ & $\begin{array}{c}2.167 \\
(1.892)\end{array}$ & $\begin{array}{l}-0.084 \\
(0.344)\end{array}$ & $\begin{array}{c}0.349 \\
(0.274)\end{array}$ & $\begin{array}{c}0.037 \\
(0.068)\end{array}$ & $\begin{array}{c}0.192 \\
(0.221)\end{array}$ \\
\hline Wholesale, Retail & $\begin{array}{c}727.668 \\
(1331.216)\end{array}$ & $\begin{array}{c}0.217 \\
(0.246)\end{array}$ & $\begin{array}{c}1.046 \\
(0.587)\end{array}$ & $\begin{array}{c}0.067 \\
(0.097)\end{array}$ & $\begin{array}{c}0.094 \\
(0.111)\end{array}$ & $\begin{array}{c}0.001 \\
(0.006)\end{array}$ & $\begin{array}{c}0.099 \\
(0.149)\end{array}$ \\
\hline Manufacturing & $\begin{array}{c}490.899 \\
(881.092)\end{array}$ & $\begin{array}{c}0.216 \\
(0.211)\end{array}$ & $\begin{array}{c}1.232 \\
(0.576)\end{array}$ & $\begin{array}{c}0.091 \\
(0.112)\end{array}$ & $\begin{array}{c}0.109 \\
(0.106)\end{array}$ & $\begin{array}{c}0.007 \\
(0.012)\end{array}$ & $\begin{array}{c}0.127 \\
(0.185)\end{array}$ \\
\hline Other & $\begin{array}{c}744.798 \\
(1884.144) \\
\end{array}$ & $\begin{array}{c}0.272 \\
(0.278) \\
\end{array}$ & $\begin{array}{c}1.178 \\
(0.788) \\
\end{array}$ & $\begin{array}{c}0.020 \\
(0.235) \\
\end{array}$ & $\begin{array}{c}0.172 \\
(0.196) \\
\end{array}$ & $\begin{array}{c}0.002 \\
(0.007) \\
\end{array}$ & $\begin{array}{c}0.183 \\
(0.220) \\
\end{array}$ \\
\hline Dot-Com & $\begin{array}{c}141.106 \\
(924.402)\end{array}$ & $\begin{array}{c}0.200 \\
(0.251)\end{array}$ & $\begin{array}{c}1.031 \\
(0.491)\end{array}$ & $\begin{array}{c}0.014 \\
(0.091)\end{array}$ & $\begin{array}{c}0.247 \\
(0.150)\end{array}$ & $\begin{array}{c}0.013 \\
(0.022)\end{array}$ & $\begin{array}{c}0.000 \\
(0.179)\end{array}$ \\
\hline Post Dot-Com & $\begin{array}{c}418.836 \\
(881.092)\end{array}$ & $\begin{array}{c}0.135 \\
(0.211)\end{array}$ & $\begin{array}{c}1.530 \\
(0.576)\end{array}$ & $\begin{array}{l}-0.067 \\
(0.112)\end{array}$ & $\begin{array}{c}0.312 \\
(0.106)\end{array}$ & $\begin{array}{c}0.022 \\
(0.012)\end{array}$ & $\begin{array}{c}0.128 \\
(0.185)\end{array}$ \\
\hline Pre Crisis & $\begin{array}{c}970.828 \\
(535.475)\end{array}$ & $\begin{array}{c}0.144 \\
(0.278)\end{array}$ & $\begin{array}{c}1.603 \\
(0.666)\end{array}$ & $\begin{array}{c}0.066 \\
(0.446)\end{array}$ & $\begin{array}{c}0.220 \\
(0.042)\end{array}$ & $\begin{array}{c}0.014 \\
(0.001)\end{array}$ & $\begin{array}{c}0.207 \\
(0.081)\end{array}$ \\
\hline Crisis & $\begin{array}{c}735.673 \\
(594.711)\end{array}$ & $\begin{array}{c}0.233 \\
(0.284)\end{array}$ & $\begin{array}{c}1.331 \\
(0.606)\end{array}$ & $\begin{array}{l}-0.227 \\
(0.218)\end{array}$ & $\begin{array}{c}0.386 \\
(0.141)\end{array}$ & $\begin{array}{c}0.051 \\
(0.009)\end{array}$ & $\begin{array}{c}0.203 \\
(0.245)\end{array}$ \\
\hline Post Crisis & $\begin{array}{c}520.065 \\
(2739.230)\end{array}$ & $\begin{array}{c}0.193 \\
(0.288)\end{array}$ & $\begin{array}{c}1.432 \\
(0.794)\end{array}$ & $\begin{array}{c}0.002 \\
(0.123)\end{array}$ & $\begin{array}{c}0.235 \\
(0.229)\end{array}$ & $\begin{array}{c}0.017 \\
(0.008)\end{array}$ & $\begin{array}{c}0.232 \\
(0.111)\end{array}$ \\
\hline
\end{tabular}


Table 3: Descriptive statistics of winning bids made by strategic and financial acquirers across industries, periods, and low and high tertiles or target characteristics

The table shows descriptive statistics (mean and standard deviation) of the number of auctions won and winning bids offered by strategic and financial bidders in various subsamples. Subsamples include top 5 industries by number of deals from the 12-industry classification of Fama and French (1997), five periods of economic activity, and targets in high and low tertiles of various target characteristics. Standard deviations are reported in parentheses. Where the difference between winning bids of strategic and financial bidders in a given subsample is statistically significant at the $5 \%$ level, the higher of the numbers is highlighted in bold. The full sample covers $01 / 01 / 2000$ to $05 / 02 / 2012$.

\begin{tabular}{|c|c|c|c|c|}
\hline & \multicolumn{2}{|c|}{ Strategic Acquirer } & \multicolumn{2}{|c|}{ Financial Acquirer } \\
\hline & Number & Winning Bid & Number & Winning Bid \\
\hline All Auctions & 369 & $\begin{array}{c}\mathbf{1 . 5 1 2} \\
(0.413) \\
\end{array}$ & 220 & $\begin{array}{r}1.427 \\
(0.468) \\
\end{array}$ \\
\hline Business Equipment & 169 & $\begin{array}{c}\mathbf{1 . 4 9 2} \\
(0.381)\end{array}$ & 64 & $\begin{array}{c}1.354 \\
(0.282)\end{array}$ \\
\hline Healthcare, Medical & 77 & $\begin{array}{c}1.562 \\
(0.529)\end{array}$ & 20 & $\begin{array}{c}1.674 \\
(0.840)\end{array}$ \\
\hline Wholesale, Retail & 16 & $\begin{array}{c}1.503 \\
(0.388)\end{array}$ & 46 & $\begin{array}{c}1.381 \\
(0.321)\end{array}$ \\
\hline Manufacturing & 23 & $\begin{array}{c}1.504 \\
(0.496)\end{array}$ & 14 & $\begin{array}{c}1.283 \\
(0.237)\end{array}$ \\
\hline Other & 34 & $\begin{array}{c}1.620 \\
(0.336) \\
\end{array}$ & 41 & $\begin{array}{c}1.532 \\
(0.624) \\
\end{array}$ \\
\hline Dot-Com & 29 & $\begin{array}{l}1.678 \\
(0.384)\end{array}$ & 17 & $\begin{array}{l}1.570 \\
(0.385)\end{array}$ \\
\hline Post Dot-Com & 83 & $\begin{array}{l}1.445 \\
(0.346)\end{array}$ & 51 & $\begin{array}{l}1.389 \\
(0.387)\end{array}$ \\
\hline Pre Crisis & 98 & $\begin{array}{l}\mathbf{1 . 4 2 1} \\
(0.256)\end{array}$ & 70 & $\begin{array}{c}1.298 \\
(0.197)\end{array}$ \\
\hline Crisis & 22 & $\begin{array}{l}1.627 \\
(0.589)\end{array}$ & 9 & $\begin{array}{c}\mathbf{2 . 6 3 7} \\
(1.337)\end{array}$ \\
\hline Post Crisis & 137 & $\begin{array}{c}\mathbf{1 . 5 6 4} \\
(0.489)\end{array}$ & 73 & $\begin{array}{c}1.395 \\
(0.296)\end{array}$ \\
\hline Low/High Size & $138 / 98$ & $\begin{array}{c}\mathbf{1 . 6 5 3} / \\
(0.519) /(0.3106)\end{array}$ & $58 / 98$ & $\begin{array}{c}1.493 / 1.373 \\
(0.590) /(0.357)\end{array}$ \\
\hline Low/High Leverage & $143 / 91$ & $\begin{array}{c}\mathbf{1 . 4 9 3} /{ }^{1.591} \\
(0.415) /(0.491)\end{array}$ & $53 / 105$ & 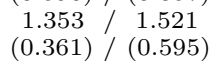 \\
\hline Low/High M/B Ratio & $104 / 147$ & $\begin{array}{c}1.657 / / \mathbf{1 . 4 5 0} \\
(0.493) /(0.398)\end{array}$ & $92 / 49$ & $\begin{array}{ccc}1.572 & / & 1.285 \\
(0.610) & / & (0.148)\end{array}$ \\
\hline Low/High Cash Flow & $139 / 112$ & $\begin{array}{c}1.626 / / 1.411 \\
(0.525) /(0.286)\end{array}$ & $57 / 84$ & $\begin{array}{c}1.693 / 1.338 \\
(0.700) /(0.246)\end{array}$ \\
\hline Low/High Cash & $89 / 158$ & $\begin{array}{c}1.501 / / 1.526 \\
(0.373) /(0.431)\end{array}$ & $107 / 38$ & $\begin{array}{ccc}1.447 & / & 1.434 \\
(0.480) & / & (0.527)\end{array}$ \\
\hline Low/High R\&D & $129 / 160$ & $\begin{array}{c}1.480 / / 1.556 \\
(0.341) /(0.472)\end{array}$ & $155 / 36$ & $\begin{array}{c}1.430 / / 1.451 \\
(0.442) /(0.536)\end{array}$ \\
\hline
\end{tabular}


Table 4: OLS regressions of takeover premiums

The table shows the estimation results (mean and standard deviation) of the OLS regression of winning bids on target and market characteristics. Column (1) shows results when the set of control variables does not include the number of bidders. Column (2) shows results when the set of control variables is complemented by the logarithm of the number of bidders and its interactions with period dummies. Columns (3) and (4) show results of the same regression in the sample of deals, in which both strategic and financial bidders simultaneously participate (428 auctions), and which do not include the untypical crisis period (558 auctions). The last two columns, collectively marked as (5), show results when the "Strategic Acquirer" dummy is interacted with target and market characteristics, allowing for a more detailed study of takeover premium differences. The latter (former) column shows coefficient estimates, which (do not) involve the "Strategic Acquirer" dummy. Standard deviations are reported in parentheses. Statistical significance is highlighted in bold for the $5 \%$ level. The bottom line reports the regressions' adjusted $R^{2}$. The sample covers $01 / 01 / 2000$ to $05 / 02 / 2012$.

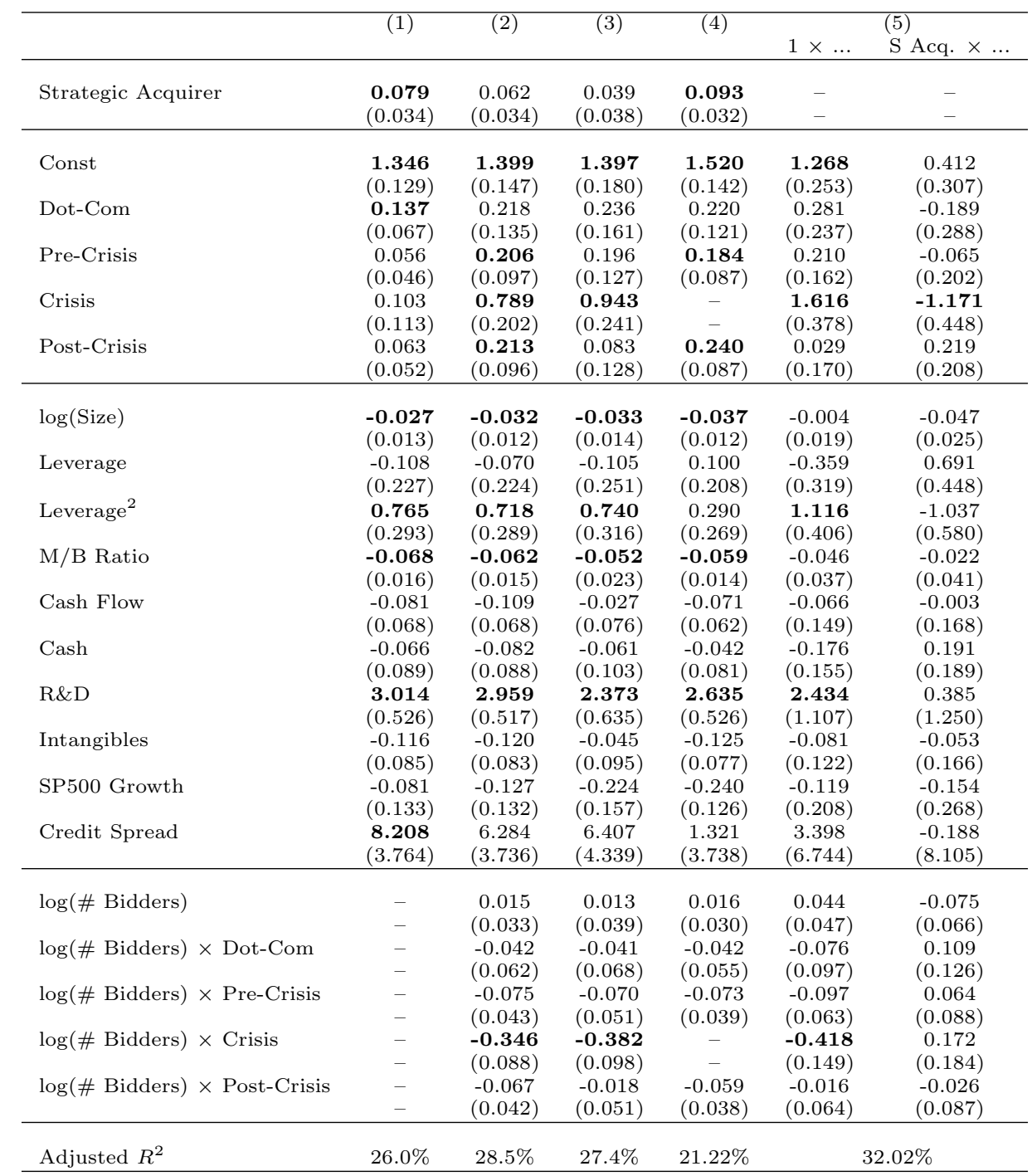


Table 5: Estimation results of the model of valuations: cases of constant and target-specific dispersions of valuations

The table shows the estimation results (mean and standard deviation) for the determinants of strategic and financial bidders' average valuations and their dispersions. The first three columns show results of the model, in which dispersions of valuations do not depend on target and market characteristics. The last six columns show results of the model, in which dispersions of valuations are target-specific. Standard deviations are reported in parentheses. Statistical significance is highlighted in bold for the $5 \%$ level. The sample covers $01 / 01 / 2000$ to $05 / 02 / 2012$.

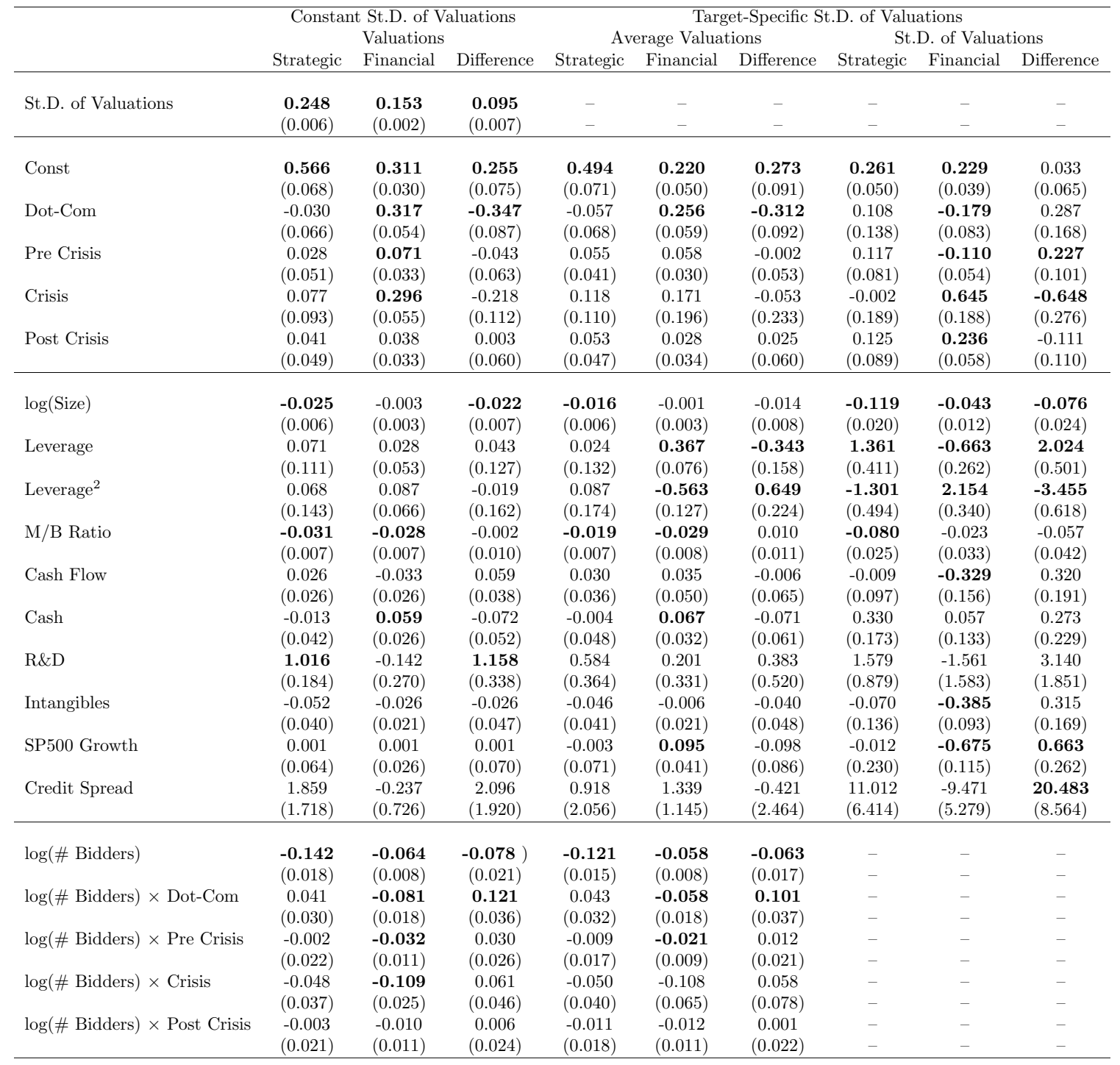


Table 6: Estimated average valuations and dispersions of valuations across industries, periods, and low and high tertiles of target characteristics: the case of target-specific dispersions of valuations

The table shows the estimation results (mean and standard deviation) for average valuations and dispersions of valuations of strategic and financial bidders in various subsamples. The estimated dispersions of valuations are target-specific and correspond to the last six columns of Table 5. Subsamples include top 5 industries by number of deals from the 12-industry classification of Fama and French (1997), five periods of economic activity, and targets in high and low tertiles of various target characteristics. Standard deviations are reported in parentheses. The test for the difference between two means in a given subsample shows a significant difference at the $5 \%$ level for all average valuations except in the Wholesale, Retail industry and in the dot-com period, and for all dispersions of valuations except in the crisis period. The full sample covers $01 / 01 / 2000$ to $05 / 02 / 2012$.

\begin{tabular}{|c|c|c|c|c|}
\hline & \multicolumn{2}{|c|}{ Strategic Bidder } & \multicolumn{2}{|c|}{ Financial Bidder } \\
\hline & Avg. Valuation & St.D. of Valuations & Avg. Valuation & St.D. of Valuations \\
\hline All Auctions & $\begin{array}{c}1.279 \\
(0.182)\end{array}$ & $\begin{array}{c}0.312 \\
(0.178)\end{array}$ & $\begin{array}{c}1.186 \\
(0.115)\end{array}$ & $\begin{array}{c}0.181 \\
(0.112)\end{array}$ \\
\hline Business Equipment & $\begin{array}{c}1.290 \\
(0.161)\end{array}$ & $\begin{array}{c}0.317 \\
(0.111)\end{array}$ & $\begin{array}{c}1.190 \\
(0.106)\end{array}$ & $\begin{array}{c}0.168 \\
(0.091)\end{array}$ \\
\hline Healthcare, Medical & $\begin{array}{l}1.330 \\
(0.231)\end{array}$ & $\begin{array}{c}0.361 \\
(0.364)\end{array}$ & $\begin{array}{l}1.194 \\
(0.129)\end{array}$ & $\begin{array}{c}0.182 \\
(0.101)\end{array}$ \\
\hline Wholesale, Retail & $\begin{array}{l}1.225 \\
(0.176)\end{array}$ & $\begin{array}{c}0.268 \\
(0.100)\end{array}$ & $\begin{array}{l}1.166 \\
(0.113)\end{array}$ & $\begin{array}{c}0.169 \\
(0.076)\end{array}$ \\
\hline Manufacturing & $\begin{array}{l}1.212 \\
(0.205)\end{array}$ & $\begin{array}{c}0.296 \\
(0.114)\end{array}$ & $\begin{array}{l}1.147 \\
(0.118)\end{array}$ & $\begin{array}{c}0.159 \\
(0.060)\end{array}$ \\
\hline Other & $\begin{array}{c}1.275 \\
(0.160) \\
\end{array}$ & $\begin{array}{c}0.304 \\
(0.108) \\
\end{array}$ & $\begin{array}{c}1.207 \\
(0.132) \\
\end{array}$ & $\begin{array}{c}0.208 \\
(0.175) \\
\end{array}$ \\
\hline Dot-Com & $\begin{array}{c}1.338 \\
(0.128)\end{array}$ & $\begin{array}{c}0.391 \\
(0.126)\end{array}$ & $\begin{array}{c}1.362 \\
(0.157)\end{array}$ & $\begin{array}{c}0.186 \\
(0.072)\end{array}$ \\
\hline Post Dot-Com & $\begin{array}{l}1.249 \\
(0.159)\end{array}$ & $\begin{array}{c}0.276 \\
(0.090)\end{array}$ & $\begin{array}{l}1.154 \\
(0.074)\end{array}$ & $\begin{array}{c}0.171 \\
(0.067)\end{array}$ \\
\hline Pre Crisis & $\begin{array}{c}1.251 \\
(0.167)\end{array}$ & $\begin{array}{c}0.265 \\
(0.089)\end{array}$ & $\begin{array}{c}1.162 \\
(0.099)\end{array}$ & $\begin{array}{c}0.131 \\
(0.035)\end{array}$ \\
\hline Crisis & $\begin{array}{c}1.417 \\
(0.347)\end{array}$ & $\begin{array}{c}0.535 \\
(0.589)\end{array}$ & $\begin{array}{l}1.188 \\
(0.181)\end{array}$ & $\begin{array}{c}0.390 \\
(0.238)\end{array}$ \\
\hline Post Crisis & $\begin{array}{l}1.288 \\
(0.172)\end{array}$ & $\begin{array}{c}0.324 \\
(0.114)\end{array}$ & $\begin{array}{l}1.187 \\
(0.090)\end{array}$ & $\begin{array}{c}0.194 \\
(0.118)\end{array}$ \\
\hline Low/High Size & $\begin{array}{c}1.341 / \\
(0.211) /(0.151)\end{array}$ & $\begin{array}{ccc}0.405 / & 0.237 \\
(0.264) & / & (0.061)\end{array}$ & $\begin{array}{c}1.204 / \\
(0.139)\end{array}$ & $\begin{array}{c}0.196 / 0.163 \\
(0.105) /(0.092)\end{array}$ \\
\hline Low/High Leverage & $\begin{array}{c}1.306 / / 1.284 \\
(0.164) /(0.210)\end{array}$ & $\begin{array}{c}0.312 / / 0.353 \\
(0.125) /(0.259)\end{array}$ & $\begin{array}{cc}1.184 / & 1.201 \\
(0.111) & /\end{array}$ & $\begin{array}{cc}0.164 / & 0.231 \\
(0.047) /(0.172)\end{array}$ \\
\hline Low/High M/B Ratio & $\begin{array}{cc}1.314 / & 1.260 \\
(0.211) /(0.143)\end{array}$ & $\begin{array}{c}0.376 / c^{2} \\
(0.260) /(0.104)\end{array}$ & $\begin{array}{c}1.219 / \\
(0.130) /(0.096)\end{array}$ & $\begin{array}{ccc}0.234 / & 0.149 \\
(0.158) & /(0.075)\end{array}$ \\
\hline Low/High Cash Flow & $\begin{array}{c}1.332 / 1.236 \\
(0.195) /(0.162)\end{array}$ & 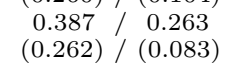 & $\begin{array}{c}1.195 / 1.170 \\
(0.124) /(0.114)\end{array}$ & $\begin{array}{c}0.236 / 0.145 \\
(0.158) /(0.050)\end{array}$ \\
\hline Low/High Cash & $\begin{array}{c}1.250 / 1.325 \\
(0.167) /(0.196)\end{array}$ & $\begin{array}{c}0.289 / 0.360 \\
(0.094) /(0.267)\end{array}$ & $\begin{array}{c}1.180 / / 1.203 \\
(0.112) /(0.125)\end{array}$ & $\begin{array}{c}0.191 / / 0.182 \\
(0.120) /(0.091)\end{array}$ \\
\hline Low/High R\&D & $\begin{array}{c}1.238 / / 1.344 \\
(0.170) /(0.190)\end{array}$ & $\begin{array}{c}0.286 / / 0.367 \\
(0.101) /(0.269)\end{array}$ & $\begin{array}{cc}1.178 / & 1.197 \\
(0.118) & /(0.115)\end{array}$ & $\begin{array}{ccc}0.187 & / & 0.179 \\
(0.127) & / & (0.101)\end{array}$ \\
\hline
\end{tabular}


Table 7: Simulated economy, 1000x original sample, at estimated parameters: cases of constant and target-specific dispersions of valuations

Panels $\mathrm{A}$ and $\mathrm{C}$ of the table show descriptive statistics (mean and standard deviation) of the composition of competition, bounds on the outcome of takeover auctions, and winning bids in a simulated economy in which bidders value targets according to the model with constant (Panel A) and target-specific (Panel C) dispersions of valuations. Panels B and D show descriptive statistics (mean and standard deviation) of target characteristics in a simulated economy in which bidders value targets according to the model with constant (Panel B) and target-specific (Panel D) dispersions of valuations. Valuation determinants for both models are shown in Table 5. Each target in the sample is replicated 1000 times and 1000 samples similar to the real sample are formed; for each replication, a different set of bidder valuations is simulated. Standard deviations are reported in parentheses. Fractions of simulated samples, in which differences between strategic and financial bidders are significant at the $5 \%$ level, are reported in brackets.

Panel A: Constant SD of PV: bidder participation, two highest valuations, and winning bids

\begin{tabular}{lccccccc}
\hline & Number & Bidders & Strategic & Financial & $2^{\text {nd }}$ Valuation & $1^{\text {st }}$ Valuation & Winning Bid \\
\hline All Auctions & 589000 & 12.183 & 4.548 & 7.635 & 1.392 & 1.632 & 1.470 \\
& & $(14.986)$ & $(4.113)$ & $(12.770)$ & $(0.208)$ & $(0.308)$ & $(0.224)$ \\
Strategic Acquirer & 408689 & 9.779 & 4.966 & 4.813 & 1.418 & 1.706 & 1.512 \\
& & $(12.512)$ & $(3.941)$ & $(9.921)$ & $(0.226)$ & $(0.324)$ & $(0.238)$ \\
Financial Acquirer & \multirow{2}{*}{180311} & 17.634 & 3.603 & 14.031 & 1.333 & 1.462 & 1.374 \\
& & $(18.328)$ & $(4.333)$ & $(15.833)$ & $(0.145)$ & $(0.174)$ & $(0.148)$ \\
\hline Difference & - & - & - & - & 0.085 & 0.244 & 0.138 \\
& - & - & - & - & $(0.018)$ & $(0.026)$ & $(0.019)$ \\
& - & - & - & - & {$[100 \%]$} & {$[100 \%]$} & {$[100 \%]$} \\
\hline
\end{tabular}

Panel B: Constant SD of PV: Target characteristics

\begin{tabular}{lccccccc}
\hline & Size & Leverage & $q$-ratio & Cash Flow & Cash & R\&D & Intangibles \\
\hline All Auctions & 607.357 & 0.168 & 1.467 & -0.006 & 0.257 & 0.019 & 0.181 \\
& $(1904.587)$ & $(0.231)$ & $(1.122)$ & $(0.280)$ & $(0.238)$ & $(0.038)$ & $(0.209)$ \\
Strategic Acquirer & 428.522 & 0.144 & 1.569 & -0.030 & 0.294 & 0.024 & 0.169 \\
& $(1043.397)$ & $(0.219)$ & $(1.239)$ & $(0.309)$ & $(0.249)$ & $(0.043)$ & $(0.199)$ \\
Financial Acquirer & 1012.701 & 0.224 & 1.234 & 0.048 & 0.174 & 0.007 & 0.209 \\
& $(3024.075)$ & $(0.247)$ & $(0.747)$ & $(0.186)$ & $(0.188)$ & $(0.017)$ & $(0.227)$ \\
\hline Difference & -584.179 & -0.080 & 0.335 & -0.078 & 0.120 & 0.017 & -0.040 \\
& $(169.286)$ & $(0.020)$ & $(0.100)$ & $(0.025)$ & $(0.021)$ & $(0.003)$ & $(0.019)$ \\
& {$[99.8 \%]$} & {$[99.5 \%]$} & {$[99.2 \%]$} & {$[96.7 \%]$} & {$[100 \%]$} & {$[100 \%]$} & {$[58.8 \%]$} \\
\hline
\end{tabular}

Panel C: Target-specific SD of PV: bidder participation, two highest valuations, and winning bids

\begin{tabular}{lccccccc}
\hline & Number & Bidders & Strategic & Financial & $2^{\text {nd }}$ Valuation & $1^{\text {st }}$ Valuation & Winning Bid \\
\hline All Auctions & 589000 & 12.183 & 4.547 & 7.637 & 1.386 & 1.630 & 1.465 \\
& & $(14.986)$ & $(4.110)$ & $(12.772)$ & $(0.247)$ & $(0.460)$ & $(0.283)$ \\
Strategic Acquirer & \multirow{2}{*}{412897} & 10.022 & 4.987 & 5.035 & 1.406 & 1.692 & 1.500 \\
& & $(12.981)$ & $(3.965)$ & $(10.379)$ & $(0.251)$ & $(0.464)$ & $(0.290)$ \\
Financial Acquirer & \multirow{2}{*}{176103} & 17.251 & 3.514 & 13.737 & 1.339 & 1.485 & 1.382 \\
& & $(17.872)$ & $(4.256)$ & $(15.490)$ & $(0.232)$ & $(0.415)$ & $(0.246)$ \\
\hline Difference & - & - & - & - & 0.067 & 0.207 & 0.118 \\
& - & - & - & - & $(0.022)$ & $(0.039)$ & $(0.025)$ \\
& - & - & - & - & {$[90.4 \%]$} & {$[99.3 \%]$} & {$[99.9 \%]$} \\
\hline
\end{tabular}

Panel D: Target-specific SD of PV: Target characteristics

\begin{tabular}{lccccccc}
\hline & Size & Leverage & $q$-ratio & Cash Flow & Cash & R\&D & Intangibles \\
\hline All Auctions & 607.357 & 0.168 & 1.467 & -0.006 & 0.257 & 0.019 & 0.181 \\
& $(1904.587)$ & $(0.231)$ & $(1.122)$ & $(0.280)$ & $(0.238)$ & $(0.038)$ & $(0.209)$ \\
Strategic Acquirer & 419.522 & 0.139 & 1.573 & -0.024 & 0.295 & 0.024 & 0.172 \\
& $(1043.992)$ & $(0.211)$ & $(1.239)$ & $(0.300)$ & $(0.249)$ & $(0.042)$ & $(0.201)$ \\
Financial Acquirer & 1047.761 & 0.238 & 1.218 & 0.036 & 0.168 & 0.007 & 0.204 \\
& $(3049.655)$ & $(0.260)$ & $(0.723)$ & $(0.220)$ & $(0.181)$ & $(0.022)$ & $(0.224)$ \\
\hline Difference & -628.239 & -0.100 & 0.355 & -0.060 & 0.128 & 0.017 & -0.032 \\
& $(170.179)$ & $(0.020)$ & $(0.100)$ & $(0.025)$ & $(0.021)$ & $(0.003)$ & $(0.019)$ \\
& {$[100 \%]$} & {$[100 \%]$} & {$[99.8 \%]$} & {$[75.9 \%]$} & {$[100 \%]$} & {$[100 \%]$} & {$[38.7 \%]$} \\
\hline
\end{tabular}


Table 8: Simulated economy, 1000x original sample, at counterfactual parameters: the case of target-specific dispersions of valuations

The table shows descriptive statistics (mean and standard deviation) of the composition of competition, bounds on the outcome of takeover auctions, and winning bids in four counterfactual simulated economies. In the first economy (Panel A), average valuations of strategic and financial bidders across the sample are set equal to each other and exactly in the middle of estimated values. In the second economy (Panel B), dispersions of valuations of strategic and financial bidders across the sample are set equal to each other and exactly in the middle of estimated values. In the third and fourth economy (Panels C and D), the number of strategic and financial bidders is increased by $50 \%$ in each auction. Other than the indicated change, bidders in each economy value targets according to the model with target-specific dispersions of valuations. Valuation determinants are shown in Table 5. Each target in the sample is replicated 1000 times and 1000 samples similar to the real sample are formed; for each replication, a different set of bidder valuations is simulated. Standard deviations are reported in parentheses. Fractions of simulated samples, in which differences between strategic and financial bidders are significant at the $5 \%$ level, are reported in brackets.

Panel A: Average valuations of strategic and financial bidders are equal across sample

\begin{tabular}{lccccccc}
\hline & Number & Bidders & Strategic & Financial & $2^{\text {nd }}$ Valuation & $1^{\text {st }}$ Valuation & Winning Bid \\
\hline All Auctions & 589000 & 12.183 & 4.546 & 7.637 & 1.378 & 1.614 & 1.455 \\
& & $(14.986)$ & $(4.106)$ & $(12.773)$ & $(0.241)$ & $(0.448)$ & $(0.273)$ \\
Strategic Acquirer & \multirow{2}{*}{373207} & 9.232 & 4.913 & 4.319 & 1.388 & 1.679 & 1.486 \\
& & $(12.141)$ & $(3.844)$ & $(9.619)$ & $(0.254)$ & $(0.474)$ & $(0.293)$ \\
Financial Acquirer & 215793 & 17.288 & 3.911 & 13.377 & 1.360 & 1.503 & 1.403 \\
& & $(17.802)$ & $(4.453)$ & $(15.274)$ & $(0.215)$ & $(0.375)$ & $(0.227)$ \\
\hline Difference & - & - & - & - & 0.029 & 0.175 & 0.082 \\
& - & - & - & - & $(0.021)$ & $(0.036)$ & $(0.023)$ \\
& - & - & - & - & {$[23.8 \%]$} & {$[99.2 \%]$} & {$[97.2 \%]$} \\
\hline
\end{tabular}

Panel B: Dispersions of valuations of strategic and financial bidders are equal across sample

\begin{tabular}{lccccccc}
\hline & Number & Bidders & Strategic & Financial & $2^{\text {nd }}$ Valuation & $1^{\text {st }}$ Valuation & Winning Bid \\
\hline All Auctions & 589000 & 12.183 & 4.549 & 7.635 & 1.401 & 1.624 & 1.472 \\
& & $(14.986)$ & $(4.111)$ & $(12.772)$ & $(0.265)$ & $(0.531)$ & $(0.290)$ \\
Strategic Acquirer & \multirow{2}{*}{365418} & 7.746 & 4.571 & 3.175 & 1.395 & 1.628 & 1.476 \\
& & $(9.637)$ & $(3.515)$ & $(7.407)$ & $(0.215)$ & $(0.348)$ & $(0.235)$ \\
Financial Acquirer & 223582 & 19.436 & 4.513 & 14.923 & 1.410 & 1.617 & 1.465 \\
& & $(18.842)$ & $(4.933)$ & $(15.951)$ & $(0.331)$ & $(0.737)$ & $(0.363)$ \\
\hline Difference & - & - & - & - & -0.015 & 0.011 & 0.010 \\
& - & - & - & - & $(0.022)$ & $(0.042)$ & $(0.024)$ \\
& - & - & - & - & {$[3.8 \%]$} & {$[5.9 \%]$} & {$[4.5 \%]$} \\
\hline
\end{tabular}

Panel C: Each auction contains 50\% more strategic bidders

\begin{tabular}{lccccccc}
\hline & Number & Bidders & Strategic & Financial & $2^{\text {nd }}$ Valuation & $1^{\text {st }}$ Valuation & Winning Bid \\
\hline All Auctions & 589000 & 14.681 & 7.044 & 7.636 & 1.474 & 1.711 & 1.549 \\
& & $(16.382)$ & $(6.185)$ & $(12.775)$ & $(0.275)$ & $(0.502)$ & $(0.323)$ \\
Strategic Acquirer & 451411 & 13.173 & 7.645 & 5.528 & 1.507 & 1.771 & 1.593 \\
& & $(14.937)$ & $(6.005)$ & $(10.812)$ & $(0.274)$ & $(0.496)$ & $(0.325)$ \\
Financial Acquirer & \multirow{2}{*}{137589} & 19.628 & 5.073 & 14.555 & 1.365 & 1.513 & 1.407 \\
& & $(19.619)$ & $(6.355)$ & $(15.894)$ & $(0.252)$ & $(0.471)$ & $(0.270)$ \\
\hline Difference & - & - & - & - & 0.142 & 0.258 & 0.186 \\
& - & - & - & - & $(0.026)$ & $(0.046)$ & $(0.030)$ \\
& - & - & - & - & {$[100 \%]$} & {$[99.6 \%]$} & {$[100 \%]$} \\
\hline
\end{tabular}

Panel D: Each auction contains 50\% more financial bidders

\begin{tabular}{lccccccc}
\hline & Number & Bidders & Strategic & Financial & $2^{\text {nd }}$ Valuation & $1^{\text {st }}$ Valuation & Winning Bid \\
\hline All Auctions & 589000 & 16.192 & 4.548 & 11.645 & 1.413 & 1.649 & 1.489 \\
& & $(21.261)$ & $(4.109)$ & $(19.196)$ & $(0.254)$ & $(0.486)$ & $(0.293)$ \\
Strategic Acquirer & \multirow{2}{*}{390947} & 12.257 & 4.988 & 7.269 & 1.423 & 1.708 & 1.518 \\
& & $(17.637)$ & $(3.933)$ & $(15.179)$ & $(0.253)$ & $(0.482)$ & $(0.297)$ \\
Financial Acquirer & \multirow{2}{*}{198053} & 23.961 & 3.679 & 20.282 & 1.393 & 1.533 & 1.433 \\
& & $(25.286)$ & $(4.305)$ & $(22.992)$ & $(0.255)$ & $(0.474)$ & $(0.277)$ \\
\hline Difference & - & - & - & - & 0.031 & 0.175 & 0.085 \\
& - & - & - & - & $(0.022)$ & $(0.040)$ & $(0.025)$ \\
& - & - & - & - & {$[26.1 \%]$} & {$[98.0 \%]$} & {$[96.3 \%]$} \\
\hline
\end{tabular}


Table 9: Simulated subsamples, 1000x original sample, at counterfactual parameters: the case of target-specific st. dev. of private valuations

The table shows descriptive statistics (mean) of winning bids offered by strategic and financial bidders in various subsamples of four counterfactual simulated economies described in Table 8. Properties of valuations and participation in Panels A-D match those in Table 8. Subsamples include top 5 industries by number of deals from the 12-industry classification of Fama and French (1997), five periods of economic activity, targets in high and low tertiles of various target characteristics, and targets which, according to results in Table 5, are most valuable to strategic and financial bidders at normal times and periods of economic distress. Where the difference between winning bids of strategic and financial bidders is statistically significant at the $5 \%$ level in more than $50 \%$ of simulated samples, the higher of the numbers is highlighted in bold.

\begin{tabular}{|c|c|c|c|c|c|c|c|c|}
\hline & \multicolumn{2}{|c|}{ Panel A } & \multicolumn{2}{|c|}{ Panel B } & \multicolumn{2}{|c|}{ Panel C } & \multicolumn{2}{|c|}{ Panel D } \\
\hline & Strategic & Financial & Strategic & Financial & Strategic & Financial & Strategic & Financial \\
\hline All Auctions & 1.486 & 1.403 & 1.476 & 1.466 & 1.593 & 1.407 & 1.518 & 1.433 \\
\hline Business Equipment & 1.480 & 1.366 & 1.473 & 1.432 & 1.599 & 1.358 & 1.516 & 1.385 \\
\hline Healthcare, Medical & 1.492 & 1.438 & 1.493 & 1.547 & 1.643 & 1.454 & 1.543 & 1.483 \\
\hline Wholesale, Rental & 1.474 & 1.362 & 1.455 & 1.405 & 1.528 & 1.351 & 1.498 & 1.385 \\
\hline Manufacturing & 1.489 & 1.371 & 1.487 & 1.452 & 1.563 & 1.382 & 1.512 & 1.389 \\
\hline Other & 1.484 & 1.453 & 1.469 & 1.498 & 1.575 & 1.470 & 1.514 & 1.502 \\
\hline Dot-Com & 1.607 & 1.482 & 1.553 & 1.600 & 1.719 & 1.518 & 1.617 & 1.551 \\
\hline Post Dot-Com & 1.424 & 1.373 & 1.422 & 1.418 & 1.527 & 1.371 & 1.460 & 1.391 \\
\hline Pre-Crisis & 1.430 & 1.324 & 1.429 & 1.386 & 1.517 & 1.306 & 1.456 & 1.331 \\
\hline Crisis & 1.666 & 1.634 & 1.683 & 1.731 & 1.863 & 1.721 & 1.749 & 1.755 \\
\hline Post-Crisis & 1.511 & 1.439 & 1.501 & 1.507 & 1.623 & 1.450 & 1.547 & 1.474 \\
\hline Low Size & 1.554 & 1.433 & 1.542 & 1.556 & 1.704 & 1.455 & 1.599 & 1.471 \\
\hline High Size & 1.412 & 1.357 & 1.408 & 1.382 & 1.487 & 1.356 & 1.437 & 1.383 \\
\hline Low Leverage & 1.469 & 1.355 & 1.472 & 1.409 & 1.602 & 1.333 & 1.514 & 1.365 \\
\hline High Leverage & 1.562 & 1.485 & 1.536 & 1.544 & 1.652 & 1.506 & 1.591 & 1.535 \\
\hline Low M/B Ratio & 1.581 & 1.493 & 1.561 & 1.561 & 1.697 & 1.511 & 1.616 & 1.544 \\
\hline High M/B Ratio & 1.419 & 1.319 & 1.421 & 1.357 & 1.530 & 1.298 & 1.458 & 1.323 \\
\hline Low Cash Flow & 1.542 & 1.556 & 1.541 & 1.683 & 1.698 & 1.625 & 1.596 & 1.634 \\
\hline High Cash Flow & 1.428 & 1.336 & 1.423 & 1.387 & 1.510 & 1.325 & 1.454 & 1.350 \\
\hline Low Cash & 1.496 & 1.423 & 1.474 & 1.471 & 1.567 & 1.439 & 1.520 & 1.460 \\
\hline High Cash & 1.497 & 1.387 & 1.495 & 1.472 & 1.644 & 1.392 & 1.544 & 1.411 \\
\hline Low R\&D & 1.479 & 1.403 & 1.461 & 1.449 & 1.551 & 1.410 & 1.503 & 1.438 \\
\hline High R\&D & 1.501 & 1.393 & 1.503 & 1.489 & 1.660 & 1.405 & 1.555 & 1.426 \\
\hline Valuable to S, Normal & 1.454 & 1.346 & 1.474 & 1.452 & 1.605 & 1.339 & 1.511 & 1.333 \\
\hline Valuable to F, Normal & 1.513 & 1.604 & 1.555 & 1.578 & 1.627 & 1.639 & 1.564 & 1.678 \\
\hline Valuable to S, Downturn & 1.606 & 1.437 & 1.531 & 1.553 & 1.693 & 1.478 & 1.615 & 1.455 \\
\hline Valuable to F, Downturn & 1.679 & 1.535 & 1.641 & 1.660 & 1.746 & 1.556 & 1.696 & 1.550 \\
\hline
\end{tabular}


Table 10: OLS regressions of takeover premiums in simulated and real economy, including omitted variables: the case of target-specific dispersions of valuations

The table shows the partial estimation results (mean and standard deviation) of the OLS regression of winning bids on target and market characteristics, and properties of bidders' valuations and participation. The focus is on the acquirer type dummy and its interactions with previously omitted variables. Table A2 in the appendix presents the full estimation results. The first four columns focus on a simulated economy in which bidders value targets according to the model with target-specific dispersions of valuations. Valuation determinants are shown in Table 5. The four columns sequentially introduce the difference in estimated average valuations, dispersions of valuations, and the number of strategic and financial bidders to the OLS regression presented in column (2) of Table 4. The next four columns show the results of the OLS regressions with all control variables in four counterfactual simulated economies described in Table 8. Properties of valuations and participation in Panels A-D match those in Table 8. The final two columns show the results of the OLS and Erickson, Jiang, and Whited (2014) regressions with all control variables in the real sample. Standard deviations are reported in parentheses. Where coefficients associated with the "Strategic Acquirer" dummy and its interactions are statistically significant at the $5 \%$ level in more than $50 \%$ of simulated samples, they are highlighted in bold. The real sample covers $01 / 01 / 2000$ to $05 / 02 / 2012$.

\begin{tabular}{|c|c|c|c|c|c|c|c|c|c|c|}
\hline & Est., (2) & $\begin{array}{c}\text { Est., (2) } \\
\Delta \text { Avg. Val }\end{array}$ & $\begin{array}{c}\text { Est., (2) } \\
\Delta \text { SD of PV }\end{array}$ & $\begin{array}{c}\text { Est., (2) } \\
\text { \# S\&F Bid. }\end{array}$ & $\begin{array}{l}\text { Sim., (2) } \\
\text { Panel A }\end{array}$ & $\begin{array}{l}\text { Sim., (2) } \\
\text { Panel B }\end{array}$ & $\begin{array}{l}\text { Sim., (2) } \\
\text { Panel C }\end{array}$ & $\begin{array}{l}\text { Sim., (2) } \\
\text { Panel D }\end{array}$ & $\begin{array}{l}\text { Data, }(2) \\
\text { \# S\&F Bid. }\end{array}$ & $\begin{array}{l}\text { Data, (2) } \\
\text { EJW }\end{array}$ \\
\hline Strategic Acquirer & $\begin{array}{c}\mathbf{0 . 0 9 6} \\
(0.022) \\
{[98.5 \%]}\end{array}$ & $\begin{array}{c}\mathbf{0 . 0 7 2} \\
(0.024) \\
{[84.9 \%]}\end{array}$ & $\begin{array}{c}\mathbf{0 . 0 4 4} \\
(0.024) \\
{[63.8 \%]}\end{array}$ & $\begin{array}{c}0.015 \\
(0.064) \\
36.6 \%\end{array}$ & $\begin{array}{c}-0.057 \\
(0.063) \\
{[30.8 \%]}\end{array}$ & $\begin{array}{c}0.096 \\
(0.070) \\
{[42.7 \%]}\end{array}$ & $\begin{array}{c}0.066 \\
(0.073) \\
{[46.9 \%]}\end{array}$ & $\begin{array}{c}-0.023 \\
(0.067) \\
29.1 \%]\end{array}$ & $\begin{array}{c}0.129 \\
(0.122) \\
-\end{array}$ & $\begin{array}{c}-0.056 \\
(0.118) \\
-\end{array}$ \\
\hline $\mathrm{S}$ Acquirer $\times \Delta$ Avg. Val & $\begin{array}{l}- \\
- \\
-\end{array}$ & $\begin{array}{c}\mathbf{0 . 3 6 7} \\
(0.160) \\
{[52.2 \%]}\end{array}$ & $\begin{array}{l}-0.115 \\
(0.185) \\
{[24.5 \%]}\end{array}$ & $\begin{array}{l}-0.205 \\
(0.212) \\
{[40.5 \%]}\end{array}$ & $\begin{array}{l}-0.078 \\
(0.204) \\
{[31.7 \%]}\end{array}$ & $\begin{array}{l}\mathbf{- 0 . 8 0 2} \\
(0.222) \\
{[81.5 \%]}\end{array}$ & $\begin{array}{l}-0.183 \\
(0.229) \\
{[40.4 \%]}\end{array}$ & $\begin{array}{l}-0.217 \\
(0.211) \\
{[37.7 \%]}\end{array}$ & $\begin{array}{c}-0.341 \\
(0.376) \\
-\end{array}$ & $\begin{array}{l}-0.036 \\
(0.488)\end{array}$ \\
\hline $\mathrm{S}$ Acquirer $\times \Delta \mathrm{SD}$ of $\mathrm{PV}$ & $\begin{array}{l}- \\
- \\
-\end{array}$ & $\begin{array}{l}- \\
- \\
-\end{array}$ & $\begin{array}{l}\mathbf{0 . 5 8 5} \\
(0.113) \\
{[72.9 \%]}\end{array}$ & $\begin{array}{l}\mathbf{0 . 6 1 5} \\
(0.114) \\
{[79.5 \%]}\end{array}$ & $\begin{array}{l}\mathbf{0 . 5 8 1} \\
(0.110) \\
{[79.6 \%]}\end{array}$ & $\begin{array}{l}\mathbf{0 . 7 5 5} \\
(0.120) \\
{[95.4 \%]}\end{array}$ & $\begin{array}{l}\mathbf{0 . 6 5 9} \\
(0.115) \\
{[81.4 \%]}\end{array}$ & $\begin{array}{l}\mathbf{0 . 7 1 7} \\
(0.118) \\
{[87.3 \%]}\end{array}$ & $\begin{array}{c}\mathbf{0 . 6 6 2} \\
(0.223) \\
-\end{array}$ & $\begin{array}{c}\mathbf{0 . 6 6 3} \\
(0.300)\end{array}$ \\
\hline $\mathrm{S}$ Acquirer $\times \log (\# \mathrm{~S}$ Bidders $)$ & $\begin{array}{l}- \\
- \\
-\end{array}$ & $\begin{array}{l}- \\
- \\
-\end{array}$ & $\begin{array}{l}- \\
- \\
-\end{array}$ & $\begin{array}{c}\mathbf{0 . 0 6 1} \\
(0.027) \\
{[56.4 \%]}\end{array}$ & $\begin{array}{c}0.053 \\
(0.028) \\
{[44.5 \%]}\end{array}$ & $\begin{array}{c}-0.01 \\
(0.031) \\
{[7.9 \%]}\end{array}$ & $\begin{array}{c}\mathbf{0 . 0 5 9} \\
(0.027) \\
{[54.9 \%]}\end{array}$ & $\begin{array}{c}0.049 \\
(0.028) \\
{[42.6 \%]}\end{array}$ & $\begin{array}{c}-0.026 \\
(0.057) \\
-\end{array}$ & $\begin{array}{c}0.049 \\
(0.046)\end{array}$ \\
\hline $\mathrm{S}$ Acquirer $\times \log (\# \mathrm{~F}$ bidders $)$ & $\begin{array}{l}- \\
- \\
-\end{array}$ & $\begin{array}{l}- \\
- \\
-\end{array}$ & $\begin{array}{l}- \\
- \\
-\end{array}$ & $\begin{array}{c}-\mathbf{0 . 0 5 1} \\
(0.015) \\
{[84.8 \%]}\end{array}$ & $\begin{array}{l}-0.021 \\
(0.015) \\
{[38.8 \%]}\end{array}$ & $\begin{array}{c}-\mathbf{0 . 0 6 6} \\
(0.017) \\
{[94.8 \%]}\end{array}$ & $\begin{array}{c}-\mathbf{0 . 0 7 5} \\
(0.016) \\
{[95.8 \%]}\end{array}$ & $\begin{array}{c}-\mathbf{0 . 0 2 8} \\
(0.014) \\
{[56.2 \%]}\end{array}$ & $\begin{array}{c}-0.021 \\
(0.031) \\
-\end{array}$ & $\begin{array}{c}-0.004 \\
(0.029)\end{array}$ \\
\hline
\end{tabular}


Table 11: Estimation results of the model of valuations in simulated economy: limited bidder data

The table shows estimation results (mean and standard deviation) for the difference in winning bids, average valuations, and dispersions of valuations of type- $a$ and type- $b$ bidders in simulated economies, when losing bids are unobservable and information on losing bidder types may be limited. Each simulated sample contains 1000 asset sales with identical target and market characteristics. In each asset sale, the winning bid is equal to the second-highest valuation. The baseline simulation parameters are: $N=2$, $N_{a}=1, N_{b}=1, \mu_{a}=\mu_{b}=0.35, \sigma_{a}=0.1, \sigma_{b}=0.05$. The first column changes the baseline parameters one by one for eight different simulated economies. In addition, the first column assumes limitations on information on losing bidder types that the researcher faces: (1) types of losing bidders are known (rows $1-6)$; (2) types of individual losing bidders are unknown but their probability to be type- $a$ or type- $b$ is known (row 7); (3) no information on losing bidders is available whatsoever and has to be inferred from type-specific probabilities of winning (row 8). The second column shows the difference in winning bids made by type- $a$ and type- $b$ acquirers. The next three columns show estimates of average valuations of type- $a$ and type- $b$ bidders. The final three columns show estimates of dispersions of valuations of type- $a$ and type- $b$ bidders. Standard deviations are reported in parentheses.

\begin{tabular}{lccccccc}
\hline Parameters and Data Limitations & Winning Bids & \multicolumn{3}{c}{ Average Valuations } & \multicolumn{3}{c}{ St.D. of Valuations } \\
& Difference & Type $a$ & Type $b$ & Difference & Type $a$ & Type $b$ & Difference \\
\hline & & & & & & & \\
1. Baseline & 0.070 & 0.352 & 0.351 & 0.001 & 0.102 & 0.051 & 0.051 \\
& $(0.005)$ & $(0.004)$ & $(0.002)$ & $(0.005)$ & $(0.003)$ & $(0.001)$ & $(0.004)$ \\
2. $\mu_{a}=0.25$ & 0.121 & 0.255 & 0.351 & -0.096 & 0.100 & 0.053 & 0.047 \\
& $(0.008)$ & $(0.003)$ & $(0.003)$ & $(0.005)$ & $(0.003)$ & $(0.002)$ & $(0.004)$ \\
3. $\mu_{a}=0.45$ & 0.041 & 0.463 & 0.350 & 0.114 & 0.110 & 0.050 & 0.060 \\
& $(0.005)$ & $(0.009)$ & $(0.002)$ & $(0.009)$ & $(0.007)$ & $(0.001)$ & $(0.007)$ \\
4. $N=20, N_{a}=1, N_{b}=19$ & 0.015 & 0.354 & 0.346 & 0.008 & 0.089 & 0.052 & 0.037 \\
& $(0.003)$ & $(0.014)$ & $(0.002)$ & $(0.014)$ & $(0.014)$ & $(0.001)$ & $(0.015)$ \\
5. $N=20, N_{a}=19, N_{b}=1$ & 0.090 & 0.340 & 0.383 & -0.043 & 0.104 & 0.037 & 0.067 \\
& $(0.026)$ & $(0.003)$ & $(0.015)$ & $(0.016)$ & $(0.002)$ & $(0.008)$ & $(0.008)$ \\
6. $N=4, \operatorname{Prob}\left\{t_{i}=a\right\}=0.5$ & 0.033 & 0.344 & 0.349 & -0.006 & 0.105 & 0.048 & 0.056 \\
& $(0.004)$ & $(0.003)$ & $(0.002)$ & $(0.004)$ & $(0.005)$ & $(0.002)$ & $(0.006)$ \\
7. $N=4, \operatorname{Prob}\left\{t_{i}=a\right\}=0.5$ & 0.033 & 0.350 & 0.344 & 0.007 & 0.093 & 0.053 & 0.040 \\
Losing types unknown & $(0.004)$ & $(0.004)$ & $(0.003)$ & $(0.006)$ & $(0.005)$ & $(0.002)$ & $(0.007)$ \\
8. $N=4, \operatorname{Prob}\left\{t_{i}=a\right\}=0.5$ & 0.033 & 0.425 & 0.321 & 0.104 & 0.049 & 0.054 & -0.005 \\
No losing bidder info & $(0.004)$ & $(0.004)$ & $(0.001)$ & $(0.004)$ & $(0.003)$ & $(0.001)$ & $(0.003)$ \\
\hline
\end{tabular}




\section{Table 12: Estimation results of the model of valuations in real economy: limited bidder data}

The table shows the estimation results (mean and standard deviation) for the determinants of strategic and financial bidders' average valuations and their dispersions, when losing bids are unobservable and information on losing bidder types may be limited. The dispersions of valuations do not depend on target and market characteristics. In Panel A, average valuations do not depend on target and market characteristics. In Panel B, average valuations correlate with periods of economic activity. The first three columns show the results when types of individual losing bidders are unknown but their probability to be strategic or financial is known. The last three columns show the results when no information on losing bidders is available whatsoever and has to be inferred from type-specific probabilities of winning. In all cases, the winning bid is assumed to be equal to the second-highest valuation. Statistical significance is highlighted in bold for the $5 \%$ level. Standard deviations are reported in parentheses. The sample covers $01 / 01 / 2000$ to $05 / 02 / 2012$.

Panel A: Average valuations are constant

\begin{tabular}{lcccccc}
\hline & \multicolumn{3}{c}{ Losing types unknown } & \multicolumn{3}{c}{ No losing bidder info } \\
& Valuations & Valuations \\
& Strategic & Financial & Difference & Strategic & Financial & Difference \\
\hline \multirow{2}{*}{ St.D. of Valuations } & $\mathbf{0 . 5 1 9}$ & $\mathbf{0 . 4 2 5}$ & $\mathbf{0 . 0 9 4}$ & $\mathbf{0 . 3 2 5}$ & $\mathbf{0 . 3 3 3}$ & -0.008 \\
& $(0.016)$ & $(0.015)$ & $(0.026)$ & $(0.020)$ & $(0.008)$ & $(0.021)$ \\
\hline \multirow{3}{*}{ Const } & & & & & & \\
& $\mathbf{- 0 . 0 5 8}$ & $\mathbf{- 0 . 2 9 0}$ & $\mathbf{0 . 2 3 2}$ & $\mathbf{0 . 5 7 6}$ & $\mathbf{- 0 . 2 4 2}$ & $\mathbf{0 . 8 1 8}$ \\
& $(0.016)$ & $(0.021)$ & $(0.033)$ & $(0.032)$ & $(0.010)$ & $(0.031)$ \\
\hline
\end{tabular}

Panel B: Average valuations correlate with a period of economic activity

\begin{tabular}{lcccccc}
\hline & \multicolumn{3}{c}{ Losing types unknown } & \multicolumn{3}{c}{ No losing bidder info } \\
& Valuations & Valuations \\
& Strategic & Financial & Difference & Strategic & Financial & Difference \\
\hline \multirow{3}{*}{ St.D. of Valuations } & $\mathbf{0 . 5 0 4}$ & $\mathbf{0 . 4 0 7}$ & $\mathbf{0 . 0 9 7}$ & $\mathbf{0 . 2 9 8}$ & $\mathbf{0 . 3 1 5}$ & -0.016 \\
& $(0.017)$ & $(0.015)$ & $(0.027)$ & $(0.018)$ & $(0.007)$ & $(0.019)$ \\
\hline \multirow{3}{*}{ Const } & & & & & & \\
& $\mathbf{- 0 . 0 6 3}$ & $\mathbf{- 0 . 2 6 0}$ & $\mathbf{0 . 1 9 7}$ & $\mathbf{0 . 5 5 5}$ & $\mathbf{- 0 . 1 9 8}$ & $\mathbf{0 . 7 5 2}$ \\
Dot-Com & $(0.025)$ & $(0.027)$ & $(0.046)$ & $(0.051)$ & $(0.014)$ & $(0.048)$ \\
& $\mathbf{0 . 0 8 7}$ & $\mathbf{0 . 1 3 4}$ & -0.047 & 0.151 & $\mathbf{0 . 1 0 8}$ & 0.043 \\
Pre-Crisis & $(0.041)$ & $(0.038)$ & $(0.070)$ & $(0.095)$ & $(0.020)$ & $(0.091)$ \\
& $\mathbf{- 0 . 0 9 5}$ & $\mathbf{- 0 . 0 5 8}$ & -0.038 & -0.080 & $\mathbf{- 0 . 0 6 4}$ & -0.016 \\
Crisis & $(0.028)$ & $(0.024)$ & $(0.047)$ & $(0.066)$ & $(0.012)$ & $(0.062)$ \\
& $\mathbf{0 . 1 1 5}$ & 0.041 & 0.073 & $\mathbf{0 . 2 8 6}$ & $\mathbf{0 . 0 5 6}$ & $\mathbf{0 . 2 3 0}$ \\
Post-Crisis & $(0.048)$ & $(0.052)$ & $(0.088)$ & $(0.082)$ & $(0.026)$ & $(0.085)$ \\
& $\mathbf{0 . 0 7 1}$ & 0.015 & 0.056 & 0.033 & -0.014 & 0.047 \\
& $(0.027)$ & $(0.026)$ & $(0.048)$ & $(0.054)$ & $(0.012)$ & $(0.051)$ \\
\hline
\end{tabular}




\section{Appendix}

\section{A. Estimation of the main model}

Consider the model of Section 2. Let $N_{a, i}$ and $N_{b, i}$ be the observable number of bidders of type $a$ and $b$ in asset sale $i$, and $N_{u, i}=N_{i}-N_{a, i}-N_{b, i} \geq 0$ be the number of bidders of unobservable type. The two-stage estimation method is similar to the expectation maximization (EM) algorithm, first introduced by Dempster, Laird, and Rubin (1977). At the first stage, the probability $\hat{p}_{t_{i, j}, i}$ that a bidder is of type $t_{i, j} \in\{a, b\}$ is estimated from the observable data on losing bidders. ${ }^{28}$ At the second stage, the expected likelihood function is maximized with respect to model parameters. This likelihood is the weighted sum of likelihoods conditional on the type $t_{i, j}$ with probability weights of each type given by the first stage's estimate.

\section{A.1. First stage}

Suppose that in asset sale $i$, a losing bidder is of type $a$ with probability $p_{a, i}=\Gamma\left(Z_{i}^{\prime} \gamma\right)$, where $\Gamma$ is any parametric function that limits its values to $[0,1]$, for example, Logistic function, and $Z_{i}$ includes $X_{i}$ as well as all the available information about asset sale outcomes. Then the number of losing bidders of type $a$ in auction $i$ is distributed as Bernoulli $\left(\left(N_{i}-N_{u, i}\right) p_{a, i},\left(N_{i}-N_{u, i}\right) p_{a, i}\left(1-p_{a, i}\right)\right)$. The probability that $N_{a, i}$ losing bidders are of type $a$ in asset sale $i$ is then

$$
\mathbb{P}\left\{N_{a, i} \mid N_{i}, N_{u, i}, Z_{i} ; \gamma\right\}=C_{N_{i}}^{N_{a, i}} p_{a, i}^{N_{a, i}}\left(1-p_{a, i}\right)^{N_{i}-N_{u, i}-N_{a, i}}
$$

The complete likelihood function for the probability of a losing bidder to be of type $a$ is

$$
L\left(N_{a} \mid N, N_{u}, Z ; \gamma\right)=\prod_{i=1}^{I} C_{N_{i}}^{N_{a, i}} p_{a, i}^{N_{a, i}}\left(1-p_{a, i}\right)^{N_{i}-N_{u, i}-N_{a, i}}
$$

Taking the logarithm,

$$
\begin{aligned}
\mathfrak{L}\left(N_{a} \mid N, N_{u}, Z ; \gamma\right) & =\sum_{i=1}^{I} \log C_{N_{i}}^{N_{a, i}} p_{a, i}^{N_{a, i}}\left(1-p_{a, i}\right)^{N_{i}-N_{u, i}-N_{a, i}} \\
& =\text { const }+\sum_{i=1}^{I} \sum_{j=1}^{N_{a, i}} \log p_{a, i}+\sum_{i=1}^{I} \sum_{j=1}^{N_{b, i}} N_{b, i} \log \left(1-p_{a, i}\right) .
\end{aligned}
$$

\footnotetext{
${ }^{28}$ The winning bidder is excluded from calculations of $\hat{p}_{t_{i, j}, i}$ because of the potentially large selection bias that perfect knowledge of the winner in each asset sale introduces to the estimation.
} 
Maximizing (6) with respect to $\gamma$, I obtain the estimate $\hat{\gamma}$ and the probability of a losing bidder to be of type $a, \hat{p}_{a, i}$, and $b, \hat{p}_{b, i}=1-\hat{p}_{a, i}$. This estimate only depends on observable quantities: $Z_{i}$ and numbers of bidders of types $a$ and $b$ in each auction. For any bidder, whose type is known to be $a(b)$, I set $\hat{p}_{a, i}=1$ $\left(\hat{p}_{a, i}=0\right)$.

\section{A.2. Second stage}

First, suppose that all types are known. Suppose further that within each asset sale, bidders are sorted in descending order by their final bid, as described in Section 2. Let $b_{i, j}$ and $t_{i, j}$ denote their final bids and types. The likelihoods of bidder-level events from Section 2 are then:

1. Bidder 1 submits formal bid $b_{i, 1}$ and wins. By Assumption 1, the likelihood of this event is

$$
l_{i, 1}\left(v_{i, 1} \mid X_{i}, b_{i, 1}, t_{i, 1} ; \theta\right)=\operatorname{Prob}\left\{b_{i, 1} \leq v_{i, 1} \mid X_{i}, t_{i, 1} ; \theta\right\}=1-\Phi\left(\frac{\log \frac{b_{i, 1}}{M_{i}}-X_{i} \beta_{t_{i, 1}}}{\sigma_{t_{i, 1}}^{0} e^{Y_{i} \delta_{t_{i, 1}}}}\right) .
$$

2. Bidder $j>1$ submits formal bid $b_{i, j}$ and loses to bidder 1 . By Assumptions 1 and 2,

$$
l_{i, j}\left(v_{i, j} \mid X_{i}, b_{i, j}, t_{i, j} ; \theta\right)=\operatorname{Prob}\left\{b_{i, j} \leq v_{i, j} \leq b_{i, 1} \mid X_{i}, t_{i, j} ; \theta\right\}=\Phi\left(\frac{\log \frac{b_{i, 1}}{M_{i}}-X_{i} \beta_{t_{i, j}}}{\sigma_{t_{i, j}}^{0} e^{Y_{i} \delta_{t_{i, j}}}}\right)-\Phi\left(\frac{\log \frac{b_{i, j}}{M_{i}}-X_{i} \beta_{t_{i, j}}}{\sigma_{t_{i, j}}^{0} e^{Y_{i} \delta_{t_{i, j}}}}\right) .
$$

3. Bidder $j>1$ submits informal bid of any size and loses to bidder 1. By Assumptions 1-3,

$$
l_{i, j}\left(v_{i, j} \mid X_{i}, b_{i, j}, t_{i, j} ; \theta\right)=\operatorname{Prob}\left\{M_{i} \leq v_{i, j} \leq b_{i, 1} \mid X_{i}, t_{i, j} ; \theta\right\}=\Phi\left(\frac{\log \frac{b_{i, 1}}{M_{i}}-X_{i} \beta_{t_{i, j}}}{\sigma_{t_{i, j}}^{0} e^{Y_{i} \delta_{t_{i, j}}}}\right)-\Phi\left(\frac{-X_{i} \beta_{t_{i, j}}}{\sigma_{t_{i, j}}^{0} e^{Y_{i} \delta_{t_{i, j}}}}\right) .
$$

4. Bidder $j>1$ does not submit any bid. By Assumptions 1 and 2,

$$
l_{i, j}\left(v_{i, j} \mid X_{i}, b_{i, j}, t_{i, j} ; \theta\right)=\operatorname{Prob}\left\{0 \leq v_{i, j} \leq b_{i, 1} \mid X_{i}, t_{i, j} ; \theta\right\}=\Phi\left(\frac{\log \frac{b_{i, 1}}{M_{i}}-X_{i} \beta_{t_{i, j}}}{\sigma_{t_{i, j}}^{0} e^{Y_{i} \delta_{t_{i, j}}}}\right) \cdot{ }^{29}
$$

Second, when some types are unobservable, each expected bidder-level likelihood for $j \geq 1$ is

$$
\mathbb{E}\left[l_{i, j}\left(v_{i, j} \mid X_{i}, b_{i, j}, t_{i, j} ; \theta\right) \mid t_{i, j}\right]=\sum_{t_{i, j} \in\{a, b\}} l_{i, j}\left(v_{i, j} \mid X_{i}, b_{i, j}, t_{i, j} ; \theta\right) \hat{p}_{t_{i, j}, i},
$$

\footnotetext{
${ }^{29}$ Sometimes (e.g., in takeover auctions), a bidder, who does not submit any bid, informs the seller that its valuation is below the seller's value $M_{i}$. Then by Assumption $1, l_{i, j}\left(v_{i, j} \mid X_{i}, b_{i, j}, t_{i, j} ; \theta\right)=\operatorname{Prob}\left\{0 \leq v_{i, j} \leq M_{i} \mid X_{i}, t_{i, j} ; \theta\right\}=\Phi\left(\frac{-X_{i} \beta_{t_{i, j}}}{\sigma_{t_{i, j}}^{0} e^{Y_{i} \delta_{t_{i, j}}}}\right)$.
} 
where estimates of the probability of a bidder to be of type $a$ or $b$ are obtained at the first stage. Because types are independent across all the bidders in the economy, the expected likelihood for asset sale $i$ is

$$
\mathbb{E}\left[L_{i}\left(v_{i} \mid N_{a, i}, N_{b, i}, N_{u, i}, X_{i}, b_{i}, t_{i} ; \theta\right) \mid t_{i}\right]=\prod_{j=1}^{N_{i}} \sum_{t_{i, j} \in\{a, b\}} l_{i, j}\left(v_{i, j} \mid X_{i}, b_{i, j}, t_{i, j} ; \theta\right) \hat{p}_{t_{i, j}, i},
$$

and the corresponding expected log-likelihood is

$$
\mathfrak{L}_{i}\left(v_{i} \mid N_{a, i}, N_{b, i}, N_{u, i}, X_{i}, b_{i}, t_{i} ; \theta\right)=\sum_{j=1}^{N_{i}} \sum_{t_{i, j} \in\{a, b\}} l_{i, j}\left(v_{i, j} \mid X_{i}, b_{i, j}, t_{i, j} ; \theta\right) \hat{p}_{t_{i, j}, i} .
$$

Finally, the joint likelihood across all asset sales and bidders is

$$
\mathfrak{L}\left(v \mid N_{a}, N_{b}, N_{u}, X, b, t ; \theta\right)=\sum_{i=1}^{I} \sum_{j=1}^{N_{i}} \sum_{t_{i, j} \in\{a, b\}} l_{i, j}\left(v_{i, j} \mid X_{i}, b_{i, j}, t_{i, j} ; \theta\right) \hat{p}_{t_{i, j}, i} .
$$

This likelihood is maximized with respect to $\theta$. In the presence of losing bidders with unobservable types, the log-likelihood is non-concave, so I use the algorithm of Nelder and Mead (1967) to search for the global maximum. Gorbenko and Malenko (2014) show that asymptotic properties of this estimator are typical for ML estimators.

\section{B. Estimation of the model with limited bidder data: $b_{i, 1}=V_{i}^{(2)}$.}

Consider the model modification of Section 6, in which valuations are estimated using winning bids only, and the assumption is that in any asset sale, the winning bid is equal to the second-highest valuation among bidders. Estimation of this model proceeds in two stages. The first stage is identical to that described in Appendix A. Here, I focus on the second stage.

First, suppose that all types are known. Suppose that the winning bid in asset sale $i$ is $b_{i, 1}$ and the winning type is $t_{i, 1}$. Using properties of order statistics, the p.d.f. of the second-highest valuation among all bidders, which is also the asset sale-level likelihood, is

$$
\begin{gathered}
L_{i}\left(v_{i} \mid N_{a, i}, N_{b, i}, X_{i}, b_{i, 1}, t_{i} ; \theta\right)=\operatorname{Prob}\left\{v_{i}^{(1)} \geq b_{i, 1}, v^{(2)}=b_{i, 2}, v^{(k)} \leq b_{i, 1}\right\} \\
=N_{t_{i, 1}}\left(1-\Phi\left(\frac{\log \frac{b_{i, 1}}{M_{i}}-X_{i} \beta_{t_{i, 1}}}{\sigma_{t_{i, 1}}^{0} e^{Y_{i} \delta_{t_{i, 1}}}}\right)\right) \times d\left(\Phi\left(\frac{\log \frac{b_{i, 1}}{M_{i}}-X_{i} \beta_{a}}{\sigma_{a}^{0} e^{Y_{i} \delta_{a}}}\right)^{N_{a, i}-\mathbf{1}_{t_{i, 1}=a}} \Phi\left(\frac{\log \frac{b_{i, 1}}{M_{i}}-X_{i} \beta_{b}}{\sigma_{b}^{0} e^{Y_{i} \delta_{b}}}\right)^{N_{b, i}-\mathbf{1}_{t_{i, 1}=b}}\right),
\end{gathered}
$$

where, e.g., $\mathbf{1}_{t_{i, 1}=a}$ is equal to one, if the winner is of type $a$, and zero otherwise, and $d(\cdot)$ denotes the 
derivative with respect to the full argument, $v_{i, j}$, of standard Normal c.d.f's. ${ }^{30}$

Second, when some losing types are unobservable, the estimation needs to take into account that the number of losing bidders of both types has a Bernoulli distribution. The expected asset sale-level likelihood is then

$$
\begin{aligned}
& \mathbb{E}\left[L_{i}\left(v_{i} \mid N_{a, i}, N_{b, i}, N_{u, i}, X_{i}, b_{i, 1}, t_{i} ; \theta\right) \mid t_{i}\right]= \\
& \sum_{k=0}^{N_{u, i}} C_{N_{u, i}}^{k} \hat{p}_{a, i}^{k}\left(1-\hat{p}_{a, i}\right)^{N_{u, i}-k} L_{i}\left(v_{i} \mid N_{a, i}+k, N_{b, i}+N_{u, i}-k, X_{i}, b_{i, 1}, t_{i} ; \theta\right),
\end{aligned}
$$

The joint likelihood across all asset sales is

$$
\begin{aligned}
& \mathbb{E}\left[L\left(v \mid N_{a}, N_{b}, N_{u}, X_{i}, b_{1}, t ; \theta\right) \mid t\right]= \\
& \prod_{i=1}^{I} \sum_{k=0}^{N_{u, i}} C_{N_{u, i}}^{k} \hat{p}_{a, i}^{k}\left(1-\hat{p}_{a, i}\right)^{N_{u, i}-k} L_{i}\left(v_{i} \mid N_{a, i}+k, N_{b, i}+N_{u, i}-k, X_{i}, b_{i, 1}, t_{i} ; \theta\right),
\end{aligned}
$$

and the corresponding expected log-likelihood is

$$
\begin{aligned}
& \mathfrak{L}\left(v \mid N_{a}, N_{b}, N_{u}, X_{i}, b_{1}, t ; \theta\right)= \\
& \sum_{i=1}^{I} \sum_{k=0}^{N_{u, i}} C_{N_{u, i}}^{k} \hat{p}_{a, i}^{k}\left(1-\hat{p}_{a, i}\right)^{N_{u, i}-k} L_{i}\left(v_{i} \mid N_{a, i}+k, N_{b, i}+N_{u, i}-k, X_{i}, b_{i, 1}, t_{i} ; \theta\right) .
\end{aligned}
$$

This likelihood is maximized with respect to $\theta$. Paarsch and Hong (2006) provide asymptotic properties of this estimator, which are typical for ML estimators.

\section{Simulation of premiums in takeover auctions}

I simulate takeover auction outcomes in two stages. First, I estimate the expected fraction of the difference between the first- and second-highest valuation, which is paid to the target, as a function of real data auction outcomes. Second, I use this estimate to obtain takeover premiums in the simulated data. The procedure is as follows:

Stage 1: real data:

1. For each auction $i$, I simulate $V_{i, j}^{(1)}$ and $V_{i, j}^{(2)}$ for $j=1 . .100000$ conditional on winning and losing bids, types of bidders, and characteristics $X_{i}$. Appendix E shows that $V_{i, j}^{(1)}$ is drawn from a truncated log-normal distribution on interval $\left[b_{i, 1}, \infty\right)$ with parameters $X_{i}^{\prime} \hat{\beta}_{t_{i, 1}}$ and $\hat{\sigma}_{t_{i, 1}}^{2} \cdot V_{i, j}^{(2)}$ is the highest of $k=1 . . N_{i}-1$ valuations drawn from a truncated log-normal distribution on interval $\left[b_{i, k}, b_{i, 1}\right)$ with

\footnotetext{
${ }^{30}$ See, e.g., Paarsch and Hong (2006) for details of the derivation of this result.
} 
parameters $X_{i}^{\prime} \hat{\beta}_{t_{i, k}}$ and $\hat{\sigma}_{t_{i, k}}^{2}$. An informal bid implies $b_{i, k}=M_{i}$. No bid implies $b_{i, k}=0$. Whenever a bidder's type is not known, it is assigned using the estimate of the probability that such bidder is either strategic or financial.

2. For each auction $i$, I average simulated valuations over $j$ to obtain $\mathbb{E}\left[V_{i}^{(1)}\right]$ and $\mathbb{E}\left[V_{i}^{(2)}\right]$.

3. For each auction $i$, I compute the fraction of the difference between the first- and second-highest expected valuation that the buyer pays, $\lambda_{i}=\left(b_{i, 1}-\mathbb{E}\left[V_{i}^{(2)}\right]\right) /\left(\mathbb{E}\left[V_{i}^{(1)}\right]-\mathbb{E}\left[V_{i}^{(2)}\right]\right)$.

4. I run a cross-sectional regression $\lambda_{i}=f\left(X_{i}\right)+\eta_{i}$ and compute fitted $\hat{\lambda}_{i}$.

Stage 2: simulated data:

1. For each simulation $j=1 . .1000$ of auction $i$ and each bidder $k=1 . . N_{i}$, I simulate $V_{i, k, j}$ conditional on types of bidders and characteristics $X_{i} . V_{i, k, j}$ is drawn from a log-normal distribution with parameters $X_{i}^{\prime} \hat{\beta}_{t_{i, k}}$ and $\hat{\sigma}_{t_{i, k}}^{2}$. Whenever a bidder's type is not known, it is assigned using the estimate of the probability that such bidder is either strategic or financial.

2. For each simulation $j$ of auction $i$, I use fitted $\hat{\lambda}_{i}$ to obtain the takeover premium, $\widehat{b_{i, j, 1}}=\hat{\lambda}_{i} V_{i, j}^{(1)}+$ $\left(1-\hat{\lambda}_{i}\right) V_{i, j}^{(2)}$.

\section{Robustness checks}

\section{D.1. Restructuring of acquired assets}

Consider the following generalization of the main model. Suppose that the asset is valued by the seller (indexed by type 0) as

$$
\log M_{i}=X_{i}^{\prime} \beta_{0}+\epsilon_{i, 0} \sigma_{0} .
$$

Suppose that upon acquisition, bidder $i$ restructures fraction $1-\alpha_{t_{i, j}}$ of the original asset value, $\log M_{i}$. Specifically, it replaces the restructured part of the asset, $\left(1-\alpha_{t_{i, j}}\right) \log M_{i}$, with a bidder-specific value $X_{i}^{\prime} \beta_{t_{i, j}}+\epsilon_{i, j} \sigma_{t_{i, j}}$, so that the post-acquisition value of the asset is

$$
\log V_{i}=X_{i}^{\prime}\left(\beta_{t_{i, j}}+\alpha_{t_{i, j}} \beta_{i, 0}\right)+\left(\epsilon_{i, j} \sigma_{t_{i, j}}+\alpha_{t_{i, j}} \epsilon_{i, 0} \sigma_{i, 0}\right)
$$

The incremental value from the acquisition in the presence of restructuring is

$$
\log \left(\frac{V_{i}}{M_{i}}\right)=X_{i}^{\prime} \beta_{t_{i, j}}^{\Delta}+\tilde{\epsilon}_{i, j} \sigma_{t_{i, j}}^{\Delta}=X_{i}^{\prime}\left(\beta_{t_{i, j}}-\left(1-\alpha_{t_{i, j}}\right) \beta_{0}\right)+\left(\epsilon_{i, j} \sigma_{t_{i, j}}-\left(1-\alpha_{t_{i, j}}\right) \epsilon_{i, 0} \sigma_{0}\right)
$$

In particular, $\alpha_{t_{i, j}}=1, t_{i, j} \in\{a, b\}$ corresponds to the main model. $\beta_{t_{i, j}}^{\Delta}=\beta_{t_{i, j}}$ and $\sigma_{t_{i, j}}^{\Delta}=\sigma_{t_{i, j}}$ then measure the incremental impact of a bidder on the asset value, assuming that the original asset structure 
and synergies are retained. Another extreme is $\alpha_{t_{i, j}}=0, t_{i, j} \in\{a, b\}$. Here, $\beta_{t_{i, j}}^{\Delta}=\beta_{t_{i, j}}-\beta_{0} \neq \beta_{t_{i, j}}$ and $\tilde{\epsilon}_{t_{i, j}} \sigma_{t_{i, j}}^{\Delta}=\epsilon_{i, j} \sigma_{t_{i, j}}-\epsilon_{i, 0} \sigma_{0} \neq \epsilon_{i, j} \sigma_{t_{i, j}}$ measure the incremental impact of a bidder on the asset value assuming that the asset structure is completely overhauled and no synergies are retained.

Because for $\alpha_{t_{i, j}}<1$, the restructured private component of valuations $\epsilon_{i, 0} \sigma_{0}$ is the same across all bidders in a given asset sale, their valuations in (21) become affiliated. Using information in relative bids, $\log \left(\frac{b_{i, j}}{M_{i}}\right)$, alone, it becomes prohibitively costly to estimate model parameters. ${ }^{31}$ However, in many settings typically considered in the financial literature (e.g., takeover and bankruptcy auctions), one also observes sellers' market values and can use them to infer the seller-specific private component of valuations. Consider a regression of sellers' market values on valuation determinants (19). The estimate of the average seller's valuation is $\log \hat{M}_{i}=X_{i}^{\prime} \hat{\beta}_{i, 0}$ and the estimate of the seller-specific deviation from the average is $\hat{\epsilon}_{i, 0} \sigma_{0}=\log \left(\frac{M_{i}}{\hat{M}_{i}}\right)$. Insert this estimate into (21) to obtain

$$
\log v_{i, j}=-\left(1-\alpha_{t_{i, j}}\right) \hat{\epsilon}_{i, 0} \sigma_{0}+X_{i}^{\prime} \beta_{t_{i, j}}^{\Delta}+\epsilon_{i, j} \sigma_{t_{i, j}}
$$

where unobservable parts of valuations are now uncorrelated across bidders and have the dispersion of $\sigma_{t_{i, j}}$. The model can be estimated by simply adding $\log \left(\frac{M_{i}}{\hat{M}_{i}}\right)$ to the set of controls. I estimate it on the sample of strategic and financial bidders competing in takeover auctions.

The results are reported in the first three columns of Table A1 in the appendix. In addition, the fourth column of Table A1 reports estimates of model (19) of targets' valuations, $\hat{\beta}_{0}$. Sensitivities of bidder-specific values to $X_{i}$ can be computed from their incremental values as $\hat{\beta}_{t_{i, j}}=\hat{\beta}_{0}+\hat{\beta}_{t_{i, j}}^{\Delta}$. For strategic acquirers, $1-\hat{\alpha_{s}}$ is insignificantly different from zero, while financial acquirers restructure approximately $2 \%$ of the company's assets post-acquisition. These results suggest that in takeovers, the winning bidder retains most of the target company's assets. ${ }^{32}$ Further, the difference in dispersions remains the major factor driving the difference between strategic and financial premiums. While restructuring of acquired assets does not appear to be large in the market for corporate control, it is likely that a higher fraction of assets is restructured by acquirers of distressed assets in bankruptcy auctions.

\footnotetext{
${ }^{31}$ Instead of the likelihood of an asset sale outcome being the product of likelihoods of individual bidder outcomes, now the likelihood of an asset sale is a joint likelihood of all bidder outcomes. Assuming that all bidder types are observable, and following the notation in Appendix A, $L_{i}\left(v_{i} \mid N_{s, i}, N_{f, i}, X_{i}, b_{i}, t_{i} ; \theta\right)=\operatorname{Prob}\left\{b_{i, 1} \leq v_{i, 1}, b_{i, 2} \leq v_{i, 2} \leq b_{i, 2}, \ldots, b_{i, N_{i}} \leq\right.$ $\left.v_{i, N_{i}} \leq b_{i, N_{i}} \mid X_{i}, t_{i} ; \theta\right\}$, where $b_{i, j}=M_{i}$ (or 0 ) if an informal (or no) bid is made. The likelihood of an asset sale outcome is an area under the p.d.f. of a multivariate normal distribution with a non-diagonal covariance matrix, constrained by an $N_{i}$-dimensional cube. Computation of this area requires the use of MCMC/Gibbs sampler and is extremely slow even for one set of model parameters: e.g., in the sample of takeovers, some auctions have more than 50 bidders.

${ }^{32} \mathrm{I}$ also estimated the model by assuming full restructuring and restricting $1-\alpha_{t_{i, j}}$ to 1 . This estimation produced very highly correlated $\hat{\epsilon}_{i, 0}$ and $\hat{\epsilon}_{i, j}$, suggesting model misspecification.
} 


\section{D.2. Ex-Ante heterogeneity of valuations}

In addition to post-due diligence difference in valuations, bidders can be ex-ante different within a type, implying a modified model of valuations:

$$
\log \left(\frac{V_{i, j}}{M_{i}}\right)=X_{i}^{\prime} \beta_{t_{i, j}}+\phi_{i, j}+\epsilon_{i, j} \sigma_{t_{i, j}}
$$

where $\phi_{i, j}$ captures the potentially type-dependent degree of ex-ante heterogeneity. In the main model, I proxy for ex-ante heterogeneity within a type by adding the number of bidders to the set of controls and find that average valuations decrease with the number of bidders. This finding is consistent with the story that ex-ante stronger bidders either identify a potential seller or are approached by it faster, and hence enter the asset sale faster. As more bidders enter, their average quality decreases. This story is supported by detailed descriptions of pre-auction interactions between targets and potential bidders in takeover deal backgrounds. However, if the number of bidders imperfectly proxies for ex-ante heterogeneity $\phi_{i, j}$, the estimate of $\sigma_{t_{i, j}}$ can be affected. In particular, a higher number of bidders can drive this estimate up.

I modify the model to explicitly allow the bidders to be ex-ante different within a type. I assume that $\phi_{i, j}=-\log r_{i, j} \gamma_{t_{i, j}}, t_{i, j} \in\{a, b\}$, where $r_{i, j}$ is the deterministic quality ranking of bidder $j$ within a type in asset sale $i$. The difference in average valuations between the 1 -st and $k$-th ex-ante strongest bidder of type $t_{i, j}$ is then $\log k \gamma_{t_{i, j}}$. The ex-post ranking of bidders can be different from their ex-ante ranking because of their private valuation components. Thus, I model in reduced form the idea that ex-ante strongest bidders enter the asset sale faster. The advantage of modeling ex-ante heterogeneity via a deterministic quality ranking is that deterministic $\phi_{i, j}$ severs the link between the bidding and entry stage. In turn, $\gamma_{t_{i, j}}$ can be estimated from data on bids alone without the need to impose numerous additional assumptions to model the entry stage.

Estimation of this model modification using both winning and losing bids is extremely computationally intensive. Because the ex-ante ranking of a bidder with bid $b_{i, j}$ (formal, informal, or no bid) is unobservable, the likelihood of any asset sale-level event has to account for every possible combination of bids and ex-ante bidder rankings. The number of such combinations in asset sales with many bidders is very large. To save on complexity, the estimation only uses information about winning bids and types of losing bidders but not their bids. ${ }^{33}$ As shown in Section 6, this approach yields reasonable estimates of average valuations and valuation dispersions.

Estimation of the model proceeds in two stages. The first stage is identical to that described in Appendix A. At the second stage, first, suppose that the type of every bidder, $t_{i, j} \in\{a, b\}$, is known. Even in this case, the ranking of a bidder within its type, $r_{i, j}$, is unobservable (that is, e.g., $r_{i, j}=3$ and $t_{i, j}=a$ mean

\footnotetext{
${ }^{33}$ For the same reason, I omit control variables related to periods and the number of bidders.
} 
that bidder $j$ in asset sale $i$ is of type $a$ and its ex-ante ranking is 3 among all bidders of type $a$ ). Suppose that the winning bid in asset sale $i$ is $b_{i, 1}$ and the winning type is $t_{i, 1}$. Using properties of order statistics, the p.d.f. of the second-highest valuation among all bidders, which is also the asset sale-level likelihood, is

$$
\begin{gathered}
L_{i}\left(v_{i} \mid N_{s, i}, N_{f, i}, X_{i}, b_{i, 1}, t_{i} ; \theta\right)=\operatorname{Prob}\left\{v_{i}^{(1)} \geq b_{i, 1}, v^{(2)}=b_{i, 2}, v^{(k)} \leq b_{i, 1}\right\} \\
=\sum_{k=1}^{N_{t_{i, 1}}, i}\left\{\left(1-\Phi\left(\frac{\log \frac{b_{i, 1}}{M_{i}}-X_{i} \beta_{t_{i, 1}}+\log k \beta_{t_{i, 1}, r}}{\sigma_{t_{i, 1}}^{0} e^{Y_{i} \delta_{t_{i, 1}}}}\right)\right) \times d\left(\prod_{j=1, j \neq k}^{N_{i}} \Phi\left(\frac{\log \frac{b_{i, 1}}{M_{i}}-X_{i} \beta_{t_{i, j}}+\log r_{i, j} \beta t_{i, j}, r}{\sigma_{t_{i, j}}^{0} e^{Y_{i} \delta_{t_{i, j}}}}\right)\right)\right\},
\end{gathered}
$$

where $d(\cdot)$ denotes the derivative with respect to the full argument, $v_{i, j}$, of standard Normal c.d.f's. The rest of the estimation proceeds similarly to the case of no extra heterogeneity within a type, explained in Appendix B. I estimate the model on the sample of strategic and financial bidders competing in takeover auctions.

The results are shown in the last three columns of Table A1 in the appendix. The difference in the decline of the ex-ante quality of strategic and financial bidders within a type, $\hat{\gamma}_{s}-\hat{\gamma}_{f}$, is statistically insignificant, suggesting that ex-ante, strategic and financial valuations are similarly dispersed. At the same time, the difference in post due-diligence dispersions of strategic and financial valuations remains significant. Further, the difference in post-due diligence dispersions remains the major factor driving the difference between strategic and financial premiums.

\section{E. [Online appendix] The impact of market conditions on valuations in takeover auctions}

This section expands the analysis of the impact of market conditions on properties of strategic and financial bidders' valuations in takeovers. For type $t \in\{s, f\}$ and auction $i$, write the estimate of average logvaluation premiums in (2) as a function of period $p_{i}$, in which the auction occurs, and the number of bidders $N_{i}$ :

$$
\hat{\mu}_{t}\left(p_{i}, N_{i}\right)=X_{i,-p,-N}^{\prime} \hat{\beta}_{t,-p,-N}+\log N_{i} \hat{\beta}_{t, N}+\sum_{j \in \mathbb{J}} \mathbf{1}_{p_{i}=j} \hat{\beta}_{t, j}+\sum_{j \in \mathbb{J}} \mathbf{1}_{p_{i}=j} \log N_{i} \hat{\beta}_{t, j, N} .
$$

Here, (1) $X_{i,-p,-N}$ are all controls that do not include period dummies and the number of bidders; (2) $p_{i} \in\{$ dot-com, post dot-com, pre crisis, crisis, post crisis $\}$ denotes the period; (3) the post dot-com period is the baseline period; (4) $\mathbf{1}_{p_{i}=j}, j \in \mathbb{J}=\{$ dot-com, pre crisis, crisis, post crisis $\}$ are dummies for all other periods. As explained in Section 3.1, assume that the number of bidders proxies for ex-ante heterogeneity of bidders within a type observable to competitors but not to the researcher. Then, the average log-valuation of the ex-ante strongest bidder of type $t$ in auction $i$ in the baseline period is given by $\hat{\mu}_{t}($ post dot-com, 1$)=$ 
$X_{i,-p,-N}^{\prime} \hat{\beta}_{t,-p,-N}$. The average log-valuation across all bidders of type $t$ in auction $i$ in the baseline period is $\hat{\mu}_{t}\left(\right.$ post dot-com, $\left.N_{i}\right)$. The average log-valuation of the ex-ante strongest bidder of type $t$ in auction $i$ in any other period is $\hat{\mu}_{t}(j, 1), j \in \mathbb{J}$. Finally, the average log-valuation across all bidders of type $t$ in auction $i$ in any other period is $\hat{\mu}_{t}\left(j, N_{i}\right), j \in \mathbb{J}$. The actual average valuation premium of any bidder in any period can be obtained from parameters of log-valuations using equation (1).

I use the introduced notation to explore the economic impact of market conditions on valuations. Consider a target from the baseline post dot-com period, who has a period-typical market value, $\$ 476$ million, and a typical number of bidders, 12. Suppose that strategic and financial bidders have periodtypical average valuations of $24.9 \%$ and $15.4 \%$, and period-typical dispersions of valuations of $27.6 \%$ and $17.1 \%$, as shown in Table 6 . These numbers imply $\hat{\mu}_{s}$ (post dot-com, 12) $=0.199, \hat{\sigma}_{s}$ (post dot-com) $=$ $0.218, \hat{\mu}_{f}($ post dot-com, 12$)=0.132, \hat{\sigma}_{f}($ post dot-com $)=0.147$. Suppose that target characteristics remain otherwise unaffected as it moves through economic periods. To interpret changes in valuations across periods, I use estimates provided in Table 5.

In the baseline period, the average valuation of the ex-ante strongest strategic and financial bidder is higher than that across all bidders of the same type in an auction by $e^{-\hat{\beta}_{s, N} \times \log (12)}-1=35.1 \%$ and $15.5 \%$, which corresponds to a $1.249 \times 1.351=68.7 \%$ and $33.3 \%$ premium above the target value. In dollar terms, the average valuation of the ex-ante strongest strategic and financial bidder is higher than that across all bidders of the same type by $\$ 476 \times(0.687-0.249)=\$ 208$ and $\$ 85$ million. Next, compared to the baseline period, during the dot-com and the crisis period the average valuation of the ex-ante strongest financial bidder is higher by $e^{\hat{\beta}_{f, d c}+\frac{\left(\hat{\sigma}_{f}(\text { post dot-com }) e^{\left.\hat{\gamma}_{f}, \mathrm{dot}-\mathrm{com}\right)^{2}-\hat{\sigma}_{f}(\mathrm{post} \mathrm{dot}-\mathrm{com})^{2}}\right.}{2}}-1=28.8 \%$ and $22.1 \%$, which corresponds to a $1.333 \times 1.288=71.7 \%$ and $62.8 \%$ premium above the target value. In dollar terms, if the target value is unaffected by a period, the average valuation of the ex-ante strongest financial bidder increases between periods by $\$ 183$ and $\$ 140$ million. The target value in periods of economic downturn has to drop by $45-50 \%$ to erase this dollar increase. Finally, compared to the baseline period, during the dot-com and the crisis period the average valuation across all financial bidders in an auction is higher by $e^{\hat{\beta}_{f, \text { dot-com }}+\hat{\beta}_{f, \text { dot-com }, N} \log (12)+\frac{\left(\hat{\sigma}_{s}(\text { post dot-com }) e^{\left.\hat{\gamma}_{f}, \mathrm{dot}-\mathrm{com}\right)^{2}-\hat{\sigma}_{f}(\mathrm{post} \mathrm{dot}-\mathrm{com})^{2}}\right.}{2}}-1=11.5 \%$ and $-6.7 \%$, which corresponds to a $28.7 \%$ and $7.7 \%$ premium above the target value. In dollar terms, if the target value is unaffected by a period, the average valuation across all financial bidders increases between periods by $\$ 63$ and $-\$ 37$ million. The average valuation of both the ex-ante strongest strategic bidder and across all strategic bidders in an auction is substantially more stable over time.

Altogether, consistent with Martos-Vila et al. (2013), time variation in financial valuations is economically important and can reach hundreds of millions of dollars. The impact of periods of economic activity on valuations appears to be stronger for the ex-ante strongest financial bidder as compared to an average financial bidder. This finding explains why during the crisis, financial acquirers pay substantially higher 
premiums despite low levels of financial participation. A caveat is that, in practice, participation can also change between periods, affecting the above analysis.

An alternative way to show that financial bidders become much stronger competitors in crises is to decompose the winning bidders' private valuation component into shares retained by the bidder and received by the target through the payment. Fig. 1 in the appendix shows the distribution of the ratio of the winning bid to the expected valuation of strategic and financial acquirers across five periods. Intuitively, the winning slack, which is defined as $100 \%$ minus the depicted ratio, captures the expected share of the private valuation component retained by the winning bidder and hence its ability to increase the payment if faced with stronger competition. Formally, for each strategic or financial acquirer in the sample, the expected valuation conditional on all auction characteristics and outcomes is

$$
\mathbb{E}\left[V_{i}^{(1)} \mid X_{i}, b_{i, 1}, t_{i, 1}\right]=\mathbb{E}\left[V_{i}^{(1)} \mid X_{i}, V_{i}^{(1)} \geq b_{i, 1}, V_{i}^{(2)} \leq b_{i, 1}, t_{i, 1}\right]
$$

where $V_{i}^{(k)}, k \in\left\{1 . . N_{i}\right\}$ is the $k$-th highest valuation among $N_{i}$ bidders. By properties of order statistics, the expected valuation of the winning bidder has a truncated log-normal distribution with parameters $X_{i}^{\prime} \hat{\beta}_{t_{i, 1}}$ and $\hat{\sigma}_{t_{i, 1}}^{2}$ on interval $\left[b_{i, 1}, \infty\right)$.

The next-to-last row of graphs in Fig. 1 shows that the average winning slack of financial bidders in the crisis period increases to $16.0 \%$ from the sample-average of $8.6 \%$. Moreover, there are four instances of the slack exceeding 15\%, which is rare in the remaining data, and no instances of the slack below 5\%. Fig. 1 thus confirms the finding that top financial bidders are much stronger competitors in crises. 

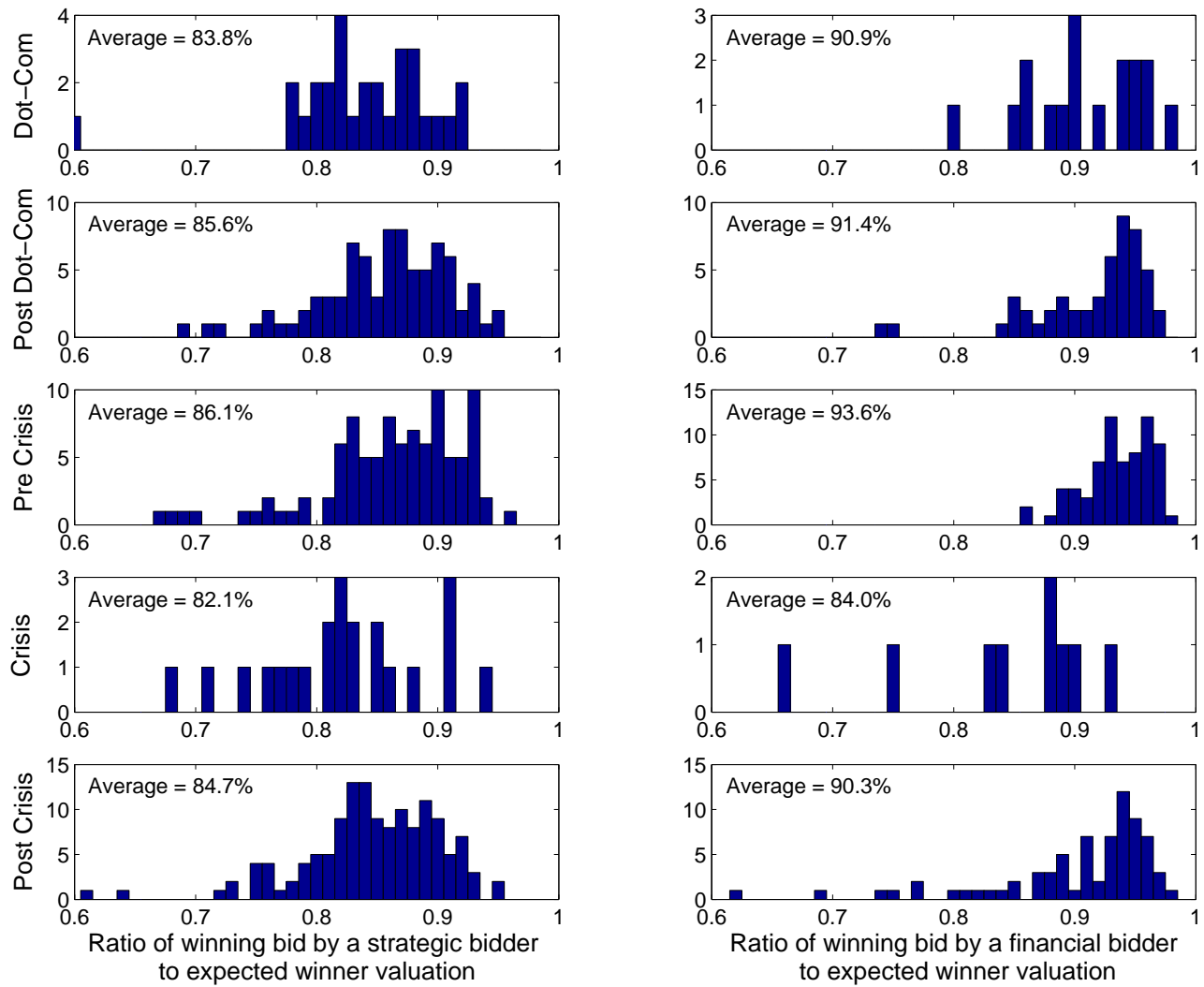

Figure 1: Distribution of the winning slack by periods: the case of target-specific dispersions of private valuations. The figure shows histograms of 1- Winning Slack for strategic and financial bidders across five time periods: crisis (September 2008-2009), dot-com (2000-2001), post dot-com (2002-2005), pre crisis (2006-August 2008), and post crisis (2010-2012). 1-Winning Slack is defined as the ratio of the winning bid to the ex-post mean valuation of the winner, conditional on the observable winning bid. Higher winning slack means that a bidder is able to raise its bid more if faced with stronger competition. The top-left corner of each histogram shows the average value of 1-Winning Slack in a given period. The average value across all periods is $85.1 \%$ for strategic bidders and $91.4 \%$ for financial bidders. 
Table A1: Estimation results of the model of valuations: cases of restructuring of the target asset and ex-ante bidder heterogeneity within a type

The table provides robustness checks of two assumptions in the main model: (1) the winning bidder does not restructure the target asset but keeps running it as a going concern and makes incremental improvements; (2) the number of bidders proxies for ex-ante bidder heterogeneity within a type observable by participants but not by the researcher. The first three columns show the results for the model, which includes the asset restructuring parameter, on the sample of all bids. The fourth column shows estimates of the regression of target's market values on controls, errors from which serve as an additional control in the model of valuations. The regression's adjusted $R^{2}$ is $70.6 \%$. The last three columns show the results for the model, in which ex-ante bidder heterogeneity is modeled as the deterministic ex-ante ranking of each bidder within its type, on the sample of winning bids. The winning bid here is assumed to be equal to the second-highest valuation. The dispersions of valuations do not depend on target and market characteristics. Statistical significance is highlighted in bold for the $5 \%$ level. Standard deviations are reported in parentheses. The sample covers $01 / 01 / 2000$ to $05 / 02 / 2012$.

\begin{tabular}{|c|c|c|c|c|c|c|c|}
\hline & \multicolumn{4}{|c|}{$\begin{array}{l}\text { Asset Restructuring } \\
\text { Valuations }\end{array}$} & \multicolumn{3}{|c|}{$\begin{array}{c}\text { Ex-Ante Heterogeneity } \\
\text { Valuations }\end{array}$} \\
\hline & Strategic & Financial & Difference & Market Value & Strategic & Financial & Difference \\
\hline St.D. of Valuations & $\begin{array}{c}\mathbf{0 . 2 4 9} \\
(0.006) \\
\end{array}$ & $\begin{array}{c}\mathbf{0 . 1 5 2} \\
(0.002) \\
\end{array}$ & $\begin{array}{c}\mathbf{0 . 0 9 7} \\
(0.007) \\
\end{array}$ & $\begin{array}{c}0.439 \\
- \\
\end{array}$ & $\begin{array}{c}\mathbf{0 . 3 5 5} \\
(0.016) \\
\end{array}$ & $\begin{array}{c}\mathbf{0 . 2 9 0} \\
(0.020) \\
\end{array}$ & $\begin{array}{c}\mathbf{0 . 0 6 5} \\
(0.024) \\
\end{array}$ \\
\hline Const & $\begin{array}{c}\mathbf{0 . 5 7 0} \\
(0.068)\end{array}$ & $\begin{array}{c}\mathbf{0 . 3 1 6} \\
(0.043)\end{array}$ & $\begin{array}{c}\mathbf{0 . 2 5 4} \\
(0.083)\end{array}$ & $\begin{array}{l}-0.076 \\
(0.257)\end{array}$ & $\begin{array}{c}\mathbf{0 . 6 4 5} \\
(0.107)\end{array}$ & $\begin{array}{c}\mathbf{0 . 5 1 0} \\
(0.116)\end{array}$ & $\begin{array}{c}0.135 \\
(0.160)\end{array}$ \\
\hline Dot-Com & $\begin{array}{l}-0.034 \\
(0.066)\end{array}$ & $\begin{array}{c}\mathbf{0 . 3 1 5} \\
(0.054)\end{array}$ & $\begin{array}{l}\mathbf{- 0 . 3 4 8} \\
(0.087)\end{array}$ & $\begin{array}{l}-0.079 \\
(0.242)\end{array}$ & $\begin{array}{l}- \\
-\end{array}$ & $\begin{array}{l}- \\
-\end{array}$ & $\begin{array}{l}- \\
-\end{array}$ \\
\hline Pre-Crisis & $\begin{array}{c}0.025 \\
(0.051)\end{array}$ & $\begin{array}{c}\mathbf{0 . 0 7 2} \\
(0.034)\end{array}$ & $\begin{array}{l}-0.047 \\
(0.063)\end{array}$ & $\begin{array}{l}-0.213 \\
(0.174)\end{array}$ & - & $\begin{array}{l}- \\
-\end{array}$ & $\begin{array}{l}- \\
-\end{array}$ \\
\hline Crisis & $\begin{array}{c}0.098 \\
(0.094)\end{array}$ & $\begin{array}{c}\mathbf{0 . 2 8 4} \\
(0.063)\end{array}$ & $\begin{array}{l}-0.185 \\
(0.119)\end{array}$ & $\begin{array}{r}-0.771 \\
(0.363)\end{array}$ & - & $\begin{array}{l}- \\
-\end{array}$ & $\begin{array}{l}- \\
-\end{array}$ \\
\hline Post-Crisis & $\begin{array}{c}0.043 \\
(0.049) \\
\end{array}$ & $\begin{array}{c}0.042 \\
(0.033) \\
\end{array}$ & $\begin{array}{c}0.000 \\
(0.060) \\
\end{array}$ & $\begin{array}{l}\mathbf{- 0 . 3 4 7} \\
(0.173) \\
\end{array}$ & - & $\begin{array}{l}- \\
- \\
\end{array}$ & $\begin{array}{l}- \\
- \\
\end{array}$ \\
\hline $\log ($ Size $)$ & $\begin{array}{c}\mathbf{- 0 . 0 2 4} \\
(0.006)\end{array}$ & $\begin{array}{l}-0.004 \\
(0.003)\end{array}$ & $\begin{array}{r}\mathbf{- 0 . 0 2 0} \\
(0.007)\end{array}$ & $\begin{array}{c}\mathbf{0 . 4 5 6} \\
(0.022)\end{array}$ & $\begin{array}{c}\mathbf{- 0 . 0 3 4} \\
(0.009)\end{array}$ & $\begin{array}{c}0.009 \\
(0.011)\end{array}$ & $\begin{array}{r}\mathbf{- 0 . 0 4 3} \\
(0.016)\end{array}$ \\
\hline Leverage & $\begin{array}{c}0.059 \\
(0.111)\end{array}$ & $\begin{array}{c}0.028 \\
(0.054)\end{array}$ & $\begin{array}{c}0.031 \\
(0.128)\end{array}$ & $\begin{array}{l}-0.519 \\
(0.401)\end{array}$ & $\begin{array}{c}-0.053 \\
(0.173)\end{array}$ & $\begin{array}{c}0.100 \\
(0.181)\end{array}$ & $\begin{array}{c}-0.153 \\
(0.280)\end{array}$ \\
\hline Leverage $^{2}$ & $\begin{array}{c}0.072 \\
(0.143)\end{array}$ & $\begin{array}{c}0.088 \\
(0.066)\end{array}$ & $\begin{array}{c}-0.016 \\
(0.162)\end{array}$ & $\begin{array}{r}\mathbf{- 1 . 4 0 3} \\
(0.519)\end{array}$ & $\begin{array}{c}0.169 \\
(0.225)\end{array}$ & $\begin{array}{c}0.197 \\
(0.216)\end{array}$ & $\begin{array}{c}-0.028 \\
(0.352)\end{array}$ \\
\hline M/B Ratio & $\begin{array}{r}\mathbf{- 0 . 0 3 0} \\
(0.007)\end{array}$ & $\begin{array}{c}\mathbf{- 0 . 0 2 8} \\
(0.007)\end{array}$ & $\begin{array}{c}-0.002 \\
(0.010)\end{array}$ & $\begin{array}{c}\mathbf{0 . 4 0 8} \\
(0.028)\end{array}$ & $\begin{array}{c}-\mathbf{0 . 0 2 1} \\
(0.011)\end{array}$ & $\begin{array}{l}-0.046 \\
(0.025)\end{array}$ & $\begin{array}{c}0.025 \\
(0.026)\end{array}$ \\
\hline Cash Flow & $\begin{array}{c}0.027 \\
(0.026)\end{array}$ & $\begin{array}{l}-0.034 \\
(0.026)\end{array}$ & $\begin{array}{c}0.061 \\
(0.038)\end{array}$ & $\begin{array}{c}\mathbf{1 . 0 9 6} \\
(0.122)\end{array}$ & $\begin{array}{c}0.001 \\
(0.044)\end{array}$ & $\begin{array}{l}-0.002 \\
(0.076)\end{array}$ & $\begin{array}{c}0.003 \\
(0.104)\end{array}$ \\
\hline Cash & $\begin{array}{c}-0.011 \\
(0.042)\end{array}$ & $\begin{array}{c}\mathbf{0 . 0 5 2} \\
(0.026)\end{array}$ & $\begin{array}{c}-0.063 \\
(0.051)\end{array}$ & $\begin{array}{r}\mathbf{- 0 . 6 8 5} \\
(0.157)\end{array}$ & $\begin{array}{c}0.118 \\
(0.064)\end{array}$ & $\begin{array}{l}-0.118 \\
(0.094)\end{array}$ & $\begin{array}{c}0.236 \\
(0.120)\end{array}$ \\
\hline$R \& D$ & $\begin{array}{c}\mathbf{1 . 0 0 2} \\
(0.183)\end{array}$ & $\begin{array}{c}-0.156 \\
(0.259)\end{array}$ & $\begin{array}{c}\mathbf{1 . 1 5 7} \\
(0.329)\end{array}$ & $\begin{array}{c}\mathbf{- 2 . 3 7 4} \\
(0.928)\end{array}$ & $\begin{array}{c}\mathbf{1 . 6 3 0} \\
(0.368)\end{array}$ & $\begin{array}{c}0.612 \\
(0.437)\end{array}$ & $\begin{array}{c}1.018 \\
(0.626)\end{array}$ \\
\hline Intangibles & $\begin{array}{l}-0.046 \\
(0.040)\end{array}$ & $\begin{array}{c}-0.024 \\
(0.021)\end{array}$ & $\begin{array}{l}-0.022 \\
(0.047)\end{array}$ & $\begin{array}{c}\mathbf{- 0 . 3 2 5} \\
(0.149)\end{array}$ & $\begin{array}{c}0.008 \\
(0.068)\end{array}$ & $\begin{array}{l}-0.092 \\
(0.068)\end{array}$ & $\begin{array}{c}0.100 \\
(0.111)\end{array}$ \\
\hline SP500 Growth & $\begin{array}{c}0.001 \\
(0.064)\end{array}$ & $\begin{array}{c}0.001 \\
(0.029)\end{array}$ & $\begin{array}{c}0.000 \\
(0.072)\end{array}$ & $\begin{array}{l}-7.333 \\
(6.704)\end{array}$ & $\begin{array}{c}0.092 \\
(0.086)\end{array}$ & $\begin{array}{c}-0.058 \\
(0.097)\end{array}$ & $\begin{array}{c}0.149 \\
(0.146)\end{array}$ \\
\hline Credit Spread & $\begin{array}{c}1.665 \\
(1.754)\end{array}$ & $\begin{array}{l}-0.265 \\
(0.969)\end{array}$ & $\begin{array}{c}1.930 \\
(2.072)\end{array}$ & $\begin{array}{c}0.054 \\
(0.237)\end{array}$ & $\begin{array}{c}\mathbf{6 . 6 6 1} \\
(1.802)\end{array}$ & $\begin{array}{c}3.524 \\
(1.991)\end{array}$ & $\begin{array}{c}3.137 \\
(3.063)\end{array}$ \\
\hline Asset Restructuring & $\begin{array}{c}0.004 \\
(0.011) \\
\end{array}$ & $\begin{array}{c}\mathbf{0 . 0 1 8} \\
(0.006) \\
\end{array}$ & $\begin{array}{l}-0.014 \\
(0.013) \\
\end{array}$ & $\begin{array}{l}- \\
- \\
\end{array}$ & $\begin{array}{l}- \\
- \\
\end{array}$ & $\begin{array}{l}- \\
- \\
\end{array}$ & $\begin{array}{l}- \\
- \\
\end{array}$ \\
\hline $\log (\#$ Bidders $)$ & $\begin{array}{c}\mathbf{- 0 . 1 4 4} \\
(0.019)\end{array}$ & $\begin{array}{c}\mathbf{- 0 . 0 6 2} \\
(0.008)\end{array}$ & $\begin{array}{r}-\mathbf{0 . 0 8 1} \\
(0.021)\end{array}$ & $\begin{array}{c}-0.071 \\
(0.059)\end{array}$ & - & $\begin{array}{l}- \\
-\end{array}$ & $\begin{array}{l}- \\
-\end{array}$ \\
\hline $\log (\#$ Bidders $) \times$ Dot-Com & $\begin{array}{c}0.043 \\
(0.030)\end{array}$ & $\begin{array}{r}\mathbf{- 0 . 0 8 1} \\
(0.018)\end{array}$ & $\begin{array}{c}\mathbf{0 . 1 2 4} \\
(0.036)\end{array}$ & $\begin{array}{c}0.055 \\
(0.110)\end{array}$ & - & $\begin{array}{l}- \\
-\end{array}$ & - \\
\hline $\log (\#$ Bidders $) \times$ Pre-Crisis & $\begin{array}{l}-0.003 \\
(0.022)\end{array}$ & $\begin{array}{r}-\mathbf{0 . 0 3 2} \\
(0.011)\end{array}$ & $\begin{array}{c}0.029 \\
(0.026)\end{array}$ & $\begin{array}{c}0.100 \\
(0.078)\end{array}$ & - & $\begin{array}{l}- \\
-\end{array}$ & - \\
\hline $\log (\#$ Bidders $) \times$ Crisis & $\begin{array}{l}-0.055 \\
(0.038)\end{array}$ & $\begin{array}{r}\mathbf{- 0 . 1 0 6} \\
(0.025)\end{array}$ & $\begin{array}{c}0.051 \\
(0.047)\end{array}$ & $\begin{array}{c}\mathbf{0 . 3 6 0} \\
(0.157)\end{array}$ & - & - & - \\
\hline $\log (\#$ Bidders $) \times$ Post-Crisis & $\begin{array}{c}-0.004 \\
(0.021)\end{array}$ & $\begin{array}{c}-0.011 \\
(0.010)\end{array}$ & $\begin{array}{c}0.008 \\
(0.024)\end{array}$ & $\begin{array}{c}0.079 \\
(0.075)\end{array}$ & $\begin{array}{l}- \\
-\end{array}$ & $\begin{array}{l}- \\
-\end{array}$ & $\begin{array}{l}- \\
-\end{array}$ \\
\hline Ranking & $\begin{array}{l}- \\
- \\
\end{array}$ & $\begin{array}{l}- \\
- \\
\end{array}$ & $\begin{array}{l}- \\
- \\
\end{array}$ & $\begin{array}{l}- \\
- \\
\end{array}$ & $\begin{array}{r}-\mathbf{0 . 2 3 1} \\
(0.048) \\
\end{array}$ & $\begin{array}{c}\mathbf{- 0 . 2 3 2} \\
(0.050) \\
\end{array}$ & $\begin{array}{c}0.001 \\
(0.069) \\
\end{array}$ \\
\hline
\end{tabular}


Table A2: Extended results of OLS regressions in Table 10

The table shows the estimation results (mean and standard deviation) of the OLS regression of winning bids on target and market characteristics, and properties of bidders' valuations and participation. The first four columns focus on a simulated economy in which bidders value targets according to the model with target-specific dispersions of valuations. Valuation determinants are shown in Table 5. The four columns sequentially introduce the difference in estimated average valuations, dispersions of valuations, and the number of strategic and financial bidders to the OLS regression presented in column (2) of Table 4. The next four columns show the results of the OLS regressions with all control variables in four counterfactual simulated economies described in Table 8. Properties of valuations and participation in Panels A-D match those in Table 8. The final two columns show the results of the OLS and Erickson, Jiang, and Whited (2014) regressions with all control variables in the real sample. Standard deviations are reported in parentheses. Where coefficients associated with the "Strategic Acquirer" dummy and its interactions are statistically significant at the $5 \%$ level in more than $50 \%$ of simulated samples, they are highlighted in bold. The sample covers 01/01/2000 to 05/02/2012.

\begin{tabular}{|c|c|c|c|c|c|c|c|c|c|c|}
\hline & Est., (2) & $\begin{array}{c}\text { Est., (2) } \\
\Delta \text { Avg. Val }\end{array}$ & $\begin{array}{c}\text { Est., (2) } \\
\Delta \text { SD of PV }\end{array}$ & $\begin{array}{c}\text { Est., (2) } \\
\text { \# S\&F Bid. }\end{array}$ & $\begin{array}{c}\text { Sim., (2) } \\
\text { Panel A }\end{array}$ & $\begin{array}{c}\text { Sim., (2) } \\
\text { Panel B }\end{array}$ & $\begin{array}{l}\text { Sim., (2) } \\
\text { Panel C }\end{array}$ & $\begin{array}{l}\text { Sim., (2) } \\
\text { Panel D }\end{array}$ & $\begin{array}{c}\text { Data, (2) } \\
\text { \# S\&F Bid. }\end{array}$ & $\begin{array}{c}\text { Data, (2) } \\
\text { EJW }\end{array}$ \\
\hline Strategic Acquirer & $\begin{array}{c}\mathbf{0 . 0 9 6} \\
(0.022) \\
{[98.5 \%]}\end{array}$ & $\begin{array}{c}\mathbf{0 . 0 7 2} \\
(0.024) \\
{[84.9 \%]}\end{array}$ & $\begin{array}{c}\mathbf{0 . 0 4 4} \\
(0.024) \\
{[63.8 \%]}\end{array}$ & $\begin{array}{c}0.015 \\
(0.064) \\
{[36.6 \%]}\end{array}$ & $\begin{array}{l}-0.057 \\
(0.063) \\
{[30.8 \%]}\end{array}$ & $\begin{array}{c}0.096 \\
(0.070) \\
{[42.7 \%]}\end{array}$ & $\begin{array}{c}0.066 \\
(0.073) \\
{[46.9 \%]}\end{array}$ & $\begin{array}{l}-0.023 \\
(0.067) \\
{[29.1 \%]}\end{array}$ & $\begin{array}{c}0.129 \\
(0.122) \\
-\end{array}$ & $\begin{array}{c}-0.056 \\
(0.118) \\
-\end{array}$ \\
\hline S Acquirer $\times \Delta$ Avg. Val & $\begin{array}{l}- \\
- \\
-\end{array}$ & $\begin{array}{c}\mathbf{0 . 3 6 7} \\
(0.160) \\
{[52.2 \%]}\end{array}$ & $\begin{array}{l}-0.115 \\
(0.185) \\
{[24.5 \%]}\end{array}$ & $\begin{array}{l}-0.205 \\
(0.212) \\
{[40.5 \%]}\end{array}$ & $\begin{array}{l}-0.078 \\
(0.204) \\
{[31.7 \%]}\end{array}$ & $\begin{array}{c}-\mathbf{0 . 8 0 2} \\
(0.222) \\
{[81.5 \%]}\end{array}$ & $\begin{array}{l}-0.183 \\
(0.229) \\
{[40.4 \%]}\end{array}$ & $\begin{array}{l}-0.217 \\
(0.211) \\
{[37.7 \%]}\end{array}$ & $\begin{array}{c}-0.341 \\
(0.376) \\
-\end{array}$ & $\begin{array}{l}-0.036 \\
(0.488)\end{array}$ \\
\hline $\mathrm{S}$ Acquirer $\times \Delta \mathrm{SD}$ of $\mathrm{PV}$ & $\begin{array}{l}- \\
- \\
-\end{array}$ & $\begin{array}{l}- \\
- \\
-\end{array}$ & $\begin{array}{c}\mathbf{0 . 5 8 5} \\
(0.113) \\
{[72.9 \%]}\end{array}$ & $\begin{array}{l}\mathbf{0 . 6 1 5} \\
(0.114) \\
{[79.5 \%]}\end{array}$ & $\begin{array}{l}\mathbf{0 . 5 8 1} \\
(0.110) \\
{[79.6 \%]}\end{array}$ & $\begin{array}{l}\mathbf{0 . 7 5 5} \\
(0.120) \\
{[95.4 \%]}\end{array}$ & $\begin{array}{l}\mathbf{0 . 6 5 9} \\
(0.115) \\
{[81.4 \%]}\end{array}$ & $\begin{array}{l}\mathbf{0 . 7 1 7} \\
(0.118) \\
{[87.3 \%]}\end{array}$ & $\begin{array}{c}\mathbf{0 . 6 6 2} \\
(0.223) \\
-\end{array}$ & $\begin{array}{c}\mathbf{0 . 6 6 3} \\
(0.300)\end{array}$ \\
\hline $\mathrm{S}$ Acquirer $\times \log (\# \mathrm{~S}$ Bidders $)$ & $\begin{array}{l}- \\
- \\
-\end{array}$ & - & $\begin{array}{l}- \\
- \\
-\end{array}$ & $\begin{array}{c}\mathbf{0 . 0 6 1} \\
(0.027) \\
56.4 \%\end{array}$ & $\begin{array}{c}0.053 \\
(0.028) \\
\end{array}$ & $\begin{array}{c}-0.01 \\
(0.031)\end{array}$ & $\begin{array}{c}\mathbf{0 . 0 5 9} \\
(0.027) \\
\end{array}$ & $\begin{array}{c}0.049 \\
(0.028)\end{array}$ & $\begin{array}{c}-0.026 \\
(0.057)\end{array}$ & $\begin{array}{c}0.049 \\
(0.046)\end{array}$ \\
\hline $\mathrm{S}$ Acquirer $\times \log (\# \mathrm{~F}$ bidders $)$ & $\begin{array}{l}- \\
- \\
- \\
\end{array}$ & $\begin{array}{l}- \\
- \\
- \\
\end{array}$ & $\begin{array}{l}- \\
- \\
- \\
\end{array}$ & $\begin{array}{l}{\left[\begin{array}{c} \\
\mathbf{- 0 . 0 5 1}\end{array}\right]} \\
(0.015) \\
{[84.8 \%]}\end{array}$ & $\begin{array}{c}{[44.5 \%]} \\
-0.021 \\
(0.015) \\
{[38.8 \%]} \\
\end{array}$ & $\begin{array}{c}{[.9 \%]} \\
-\mathbf{0 . 0 6 6} \\
(0.017) \\
{[94.8 \%]}\end{array}$ & $\begin{array}{c}{[54.9 \%]} \\
\mathbf{- 0 . 0 7 5} \\
(0.016) \\
{[95.8 \%]}\end{array}$ & $\begin{array}{c}{[42.6 \%]} \\
\mathbf{- 0 . 0 2 8} \\
(0.014) \\
{[56.2 \%]}\end{array}$ & $\begin{array}{c}- \\
-0.021 \\
(0.031) \\
- \\
\end{array}$ & $\begin{array}{l}-0.004 \\
(0.029)\end{array}$ \\
\hline Const & $\begin{array}{c}1.387 \\
(0.090)\end{array}$ & $\begin{array}{c}1.315 \\
(0.094)\end{array}$ & $\begin{array}{l}1.419 \\
(0.094)\end{array}$ & $\begin{array}{l}1.420 \\
(0.093)\end{array}$ & $\begin{array}{c}1.419 \\
(0.089)\end{array}$ & $\begin{array}{c}1.545 \\
(0.097)\end{array}$ & $\begin{array}{c}1.503 \\
(0.102)\end{array}$ & $\begin{array}{c}1.495 \\
(0.096)\end{array}$ & $\begin{array}{c}1.417 \\
(0.157)\end{array}$ & $\begin{array}{c}1.415 \\
(0.162)\end{array}$ \\
\hline Dot-Com & $\begin{array}{c}0.105 \\
(0.082)\end{array}$ & $\begin{array}{c}0.213 \\
(0.094)\end{array}$ & $\begin{array}{c}0.026 \\
(0.098)\end{array}$ & $\begin{array}{l}-0.041 \\
(0.104)\end{array}$ & $\begin{array}{c}0.009 \\
(0.099)\end{array}$ & $\begin{array}{c}-0.251 \\
(0.109)\end{array}$ & $\begin{array}{l}-0.035 \\
(0.112)\end{array}$ & $\begin{array}{l}-0.033 \\
(0.103)\end{array}$ & $\begin{array}{l}0.065 \\
(0.174)\end{array}$ & $\begin{array}{c}0.153 \\
(0.176)\end{array}$ \\
\hline Pre-Crisis & $\begin{array}{c}0.195 \\
(0.059)\end{array}$ & $\begin{array}{c}0.190 \\
(0.058)\end{array}$ & $\begin{array}{c}0.151 \\
(0.056)\end{array}$ & $\begin{array}{c}0.131 \\
(0.056)\end{array}$ & $\begin{array}{c}0.136 \\
(0.054)\end{array}$ & $\begin{array}{c}0.144 \\
(0.059)\end{array}$ & $\begin{array}{c}0.141 \\
(0.058)\end{array}$ & $\begin{array}{c}0.146 \\
(0.056)\end{array}$ & $\begin{array}{c}0.182 \\
(0.097)\end{array}$ & $\begin{array}{c}0.180 \\
(0.083)\end{array}$ \\
\hline Crisis & $\begin{array}{c}0.246 \\
(0.123)\end{array}$ & $\begin{array}{c}0.228 \\
(0.121)\end{array}$ & $\begin{array}{l}0.242 \\
(0.117)\end{array}$ & $\begin{array}{c}0.214 \\
(0.116)\end{array}$ & $\begin{array}{c}0.220 \\
(0.113)\end{array}$ & $\begin{array}{c}0.201 \\
(0.123)\end{array}$ & $\begin{array}{c}0.259 \\
(0.120)\end{array}$ & $\begin{array}{c}0.265 \\
(0.117)\end{array}$ & $\begin{array}{c}0.782 \\
(0.202)\end{array}$ & $\begin{array}{c}0.814 \\
(0.317)\end{array}$ \\
\hline Post-Crisis & $\begin{array}{c}0.141 \\
(0.058)\end{array}$ & $\begin{array}{c}0.129 \\
(0.058) \\
\end{array}$ & $\begin{array}{c}0.132 \\
(0.056) \\
\end{array}$ & $\begin{array}{c}0.110 \\
(0.055)\end{array}$ & $\begin{array}{c}0.100 \\
(0.054) \\
\end{array}$ & $\begin{array}{c}0.125 \\
(0.058) \\
\end{array}$ & $\begin{array}{c}0.141 \\
(0.057) \\
\end{array}$ & $\begin{array}{c}0.126 \\
(0.056) \\
\end{array}$ & $\begin{array}{c}0.199 \\
(0.097) \\
\end{array}$ & $\begin{array}{c}0.200 \\
(0.112)\end{array}$ \\
\hline $\log ($ Size $)$ & $\begin{array}{c}-0.032 \\
(0.008)\end{array}$ & $\begin{array}{c}-0.026 \\
(0.008)\end{array}$ & $\begin{array}{c}-0.021 \\
(0.008)\end{array}$ & $\begin{array}{c}-0.021 \\
(0.008)\end{array}$ & $\begin{array}{l}-0.018 \\
(0.008)\end{array}$ & $\begin{array}{c}-0.028 \\
(0.008)\end{array}$ & $\begin{array}{l}-0.033 \\
(0.008)\end{array}$ & $\begin{array}{c}-0.022 \\
(0.008)\end{array}$ & $\begin{array}{c}-0.028 \\
(0.014)\end{array}$ & $\begin{array}{l}-0.023 \\
(0.014)\end{array}$ \\
\hline Leverage & $\begin{array}{c}0.171 \\
(0.136)\end{array}$ & $\begin{array}{c}0.201 \\
(0.134)\end{array}$ & $\begin{array}{l}-0.104 \\
(0.143)\end{array}$ & $\begin{array}{c}-0.091 \\
(0.142)\end{array}$ & $\begin{array}{l}-0.007 \\
(0.136)\end{array}$ & $\begin{array}{l}-0.403 \\
(0.146)\end{array}$ & $\begin{array}{l}-0.038 \\
(0.151)\end{array}$ & $\begin{array}{l}-0.168 \\
(0.141)\end{array}$ & $\begin{array}{l}-0.286 \\
(0.239)\end{array}$ & $\begin{array}{l}-0.221 \\
(0.314)\end{array}$ \\
\hline Leverage $^{2}$ & $\begin{array}{c}0.215 \\
(0.175)\end{array}$ & $\begin{array}{c}0.134 \\
(0.177)\end{array}$ & $\begin{array}{c}0.622 \\
(0.196)\end{array}$ & $\begin{array}{c}0.628 \\
(0.195)\end{array}$ & $\begin{array}{c}0.482 \\
(0.185)\end{array}$ & $\begin{array}{l}1.228 \\
(0.198)\end{array}$ & $\begin{array}{l}0.625 \\
(0.212)\end{array}$ & $\begin{array}{c}0.801 \\
(0.191)\end{array}$ & $\begin{array}{l}1.065 \\
(0.323)\end{array}$ & $\begin{array}{c}0.964 \\
(0.496)\end{array}$ \\
\hline M/B Ratio & $\begin{array}{l}-0.050 \\
(0.009)\end{array}$ & $\begin{array}{c}-0.050 \\
(0.009)\end{array}$ & $\begin{array}{c}-0.034 \\
(0.009)\end{array}$ & $\begin{array}{l}-0.039 \\
(0.009)\end{array}$ & $\begin{array}{l}-0.039 \\
(0.009)\end{array}$ & $\begin{array}{c}-0.028 \\
(0.010)\end{array}$ & $\begin{array}{l}-0.050 \\
(0.010)\end{array}$ & $\begin{array}{c}-0.036 \\
(0.010)\end{array}$ & $\begin{array}{l}-0.050 \\
(0.016)\end{array}$ & $\begin{array}{l}-0.043 \\
(0.012)\end{array}$ \\
\hline Cash Flow & $\begin{array}{l}-0.069 \\
(0.041)\end{array}$ & $\begin{array}{l}-0.075 \\
(0.041)\end{array}$ & $\begin{array}{l}-0.096 \\
(0.040)\end{array}$ & $\begin{array}{l}-0.080 \\
(0.039)\end{array}$ & $\begin{array}{l}-0.079 \\
(0.038)\end{array}$ & $\begin{array}{c}-0.109 \\
(0.041)\end{array}$ & $\begin{array}{l}-0.080 \\
(0.041)\end{array}$ & $\begin{array}{l}-0.108 \\
(0.040)\end{array}$ & $\begin{array}{l}-0.127 \\
(0.069)\end{array}$ & $\begin{array}{l}-0.136 \\
(0.119)\end{array}$ \\
\hline Cash & $\begin{array}{c}0.051 \\
(0.053)\end{array}$ & $\begin{array}{c}0.071 \\
(0.053)\end{array}$ & $\begin{array}{c}0.022 \\
(0.052)\end{array}$ & $\begin{array}{l}-0.011 \\
(0.053)\end{array}$ & $\begin{array}{c}0.001 \\
(0.051)\end{array}$ & $\begin{array}{c}-0.068 \\
(0.055)\end{array}$ & $\begin{array}{c}0.002 \\
(0.055)\end{array}$ & $\begin{array}{c}-0.024 \\
(0.053)\end{array}$ & $\begin{array}{c}-0.131 \\
(0.091)\end{array}$ & $\begin{array}{c}-0.112 \\
(0.082)\end{array}$ \\
\hline$R \& D$ & $\begin{array}{c}1.977 \\
(0.314)\end{array}$ & $\begin{array}{c}1.550 \\
(0.362)\end{array}$ & $\begin{array}{c}0.939 \\
(0.369)\end{array}$ & $\begin{array}{c}0.890 \\
(0.372)\end{array}$ & $\begin{array}{c}0.781 \\
(0.362)\end{array}$ & $\begin{array}{c}0.633 \\
(0.395)\end{array}$ & $\begin{array}{c}1.269 \\
(0.395)\end{array}$ & $\begin{array}{c}0.653 \\
(0.376)\end{array}$ & $\begin{array}{c}2.389 \\
(0.599)\end{array}$ & $\begin{array}{c}2.076 \\
(0.891)\end{array}$ \\
\hline Intangibles & $\begin{array}{c}-0.126 \\
(0.051)\end{array}$ & $\begin{array}{c}-0.111 \\
(0.050)\end{array}$ & $\begin{array}{c}-0.123 \\
(0.048)\end{array}$ & $\begin{array}{c}-0.129 \\
(0.048)\end{array}$ & $\begin{array}{l}-0.123 \\
(0.047)\end{array}$ & $\begin{array}{c}-0.158 \\
(0.050)\end{array}$ & $\begin{array}{c}-0.149 \\
(0.050)\end{array}$ & $\begin{array}{c}-0.142 \\
(0.048)\end{array}$ & $\begin{array}{c}-0.125 \\
(0.083)\end{array}$ & $\begin{array}{l}-0.120 \\
(0.078)\end{array}$ \\
\hline SP500 Growth & $\begin{array}{c}-0.036 \\
(0.080)\end{array}$ & $\begin{array}{c}-0.022 \\
(0.079)\end{array}$ & $\begin{array}{c}-0.114 \\
(0.079)\end{array}$ & $\begin{array}{c}-0.123 \\
(0.078)\end{array}$ & $\begin{array}{c}-0.103 \\
(0.076)\end{array}$ & $\begin{array}{c}-0.206 \\
(0.082)\end{array}$ & $\begin{array}{c}-0.143 \\
(0.082)\end{array}$ & $\begin{array}{c}-0.152 \\
(0.079)\end{array}$ & $\begin{array}{c}-0.176 \\
(0.134)\end{array}$ & $\begin{array}{l}-0.163 \\
(0.151)\end{array}$ \\
\hline Credit Spread & $\begin{array}{c}2.073 \\
(2.268) \\
\end{array}$ & $\begin{array}{c}1.881 \\
(2.234) \\
\end{array}$ & $\begin{array}{c}-0.656 \\
(2.210) \\
\end{array}$ & $\begin{array}{c}-0.352 \\
(2.178) \\
\end{array}$ & $\begin{array}{c}-0.053 \\
(2.125) \\
\end{array}$ & $\begin{array}{l}-1.108 \\
(2.300) \\
\end{array}$ & $\begin{array}{l}-0.020 \\
(2.268) \\
\end{array}$ & $\begin{array}{c}-0.913 \\
(2.204) \\
\end{array}$ & $\begin{array}{c}4.825 \\
(3.754) \\
\end{array}$ & $\begin{array}{c}4.889 \\
(4.127) \\
\end{array}$ \\
\hline $\log (\#$ Bidders $)$ & $\begin{array}{c}0.033 \\
(0.020)\end{array}$ & $\begin{array}{c}0.051 \\
(0.021)\end{array}$ & $\begin{array}{c}0.028 \\
(0.021)\end{array}$ & $\begin{array}{c}0.030 \\
(0.022)\end{array}$ & $\begin{array}{c}0.032 \\
(0.021)\end{array}$ & $\begin{array}{c}0.039 \\
(0.023)\end{array}$ & $\begin{array}{c}0.027 \\
(0.024)\end{array}$ & $\begin{array}{c}0.024 \\
(0.022)\end{array}$ & $\begin{array}{c}0.019 \\
(0.037)\end{array}$ & $\begin{array}{c}0.002 \\
(0.037)\end{array}$ \\
\hline $\log (\#$ Bidders $) \times$ Dot-Com & $\begin{array}{l}-0.003 \\
(0.037)\end{array}$ & $\begin{array}{l}-0.035 \\
(0.040)\end{array}$ & $\begin{array}{c}0.016 \\
(0.040)\end{array}$ & $\begin{array}{c}0.040 \\
(0.041)\end{array}$ & $\begin{array}{c}0.022 \\
(0.040)\end{array}$ & $\begin{array}{c}0.097 \\
(0.043)\end{array}$ & $\begin{array}{c}0.042 \\
(0.044)\end{array}$ & $\begin{array}{c}0.030 \\
(0.041)\end{array}$ & $\begin{array}{c}0.007 \\
(0.071)\end{array}$ & $\begin{array}{l}-0.022 \\
(0.067)\end{array}$ \\
\hline $\log (\#$ Bidders $) \times$ Pre-Crisis & $\begin{array}{c}-0.068 \\
(0.026)\end{array}$ & $\begin{array}{c}-0.069 \\
(0.026)\end{array}$ & $\begin{array}{c}-0.060 \\
(0.025)\end{array}$ & $\begin{array}{c}-0.050 \\
(0.025)\end{array}$ & $\begin{array}{c}-0.054 \\
(0.024)\end{array}$ & $\begin{array}{c}-0.056 \\
(0.026)\end{array}$ & $\begin{array}{l}-0.048 \\
(0.026)\end{array}$ & $\begin{array}{c}-0.060 \\
(0.025)\end{array}$ & $\begin{array}{l}-0.067 \\
(0.043)\end{array}$ & $\begin{array}{c}-0.071 \\
(0.036)\end{array}$ \\
\hline $\log (\#$ Bidders $) \times$ Crisis & $\begin{array}{c}-0.072 \\
(0.053)\end{array}$ & $\begin{array}{c}-0.068 \\
(0.053)\end{array}$ & $\begin{array}{c}-0.039 \\
(0.051)\end{array}$ & $\begin{array}{c}-0.028 \\
(0.051)\end{array}$ & $\begin{array}{l}-0.039 \\
(0.050)\end{array}$ & $\begin{array}{c}0.003 \\
(0.054)\end{array}$ & $\begin{array}{c}-0.041 \\
(0.053)\end{array}$ & $\begin{array}{c}-0.035 \\
(0.051)\end{array}$ & $\begin{array}{c}-0.314 \\
(0.089)\end{array}$ & $\begin{array}{c}-0.338 \\
(0.142)\end{array}$ \\
\hline $\log (\#$ Bidders $) \times$ Post-Crisis & $\begin{array}{c}-0.021 \\
(0.025)\end{array}$ & $\begin{array}{c}-0.018 \\
(0.025)\end{array}$ & $\begin{array}{c}-0.014 \\
(0.024)\end{array}$ & $\begin{array}{l}-0.007 \\
(0.024)\end{array}$ & $\begin{array}{c}-0.006 \\
(0.023)\end{array}$ & $\begin{array}{c}-0.006 \\
(0.025)\end{array}$ & $\begin{array}{c}-0.014 \\
(0.025)\end{array}$ & $\begin{array}{c}-0.012 \\
(0.024)\end{array}$ & $\begin{array}{c}-0.059 \\
(0.042)\end{array}$ & $\begin{array}{c}-0.063 \\
(0.047)\end{array}$ \\
\hline
\end{tabular}




\section{References}

Avery, C., 1998. Strategic jump bidding in English auctions. Review of Economic Studies 65, 185-210.

Boone, A., Mulherin, H., 2007. How are firms sold? Journal of Finance 62, 847-875.

Chernov, M., Gorbenko, A., Makarov, I., 2013. CDS auctions. Review of Financial Studies 26, 768-805.

Dempster, A., Laird, N., Rubin, D., 1977. Maximum likelihood from incomplete data via the EM algorithm.

Journal of Royal Statistical Society, Series B (Methodological) 39, 1-38.

Dimopoulos, T., Sacchetto, S., 2014. Preemptive bidding, target resistance, and takeover premiums. Journal of Financial Economics 114, 444-470.

Donald, S., Paarsch, H., 1996. Identification, estimation, and testing in parametric empirical models of auctions with the independent private values paradigm. Econometric Theory 12, 517-567.

Erickson, T., Jiang, C., Whited, T., 2014. Minimum distance estimation of the errors-in-variables model using linear cumulant equations. Journal of Econometrics, 183, 211-221.

Fama, E., French, K., 1997. Industry costs of equity. Journal of Financial Economics 43, 153-193.

Gentry, M., Stroup, C., 2017. Entry and competition in takeover auctions. Unpublished working paper. London School of Economics and Grinnell College.

Gorbenko, A., Malenko, A., 2014. Strategic and financial bidders in takeover auctions. Journal of Finance $69,2513-2555$.

Gorbenko, A., Malenko, A., 2016. Auctions with endogenous initiation. Unpublished working paper. USC Marshall and MIT Sloan.

Haile, P., Tamer, E., 2003. Inference with an incomplete model of English auctions. Journal of Political Economy 111, 1-51.

Hansen, R., 2001. Auctions of companies. Economic Inquiry 39, 30-43.

Harford, J., 2005. What drives merger waves. Journal of Financial Economics 77, 529-560.

Hege, U., Lovo, S., Slovin, M., Sushka, M., 2013. Asset sales and the role of buyers: strategic buyers versus private equity. Unpublished working paper. HEC Paris and Arizona State University.

Hortaçsu, A., Kastl, J., 2012. Valuing dealers' informational advantage: a study of Canadian Treasury auctions. Econometrica 80, 2511-2542.

Krishna, V., 2009. Auction theory, second edition. Academic Press.

Li, D., Taylor, L., Wang, W., 2017. Inefficiencies and externalities from opportunistic acquirers. Unpublished working paper. Georgia State University, Wharton, and Indiana University.

Martos-Vila, M., Rhodes-Kropf, M., Harford, J., 2013. Financial vs. strategic buyers. Unpublished working paper. London Business School, Harvard University, and University of Washington.

Nelder, J., Mead, R., 1967. A simplex method for function minimisation. Computer Journal 7, 308-313.

Paarsch, H., Hong, H., 2006. An introduction to the structural econometrics of auction data. MIT Press. 
Rhodes-Kropf, M., Viswanathan, S., 2004. Market valuation and merger waves. Journal of Finance 59, $2685-2718$.

Shleifer, A., Vishny, R., 2003. Stock market driven acquisitions. Journal of Financial Economics 70, 295-311.

Strömberg, P., 2000. Conflicts of interest and market illiquidity in bankruptcy auctions: theory and tests. Journal of Finance, 55, 2641-2692. 